Universidade de São Paulo

Faculdade de Filosofia, Ciências e Letras de Ribeirão Preto Departamento de Química

Programa de Pós-Graduação em Química

\title{
Avaliação de modelos microbiológicos e modelos biomiméticos no metabolismo estereosseletivo da risperidona por cromatografia líquida de alta eficiência
}

Mariana Zuccherato Bocato

Dissertação apresentada à Faculdade de Filosofia, Ciências e Letras de Ribeirão Preto da Universidade de São Paulo, como parte das exigências para a obtenção do título de Mestre em Ciências.

Área: Química

RIBEIRÃO PRETO - SP 
Universidade de São Paulo

Faculdade de Filosofia, Ciências e Letras de Ribeirão Preto Departamento de Química

Programa de Pós-Graduação em Química

\title{
Avaliação de modelos microbiológicos e modelos biomiméticos no metabolismo estereosseletivo da risperidona por cromatografia líquida de alta eficiência
}

\author{
Mariana Zuccherato Bocato
}

Prof. Dr. Anderson R. M. de Oliveira

Orientador

Dissertação apresentada à Faculdade de Filosofia, Ciências e Letras de Ribeirão Preto da Universidade de São Paulo, como parte das exigências para a obtenção do título de Mestre em Ciências.

Área: Química

RIBEIRÃO PRETO - SP 
AUTORIZO A REPRODUÇÃO E DIVULGAÇÃO TOTAL OU PARCIAL DESTE TRABALHO, POR QUALQUER MEIO CONVENCIONAL OU ELETRÔNICO, PARA FINS DE ESTUDO E PESQUISA, DESDE QUE CITADA A FONTE.

FICHA CATALOGRÁFICA

Bocato, Mariana Zuccherato

Avaliação de modelos microbiológicos e modelos biomiméticos no metabolismo estereosseletivo da risperidona por cromatografia líquida de alta eficiência 124 p.: il.; $30 \mathrm{~cm}$

Dissertação de Mestrado, apresentada à Faculdade de Filosofia, Ciências e Letras de Ribeirão Preto/USP - Área de concentração: Química.

Orientador: De Oliveira, Anderson Rodrigo Moraes

1. Análise enantiosseletiva. 2. Biotransformação 3. SPME. 4. HPLC 


\section{FOLHA DE APROVAÇÃO}

Mariana Zuccherato Bocato

Avaliação de modelos microbiológicos e modelos biomiméticos no metabolismo estereosseletivo da risperidona por cromatografia líquida de alta eficiência.

Dissertação de mestrado apresentada ao Programa de Pós-Graduação em Química para obtenção do título de Mestre em Ciências

Área de concentração: Química

Orientador: Prof. Dr. Anderson R. M. de Oliveira

Aprovada em:

Banca Examinadora

Prof. Dr.

Instituição: Assinatura:

Prof. Dr.

Instituição: Assinatura:

Prof. Dr.

Instituição: Assinatura:

Prof. Dr.

Instituição: Assinatura:

Prof. Dr.

Instituição: Assinatura: 
Dedicatória

Dedico este trabalho aos meus pais

Jair e Marlene e ao meu querido irmão, Rodolfo. 


\section{AGRADECIMENTTOS}

Agradeço a Deus pela vida, por me iluminar a cada dia e por me dar forças para conseguir realizar os meus sonhos;

Aos meus pais, Jair e Marlene, por todo o imenso amor, apoio e dedicação. Obrigada, pai, por todo o seu esforço e por acreditar que estou seguindo o caminho certo, sempre me apoiando durante estes anos. Você é meu exemplo de coragem e força. Mãe, obrigada pelas orações e por todos os dias fazer parte da minha vida, mostrando que a distância não nos separa;

Agradeço ao meu irmão Rodolfo pelas palavras de otimismo e apoio;

Agradeço aos meus avós: Giuseppe e Rosa pela força e carinho;

Ao meu querido Cássio "pretinho" pelo carinho, apoio e companheirismo;

As eternas e verdadeiras amigas: Martinha, Mariana Desjardins, Marina, Fernanda Davide Céli.

Aos amigos de graduação e "agregados": Camila, Carol Vaccari, Reinaldo, Marcela, Jú Munhoz, Vitor e Greyce. Obrigada pela amizade cada vez mais fortalecida, pelos inúmeros momentos de alegria e por todo apoio; 
Aos amigos pós-graduandos pela troca de experiência, conhecimento e pelas risadas: Leandro Calixto. Fernando Armani, Rodrigo, Thiago Barth e Keyller.

Aos amigos de laboratório: Vivi, Simone, Bruno, Liana, Fernanda, Lucas, Daniel, Gisele, Franco, Lídia, Marcela, Renan, Maísa, Alana e Tanize.

Meu agradecimento, em especial, a professora Pierina Sueli Bonato por me acolher no CROEC e tornar possivel a realização de grande parte deste projeto;

Aos professores: Marilda D. Assis, Mônica T. Pupo, Cristiane M. de Gaitani, Niegi A.J.C. Furtado, Luiz Alberto B. de Moraes e Luis Gustavo Dias por toda ajuda;

Aos técnicos do LABMETS: Thiago Cavassani e do CROEC: Valquíria e Luciana;

A Franciane pelo ajuda e compreensão;

A Faculdade de Filosofia, Ciências e Letras de Ríbeirão Preto e ao Departamento de Química pela oportunidade de realizar este projeto;

As agências de fomento: CAPES pela 6olsa de estudos e FAPESP pelo auxílio financeiro e, por fim... 
... Agradeço ao professor Anderson pelo privilégio em ser sua orientada...

..."Mr. Anderson", obrigada por abrir-me as portas do seu laboratório mesmo consciente das inúmeras dificuldades que tive durante a minha graduação. Obrigada pelas broncas e pelos "puxões-de-orelha" sempre nas horas certase, principalmente, pela sua paciência comigo.

Obrigada por todos os ensinamentos científicos e de valores humanos.

Obrigada por gastar suas horas, seus fins de semana e seus feriados dando apoio em todas as etapas do meu mestrado.

Obrigada por não desistir de mim e, também, por sempre me dizer:

"Quem acredita sempre alcança, Mariana!"essa frase tem muita força!

É de coração que eu digo este "Muito obrigada!" 
"Não é o que você faz, mas quanto amor você dedica no que faz que realmente importa"

(Madre Tereza de Calcutá) 


\section{RESUMO}

BOCATO, M. Z. Avaliação de modelos microbiológicos e modelos biomiméticos no metabolismo estereosseletivo da risperidona por cromatografia líquida de alta eficiência. 2012. 124 f. Dissertação (Mestrado). Faculdade de Filosofia, Ciências e Letras de Ribeirão Preto - Universidade de São Paulo, Ribeirão Preto, 2012.

A risperidona é um medicamento antipsicótico que quando metabolizada da origem a dois metabólitos hidroxilados quirais, a 7-hidroxirisperidona (7-RispOH) e a 9hidroxirisperidona (9-RispOH). A 9-RispOH apresenta as mesmas propriedades farmacológicas que a risperidona e já é comercializada como fármaco, com o nome genérico de paliperidona. Estudos em humanos mostram que existem diferenças na disposição cinética dos enantiômeros da 9-RispOH, com uma maior prevalência do enantiômero (+)-9-RispOH em plasma. Dessa forma, este trabalho teve como finalidade avaliar a capacidade de algumas espécies de fungos e também de catalisadores de Jacobsen em (bio)transformar enantiosseletivamente a risperidona em seu metabólito ativo 9-RispOH. Para tanto, foi desenvolvido um método de separação para a risperidona e seus metabólitos utilizando cromatografia líquida de alta eficiência quiral. Este método foi então aplicado nos estudos de biotransformação enantiosseletivo e nos estudos de catálise assimétrica. A separação cromatográfica foi realizada empregando a coluna Chiralcel $\mathrm{OJ}-\mathrm{H}{ }^{\circledR}$ e metanol:etanol $(50: 50, \mathrm{v} / \mathrm{v})+0,2 \%$ de trietilamina como fase móvel. A vazão e temperatura utilizadas foram $0,8 \mathrm{~mL} \mathrm{~min}^{-1}$ e $25^{\circ} \mathrm{C}$, respectivamente. Para extração dos analitos do meio de cultura, foi empregada a microextração em fase sólida (SPME) como técnica de preparação de amostra. O processo de SPME foi realizado utilizando uma fibra $\mathrm{C} 18$ mergulhando diretamente a fibra na amostra por 30 minutos e dessorvendo a fibra diretamente na fase móvel por 5 minutos. A validação e estudos de biotransformação foram realizados empregando a cromatografia líquida acoplada à espectrometria de massas (LC-MS/MS). O método foi validado e todos os parâmetros encontram-se de acordo com as recomendações da literatura. $O$ estudo de biotransformação foi realizado com diferentes espécies de fungos e somente os fungos do gênero Cunninghamella foram capazes de biotransformar a risperidona em seu metabólito ativo. O fungo Cunninghamella echinulata foi capaz de biotransformar estereosseletivamente a risperidona no seu metabólito ativo (+)-9RispOH com excesso enantiomérico de $100 \%$ e o fungo Cunninghamella elegans foi também capaz de biotransformar estereosseletivamente a risperidona nos dois enantiômeros da 9-RispOH em diferentes proporções. Os estudos preliminares de catálise assimétrica foram realizados empregando a cromatografia líquida e detecção por UV-Vis, injetando diretamente alíquotas no sistema cromatográfico. Esses estudos mostraram que na condição de reação 1:50:50 (em número de mols, catalisador:oxidante:substrato) houve uma catálise assimétrica da risperidona que demonstrou ser enantiosseletiva para o metabólito 7-RispOH (E1).

Palavras-chave: Análise enantiosseletiva. Biotransformação. SPME. Risperidona 
ABSTRACT

BOCATO, M. Z. Evaluation of microbiological and biomimetic models in stereoselective metabolism of risperidone by high-performance liquid chromatography. 2012. 124 f. Master's thesis. Faculdade de Filosofia, Ciências e Letras de Ribeirão Preto - Universidade de São Paulo, Ribeirão Preto, 2012.

Risperidone is an atypical antipsychotic drug. Its metabolism yields in two hydroxylated chiral metabolites, 7-hydroxyrisperidone (7-RispOH) and 9hydroxyrisperidone (9-RispOH). The 9-RispOH metabolite presents the same pharmacologic activity of the parent drug risperidone. This led this drug to be marketed as drug under the generic name paliperidone. Studies have shown differences in the kinetic disposition of the 9-RispOH enantiomers with higher prevalence of the (+)-9-RispOH enantiomer in plasma. Thus, this work aimed to evaluate the ability of some species of fungi and Jacobsen catalysts in the enantioselective (bio)transformation of risperidone into its active chiral metabolite 9$\mathrm{RispOH}$. To accomplish that, it was developed a separation method to analyze risperidone and its metabolites by chiral high-performance liquid chromatography. This method was employed in enantioselective biotransformation studies and in asymmetric catalysis studies. The chromatographic separation was performed on a Chiralcel OJ-H column using methanol:ethanol $(50: 50, \mathrm{v} / \mathrm{v})$ plus $0.2 \%$ triethylamine as the mobile phase at a flow rate of $0.8 \mathrm{~mL} \mathrm{~min}$. The SPME process was performed by immersing directly a $\mathrm{C} 18$ probe fiber in the culture medium during 30 $\mathrm{min}$. The analytes were desorbed from the fiber directly in the mobile phase during 5 min. The method validation and the biotransformation studies were performed by high-performance liquid chromatography coupled with tandem mass spectrometry (LC-MS/MS). The method was completely validated and all parameters were in agreement with the literature recommendations. The biotransformation studies were performed employing different species of fungi and only the Cunninghamella genus was able to biotransform risperidone into its active metabolite. The Cunninghamella echinulata fungus was able to biotransform risperidone into the active metabolite, (+)$9-\mathrm{RispOH}$, resulting in $100 \%$ of enantiomeric excess. The Cunninghamella elegans fungus was also able to biotransform stereoselectively risperidone into (+)- and (-)-9$\mathrm{RispOH}$ enantiomers at different rates. Preliminary studies of asymmetric catalysis were performed using high-performance liquid chromatography with UV-Vis detector (HPLC-UV). The aliquots were directly injected in the chromatography system. These studies showed that the reaction with 1:50:50 (catalyst:oxidant:substrate, in number of mols, in this sequence) presented an asymmetric catalysis of risperidone and that showed to be enantioselective to 7-RispOH (E1) metabolite.

Keywords: Enantioselective analysis. Biotransformation. SPME. Risperidone 


\section{LISTA DE FIGURAS}

Figura 1 - Esquema de metabolismo da risperidona pelas enzimas do CYP450 com formação majoritária da 9-RispOH.

Figura 2 - Esquema da fonte de ionização por eletronebulização (ESI)

Figura 3 - Esquema de funcionamento do analisador triplo quadrupolo por monitoramento de reações múltiplas.

Figura 4 - Estrutura planar do catalisador $(R, R)$-Jacobsen.

Figura 5- Amostrador da Supelco® sobre um agitador magnético simulando a extração de uma amostra.

Figura 6 - Sistema Vibrax empregado nas extrações com as fibras C18.

Figura 7 - Esquema de otimização das condições SPME. Todo o procedimento foi realizado utilizando meio de cultura líquido Czapeck em temperatura ambiente $\left(23^{\circ} \mathrm{C} \pm 2^{\circ} \mathrm{C}\right)$. As condições foram avaliadas em triplicata $(n=3)$.

Figura 8 - Esquema do processo de biotransformação com fungos.

Figura 9 - Fotos dos brancos do gênero Cunninghamella utilizados como pool de fungos.

Figura 10 - Melhor condição obtida na tentativa de separação da RISP e seus metabólitos na coluna.

Figura 11 - Melhor condição obtida na tentativa de separação da RISP e seus metabólitos na coluna Chiralpak $A D-R H^{\circledR}$. Enantiômeros da 7-RispOH (1), enantiômeros da 9-RispOH (2) e RISP (3). Fase móvel: acetonitrila:metanol (50:50, v/v) + 0,25\% TEA, vazão: $0,4 \mathrm{~mL} \mathrm{~min}^{-1}$, temperatura $25^{\circ} \mathrm{C}$, detecção em $280 \mathrm{~nm} \ldots .$.

Figura 12 - Condição obtida na separação da RISP e seus metabólitos na coluna Chiralcel OJ-H $\mathrm{H}^{\circledR}$ utilizando fase móvel no modo polarorgânico. Enantiômeros da 7-RispOH (1), enantiômeros da 9RispOH (2) e RISP (3). Fase móvel: etanol 100\% + 0,2\% TEA, vazão: $0,4 \mathrm{~mL} \mathrm{~min}{ }^{-1}$, temperatura $25^{\circ} \mathrm{C}$, detecção em $280 \mathrm{~nm}$..... 
Figura 13 - Melhor condição obtida na separação da RISP e seus metabólitos na coluna Chiralcel OJ-H ${ }^{\circledR}$ utilizando fase móvel no modo polar-orgânico. Enantiômeros da 7-RispOH (1), enantiômeros da 9-RispOH (2) e RISP (3). Fase móvel: etanol:metanol $(50: 50, \mathrm{v} / \mathrm{v})+0,2 \%$ TEA, vazão: $0,4 \mathrm{~mL} \mathrm{~min}^{-1}$,

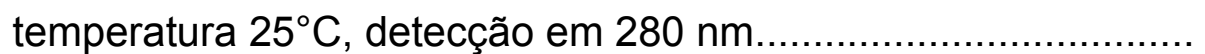

Figura 14 - Estrutura química planar do preenchimento da coluna Chiralcel OJ-H $\mathrm{H}^{\circledR}$. Tris (4-metilbenzoato) de celulose quimicamente ligado à sílica

Figura 15 - Comparação da eficiência de extração da RISP e seus metabólitos (9-RispOH e 7-RispOH) em meio de cultura Czapeck entre as fibras CW-TPR, C18 e PDMS-DVB. Extração 45 minutos a $23^{\circ} \mathrm{C} \pm 2^{\circ} \mathrm{C}$ e agitação de $900 \mathrm{rpm} ; 2 \mathrm{~mL}$ meio de

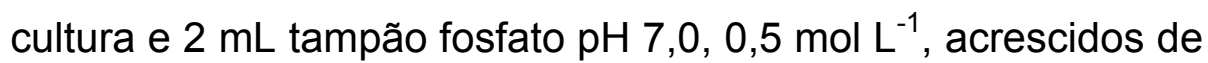
$30 \%(\mathrm{~m} / \mathrm{v})$ de $\mathrm{NaCl}$, dessorção em fase móvel etanol:metanol $(50: 50, v / v)+0,2 \%$ TEA a $25^{\circ} \mathrm{C}$ por 5 minutos. Concentração 25 $\mu \mathrm{g} \mathrm{mL} \mathrm{L}^{-1}$ de cada analito. $n=3$

Figura 16 - Esquema de extração por SPME empregando fibras C18 e agitador tipo Vibrax®. Possibilidade de extrair 36 amostras ao mesmo tempo

Figura 17 - Efeito da adição de $\mathrm{NaCl}$ na recuperação da RISP e dos enantiômeros de seus metabólitos (9-RispOH e 7-RispOH) em meio de cultura líquido Czapeck. Extração 45 minutos a $23^{\circ} \mathrm{C} \pm$ $2^{\circ} \mathrm{C}$ e agitação de $900 \mathrm{rpm} ; 2 \mathrm{~mL}$ meio de cultura e $2 \mathrm{~mL}$

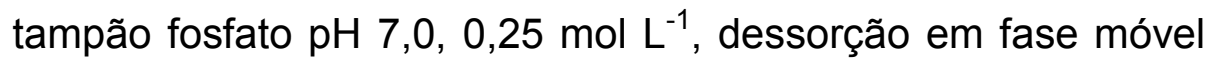
etanol:metanol $(50: 50, \mathrm{v} / \mathrm{v})+0,2 \%$ TEA a $25^{\circ} \mathrm{C}$ por 5 minutos. Concentração $25 \mu \mathrm{g} \mathrm{mL}^{-1}$ de cada analito. $n=3$. 
Figura 18 - Efeito da mudança de pH na recuperação da RISP e dos enantiômeros de seus metabólitos (9-RispOH e 7-RispOH) em meio de cultura líquido Czapeck. Extração 45 minutos a $23^{\circ} \mathrm{C} \pm$ $2^{\circ} \mathrm{C}$ e agitação de $900 \mathrm{rpm} ; 2 \mathrm{~mL}$ meio de cultura e $2 \mathrm{~mL}$ tampão fosfato ( $\mathrm{pH}$ variado), $0,25 \mathrm{~mol} \mathrm{~L}^{-1}+20 \% \mathrm{NaCl}(\mathrm{m} / \mathrm{v})$, dessorção em fase móvel etanol:metanol $(50: 50, \mathrm{v} / \mathrm{v})+0,2 \%$ TEA a $25^{\circ} \mathrm{C}$ por 5 minutos. Concentração $25 \mu \mathrm{g} \mathrm{mL}^{-1}$ de cada analito. $n=3 \ldots$

Figura 19 - Efeito da agitação na recuperação da RISP e dos enantiômeros de seus metabólitos (9-RispOH e 7-RispOH) em meio de cultura líquido Czapeck. Extração 45 minutos a $23^{\circ} \mathrm{C} \pm 2^{\circ} \mathrm{C}$. $2 \mathrm{~mL}$ meio de cultura e $2 \mathrm{~mL}$ tampão fosfato $(\mathrm{pH} 7,0), 0,25 \mathrm{~mol} \mathrm{~L}^{-1}+20 \%$ $\mathrm{NaCl}(\mathrm{m} / \mathrm{v})$, dessorção em fase móvel etanol:metanol (50:50, $\mathrm{v} / \mathrm{v})+0,2 \%$ TEA a $25^{\circ} \mathrm{C}$ por 5 minutos. Concentração $25 \mathrm{\mu g} \mathrm{mL}^{-}$

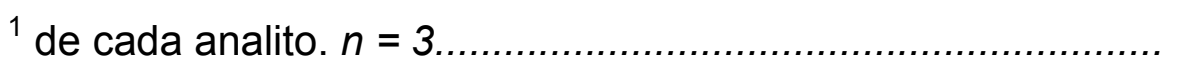

Figura 20 - Efeito do tempo de extração na recuperação da RISP e dos enantiômeros de seus metabólitos (9-RispOH e 7-RispOH) em meio de cultura líquido Czapeck. Extração a $23^{\circ} \mathrm{C} \pm 2{ }^{\circ} \mathrm{C}$ com agitação a $600 \mathrm{rpm} .2 \mathrm{~mL}$ meio de cultura e $2 \mathrm{~mL}$ tampão fosfato $(\mathrm{pH} 7,0), 0,25 \mathrm{~mol} \mathrm{~L}^{-1}+20 \% \mathrm{NaCl}(\mathrm{m} / \mathrm{v})$, dessorção em fase móvel etanol:metanol $(50: 50, \mathrm{v} / \mathrm{v})+0,2 \%$ TEA por 5 minutos. Concentração $25 \mu \mathrm{g} \mathrm{mL}^{-1}$ de cada analito. $n=3$.

Figura 21 - Efeito do volume de matriz na recuperação da RISP e dos enantiômeros de seus metabólitos (9-RispOH e 7-RispOH) em meio de cultura líquido Czapeck. Extração em 30 min a $23^{\circ} \mathrm{C} \pm$ $2^{\circ} \mathrm{C}$ com agitação a $600 \mathrm{rpm}$. Meio de cultura (quantidade variada) completando-se com tampão fosfato $(\mathrm{pH} \mathrm{7,0)} 0,25 \mathrm{~mol}$ $\mathrm{L}^{-1}$ (em um volume final de $\left.4 \mathrm{~mL}\right)+20 \% \mathrm{NaCl}(\mathrm{m} / \mathrm{v})$, dessorção em fase móvel etanol:metanol $(50: 50, \mathrm{v} / \mathrm{v})+0,2 \%$ TEA a $25^{\circ} \mathrm{C}$ por 5 minutos. Concentração $25 \mu \mathrm{g} \mathrm{mL}^{-1}$ de cada analito. $n=$ 3. 
Figura 22 - Efeito do tempo de dessorção na análise da RISP e dos enantiômeros de seus metabólitos (9-RispOH e 7-RispOH) em meio de cultura líquido Czapeck. Extração em 30 min a $23^{\circ} \mathrm{C} \pm$ $2^{\circ} \mathrm{C}$ com agitação a $600 \mathrm{rpm} .2 \mathrm{~mL}$ de meio de cultura Czapeck acrescido de $2 \mathrm{~mL}$ tampão fosfato ( $\mathrm{pH} 7,0), 0,25 \mathrm{~mol} \mathrm{~L}^{-1}+20 \%$ $\mathrm{NaCl}(\mathrm{m} / \mathrm{v})$, dessorção em fase móvel etanol:metanol (50:50, $\mathrm{v} / \mathrm{v})+0,2 \%$ TEA. Concentração $25 \mu \mathrm{g} \mathrm{mL}{ }^{-1}$ de cada analito. $n=$ 3.

Figura 23 - Efeito "carryover" na dessorção da RISP e dos enantiômeros de seus metabólitos (9-RispOH e 7-RispOH) em meio de cultura líquido Czapeck. Extração em $30 \mathrm{~min}$ a $23^{\circ} \mathrm{C} \pm 2^{\circ} \mathrm{C}$ com agitação a $600 \mathrm{rpm} .2 \mathrm{~mL}$ de meio de cultura Czapeck acrescido

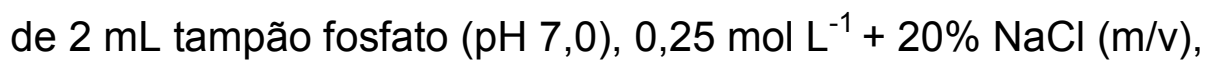
dessorção em fase móvel etanol:metanol $(50: 50, \mathrm{v} / \mathrm{v})+0,2 \%$ TEA. Concentração $25 \mu \mathrm{g} \mathrm{mL}^{-1}$ de cada analito. $n=3 \ldots \ldots \ldots \ldots \ldots . . .90$

Figura 24 - Condições otimizadas para SPME para a análise da RISP, 7RispOH e 9-RispOH em meio de cultura líquido Czapeck.

Figura 25 - Efeito da recuperação na extração dos analitos a partir do meio de cultura líquido Czapeck e do pool fungos empregando as condições estabelecidas na SPME. Concentrações de analito: risperidona $500 \mathrm{ng} \mathrm{mL}^{-1}$, metabólitos $187 \mathrm{ng} \mathrm{mL}^{-1}$. Nível de significância $\mathrm{p} \leq 0,05(n=6)$.

Figura 26 - Separação dos analitos na coluna Chiralcel OJ-H ${ }^{\circledast}$ e análise por LC-MS/MS. Cromatograma MRM de 3 canais; $1^{\circ}$ canal corresponde à transição de $\mathrm{m} / \mathrm{z} 428 \rightarrow 279$ para o padrão interno ranolazina; $2^{\circ}$ canal corresponde à transição de $\mathrm{m} / \mathrm{z} 427 \rightarrow 207$ para os metabólitos e o $3^{\circ}$ canal corresponde à transição de $\mathrm{m} / \mathrm{z}$ $411 \rightarrow 191$ para a risperidona. 1) Ranolazina 2) 7-RispOH (E1); 3) 7-RispOH (E2); 4) (+)-9-RispOH; 5) RISP e 6) (-)-9-RispOH. Fase móvel: etanol;metanol $(50: 50, v / v)+0,2 \%$ TEA, vazão: 0,8 $\mathrm{mL} \mathrm{min}^{-1}$, temperatura de análise $25^{\circ} \mathrm{C}$..

Figura 27 - Estruturas químicas da RISP (A), 9-RispOH (B) e Ranolazina (C) 
Figura 28 - A) Cromatograma representativo de meio de cultura líquido Czapeck incubado com o Cunninghamella echinulata var. elegans ATCC 8688A (controle) mostrando que este fungo não produz quaisquer metabólitos secundários no tempo de retenção dos analitos. B) Cromatograma representativo de 3 canais em modo MRM do fungo Cunninghamella echinulata var. elegans ATCC 8688A, após 168 horas de incubação. Padrão interno (1), (+)-9-RispOH (2) e RISP (3). Condições de separação e análise descritas, respectivamente, em 3.2.3. e 3.3

Figura 29 - A) Cromatograma representativo de meio de cultura líquido Czapeck incubado com o Cunninghamella elegans ATCC 10028B (controle) mostrando que este fungo não produz quaisquer metabólitos secundários no tempo de retenção dos analitos. B) Cromatograma representativo em modo MRM do fungo Cunninghamella elegans ATCC 10028B, após 168 horas de incubação com o padrão da RISP. Padrão interno (1), (+)-9RispOH (2), RISP (3) e (-)-9-RispOH (4). Condições de separação e análise descritas, respectivamente, em 3.2.3. e 3.3

Figura 30 - Cromatograma após 24 horas de reação com o catalisador $(S, S)$-Jacobsen utilizando como oxidante $m$-CPBA, na proporção 1:50:50 (catalisador:oxidante:substrato, em número de mols e condições descritas na seção 3.7.7). Condições cromatográficas descritas na seção 4.1.7. (A) Cromatograma relativo à catálise com o catalisador de Jacobsen. (B) Controle de reação. 1) 7-RispOH (E1) e 2) RISP

Figura 31 - Cromatograma após 24 horas de reação com o catalisador $(S, S)$-Jacobsen utilizando como oxidante $\mathrm{PhIO}$, na proporção 1:50:50 (catalisador:oxidante:substrato, em número de mols e condições descritas na seção 3.7.7). Condições cromatográficas descritas na seção 4.1.7. Cromatograma relativo à catálise com 0 catalisador de Jacobsen.1) RISP 
Figura 32 - Cromatograma após 4 horas de reação com o catalisador (S,S)Jacobsen utilizando como oxidante $\mathrm{H}_{2} \mathrm{O}_{2}$, na proporção 1:50:50 (catalisador:oxidante:substrato, em número de mols e condições descritas na seção 3.7.7). Condições cromatográficas descritas na seção 4.1.7. Cromatograma relativo à catálise com o catalisador de Jacobsen.1) e 2) picos não-identificadas. 3) RISP 


\section{LISTA DE TABELAS}

Tabela 1 - Alguns tipos de colunas quirais baseadas em polissacarídeos......

Tabela 2 - Principais tipos de colunas quirais baseadas em antibióticos macrocíclicos.

Tabela 3 - Fibras de SPME disponíveis comercialmente para HPLC.

Tabela 4- Alguns estudos de biotransformação estereosseletiva com fungos...

Tabela 5 - Resumo das condições MS/MS para análise dos analitos.

Tabela 6 - Comparação dos resultados obtidos com a coluna Chiralcel OJ$\mathrm{H}^{\circledR}$ para diferentes fases móveis.

Tabela 7 - Linearidade do método desenvolvido para análise da RISP e seus metabólitos por SPME-LC-MS/MS em meio de cultura Czapeck e em pool de fungos.

Tabela 8 - Precisão e exatidão das amostras de pool de fungos para análise da RISP e seus metabólitos por SPME-LC-MS/MS, quantificadas com curva analítica preparada em meio de cultura líquido Czapeck

Tabela 9 - Limite de quantificação para análise da RISP e seus metabólitos por SPME-LC-MS/MS em meio de cultura Czapeck.

Tabela 10 - Recuperação do método para análise da RISP e seus metabólitos por SPME-LC-MS/MS.

Tabela 11 - Precisão e exatidão intraensaios do método desenvolvido para análise da RISP e seus metabólitos por SPME-LC-MS/MS em meio de cultura Czapeck.

Tabela 12 - Precisão e exatidão interensaio do método desenvolvido para análise da RISP e seus metabólitos por SPME-LC-MS/MS em meio de cultura Czapeck.

Tabela 13 - Teste de estabilidade do método desenvolvido para análise da RISP e seus metabólitos por SPME-LC-MS/MS, $(n=6)$...

Tabela 14 - Estudo do efeito da matriz na ionização dos analitos em meio de cultura líquido Czapeck e em pool de fungos.

Tabela 15 - Estudos de biotransformação empregando fungos do gênero Cunninghamella. 


\section{LISTA DE ABREVIATURAS E SIGLAS}

\begin{tabular}{|c|c|}
\hline ANOVA & Análise de variância \\
\hline ANVISA & Agência Nacional de Vigilância Sanitária \\
\hline $\mathrm{APCl}$ & Ionização química à pressão atmosférica \\
\hline API & lonização à pressão atmosférica \\
\hline APPI & Fotoionização à pressão atmosférica \\
\hline ATCC & American Type Culture Collection \\
\hline CE & Eletroforese capilar \\
\hline GC & Cromatografia gasosa \\
\hline$C_{\tilde{E}}^{z \infty}$ & Concentração de analito presente na fibra no equilíbrio \\
\hline $\mathrm{C}_{0}$ & Concentração inicial \\
\hline CSP & Fase estacionária quiral \\
\hline$C_{s}=$ & Concentração do analito presente na amostra no equilíbrio \\
\hline CYP & Citocromo \\
\hline CV & Coeficiente de variação \\
\hline CW-TPR & Carbowax-templated resin \\
\hline DLLME & Microextração líquido-líquido dispersiva \\
\hline DMF & Dimetilformamida \\
\hline$D_{w}$ & Coeficiente de difusão do analito na matriz \\
\hline ESI & Ionização por eletronebulização \\
\hline ES+ & Ionização por eletronebulização em modo positivo \\
\hline FDA & Food and Drug Administration \\
\hline HF-LPME & Microextração em fase líquida por membrana cilíndrica oca \\
\hline HPLC & Cromatografia líquida de alta eficiência \\
\hline $\mathrm{K}_{\mathrm{es}}$ & Constante de distribuição \\
\hline LC-MS & Cromatografia líquida acoplada à espectrometria de massas \\
\hline LC-MS/MS & Cromatografia líquida acoplada à espectrometria de massas sequencial \\
\hline LLE & Extração líquido-líquido \\
\hline $\log P$ & Coeficiente de partição \\
\hline LOQ & Limite de quantificação \\
\hline $\bar{M}$ & Média \\
\hline MRM & Monitoramento de reações múltiplas \\
\hline PA & Poliacrilato \\
\hline PDA & Potato Dextrose Agar \\
\hline PDMS & Polidimetilsiloxano \\
\hline PDMS-DVB & Polidimetilsiloxano-divinilbenzeno \\
\hline $\mathrm{PI}$ & Padrão interno \\
\hline PVC & Poli cloreto de vinila \\
\hline
\end{tabular}


Q

QqQ

Q-ToF

RISP

7-RispOH

9-RispOH

$r_{i}$

$r_{0}$

Rs

SBSE

SPE

SPME

$t_{e}$

TEA

$t_{R}$

$\mathrm{Ve}$

Vs

$\mathrm{W}_{\mathrm{b}}$

$\delta$
Analisador quadrupolo

Analisador do tipo triploquadrupolo

Analisador do tipo quadrupolar sequencial com analisador por tempo de vôo Risperidona

7-hidroxirisperidona

9-hidroxirisperidona

Raio interno da fibra

Raio externo da fibra

Resolução

Microextração sortiva em barra de agitação

Extração por fase sólida

Microextração em fase sólida

Tempo de equilíbrio

Trietilamina

Tempo de retenção

Volume do polímero

Volume da matriz

Largura da base do pico cromatográfico

Camada estática formada ao redor da fibra 


\section{SUMÁRIO}

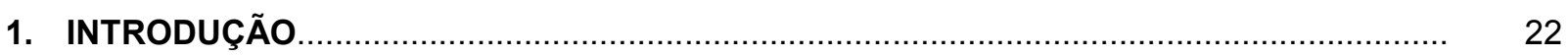

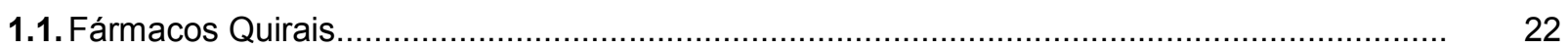

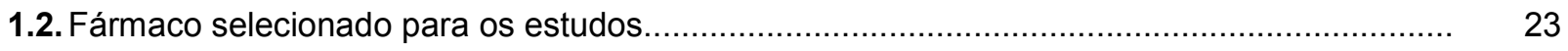

1.2.1. Análise da risperidona e seus metabólitos quirais em matrizes biológicas: Revisão da literatura......

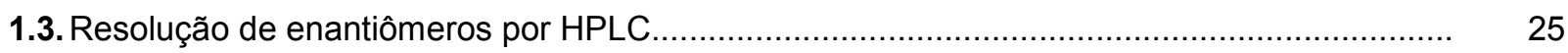

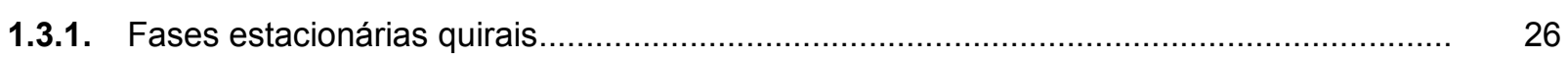

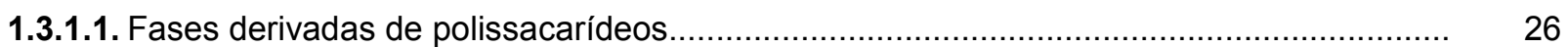

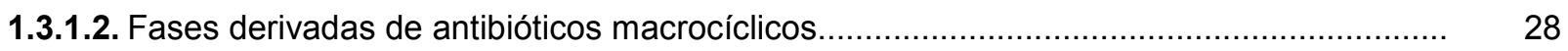

1.3.2. Modos de eluição empregados em cromatografia quiral................................................. 29

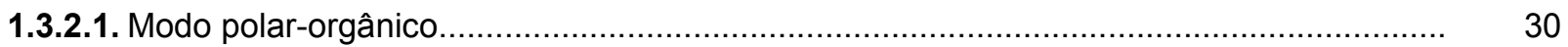

1.4. Cromatografia líquida de alta eficiência acoplada à espectrometria de massas seqüencial (LC-MS/MS)

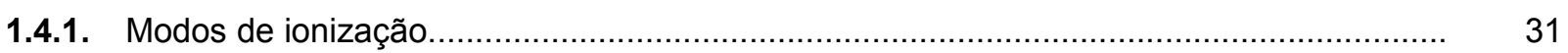

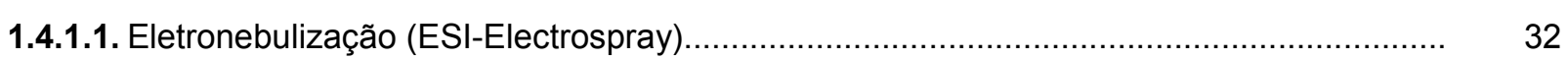

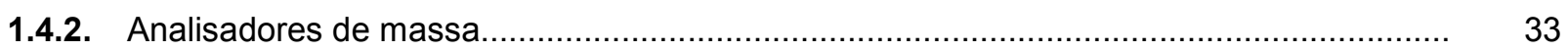

1.4.2.1. Triplo quadrupolo $(\mathrm{QqQ})$ e modos de aquisição em QqQ............................................ 34

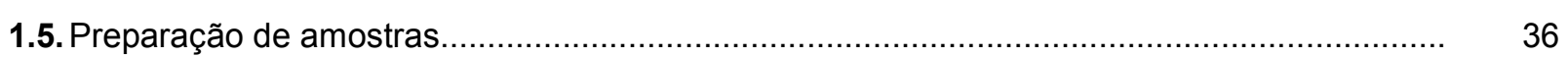

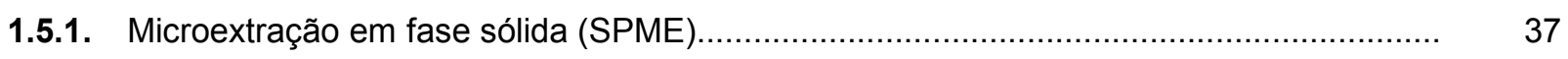

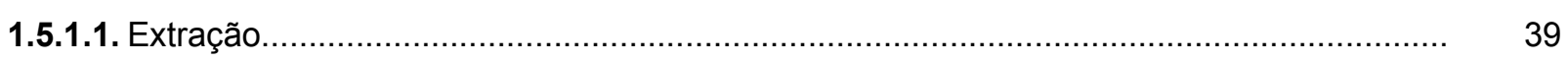

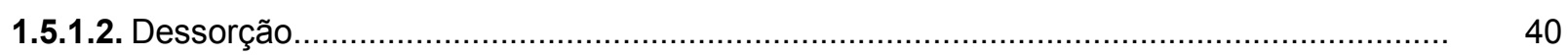

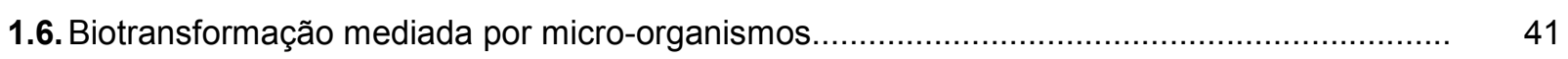

1.6.1. Biotransformação estereosseletiva mediada por fungos................................................ 42

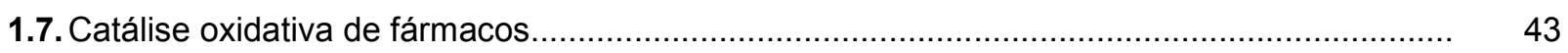

1.7.1. Catálise assimétrica empregando complexos de Jacobsen............................................. 44

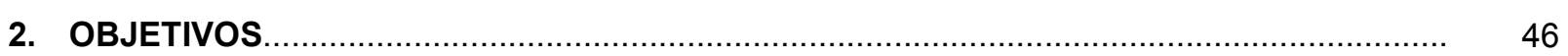

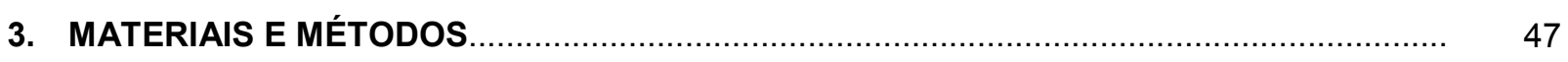

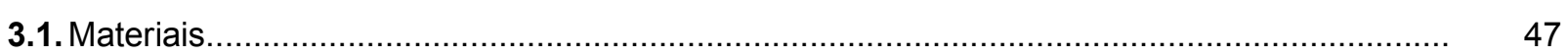

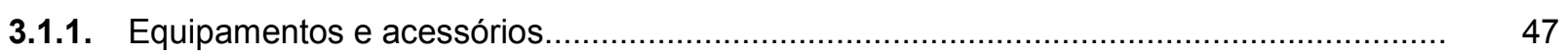

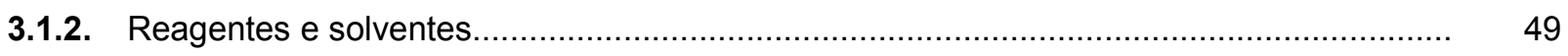

3.1.3. Colunas quirais e coluna de guarda...................................................................... 50

3.1.4. Soluções-padrão de risperidona, seus metabólitos e padrão interno.................................. 51

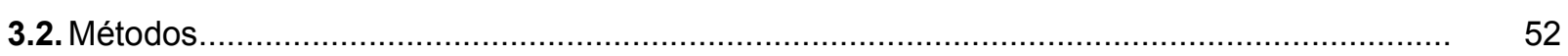

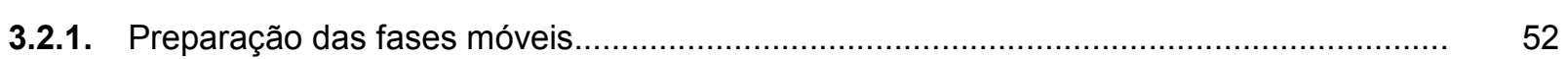

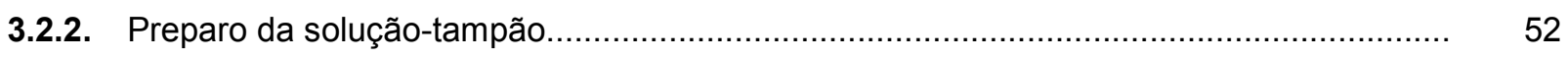

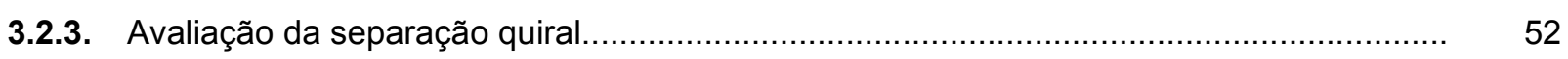

3.3. Otimização da detecção dos analitos por espectrometria de massas seqüencial (MS/MS)..... 53 
3.4. Ordem de eluição da 9-RispOH

3.5. Procedimento de preparação de amostras para análise dos analitos em meio de cultura..............

3.6. Validação da metodologia analítica.

3.6.1. Curva analítica e linearidade.

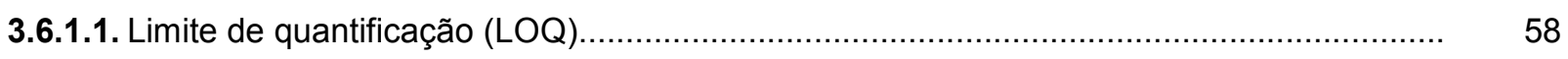

3.6.2. Recuperação.

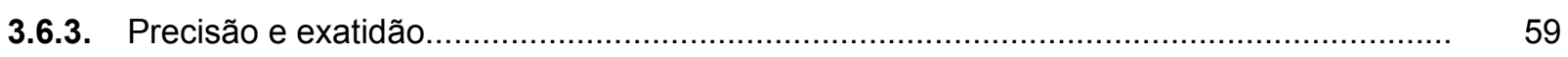

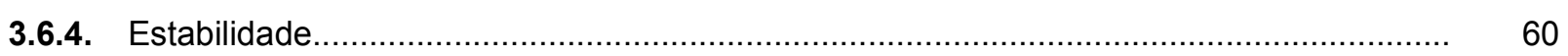

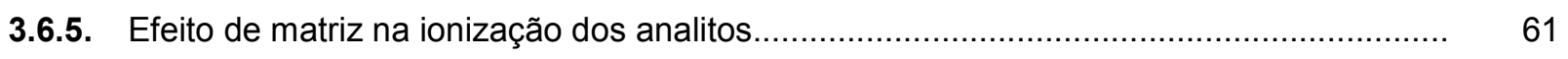

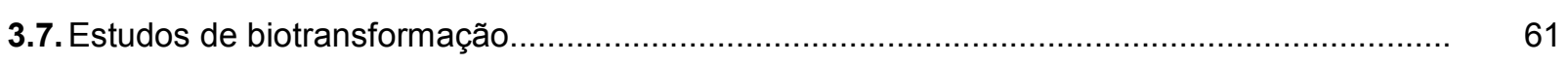

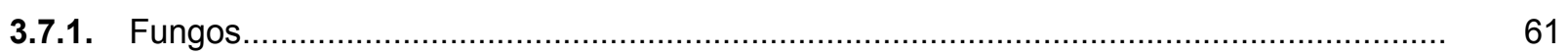

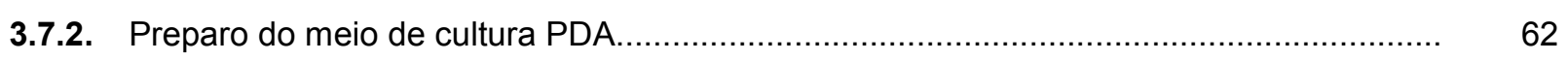

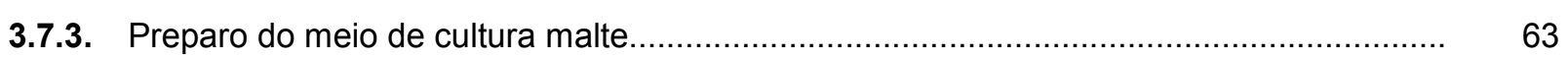

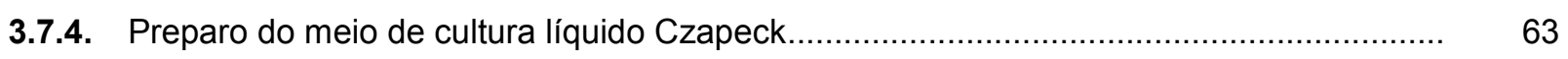

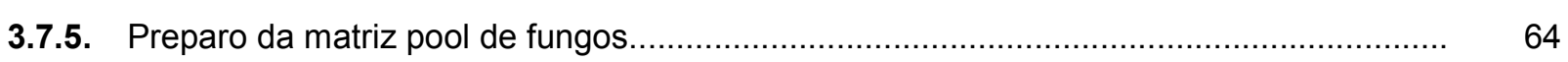

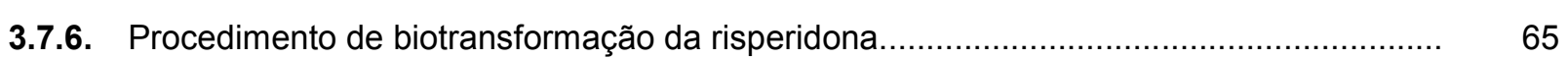

3.7.7. Estudos preliminares de catálise assimétrica empregando complexos de Jacobsen........ 66

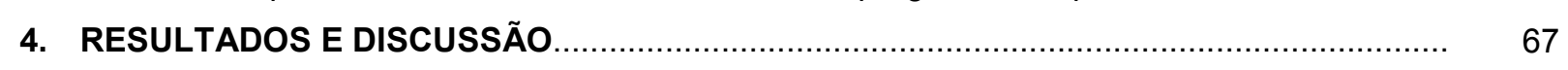

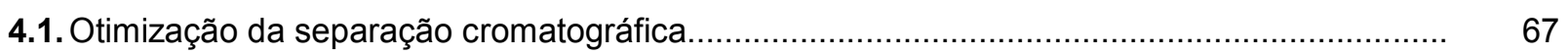

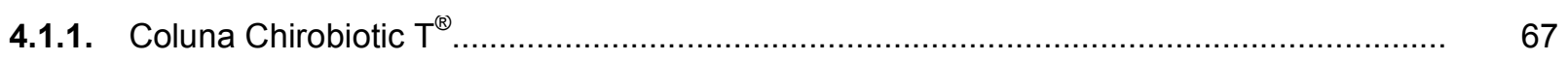

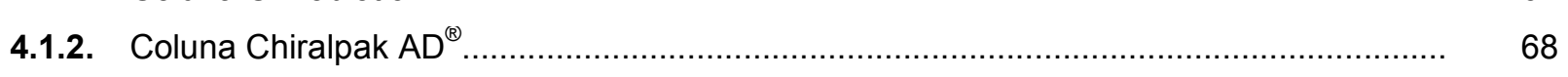

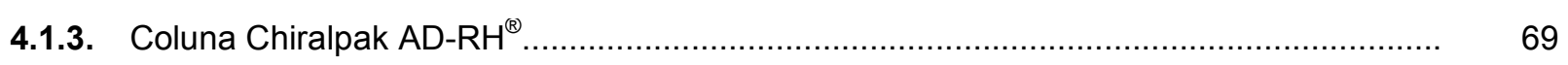

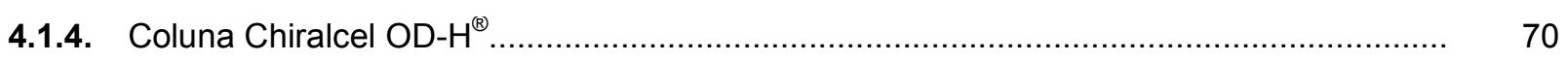

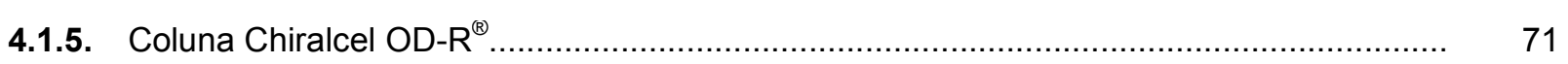

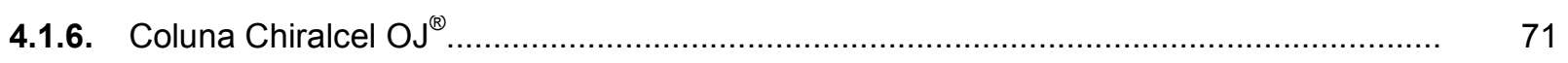

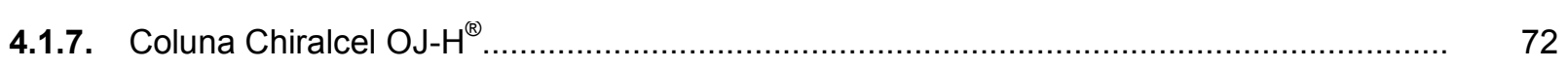

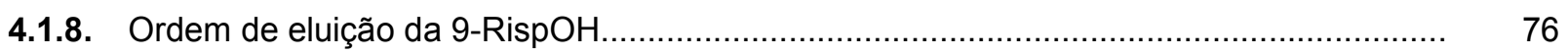

4.2. Preparação das amostras em meio de cultura empregando SPME........................................ 77

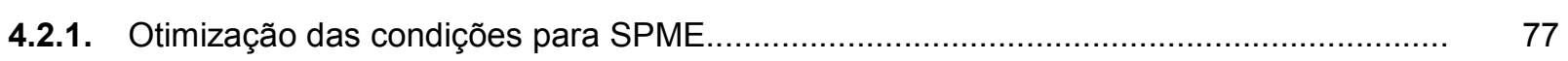

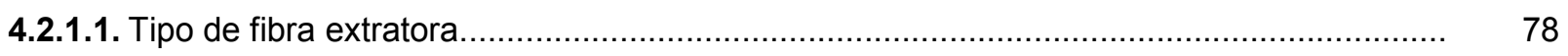

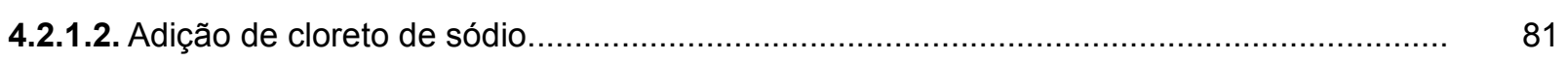

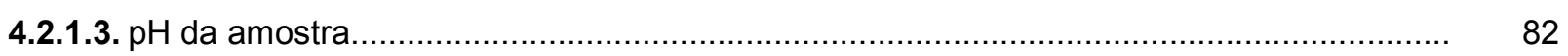

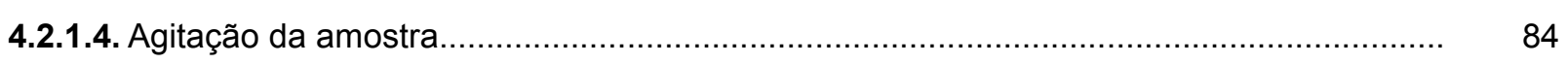

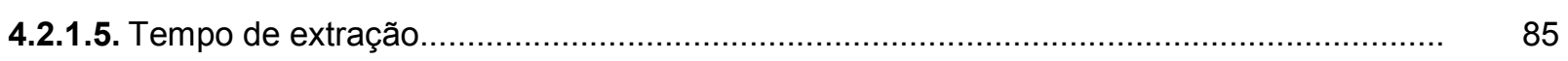

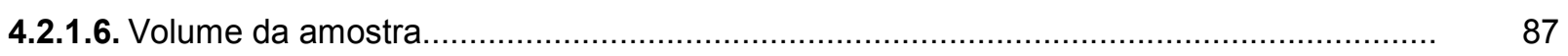

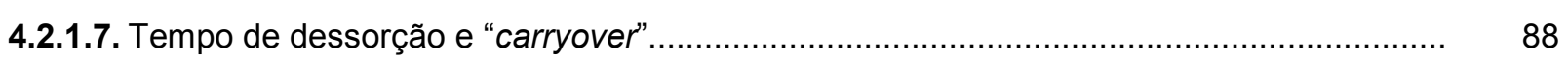

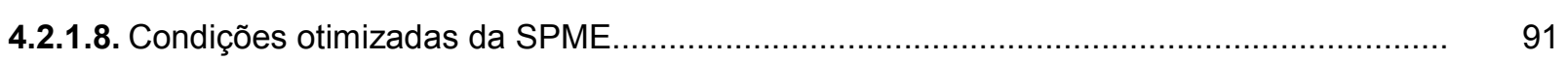

4.2.1.9. Eficiência na extração empregando diferentes matrizes............................................... 92

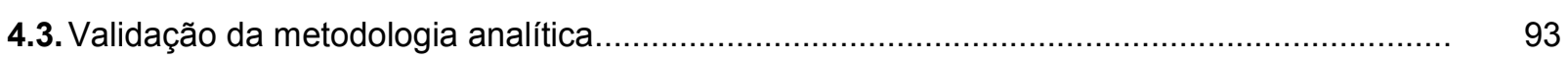

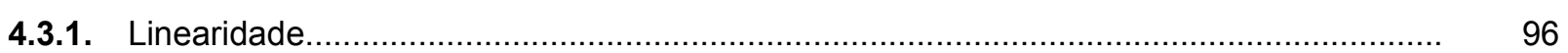


4.3.2. Limite de Quantificação...................................................................................... 98

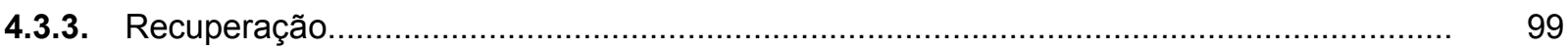

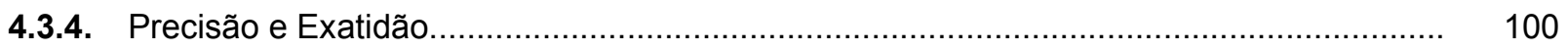

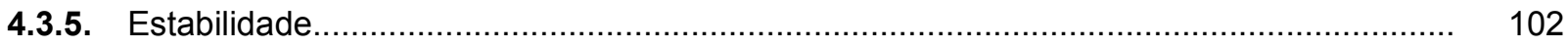

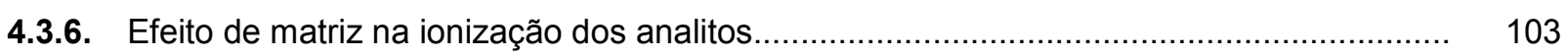

4.4. Aplicação do método em estudos de biotransformação com fungos...................................... 104

4.5. Estudos preliminares de catálise assimétrica da RISP empregando complexos de Salen...... 108

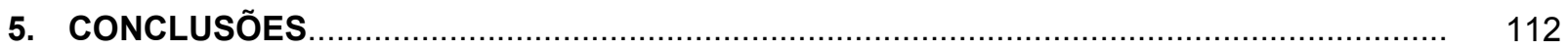

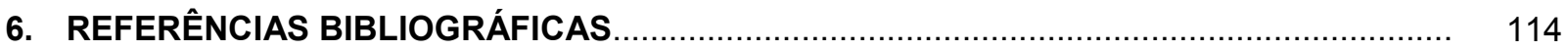




\section{1- INTRODUÇÃO}

\subsection{FÁRMACOS QUIRAIS}

Enantiômeros são compostos que partilham essencialmente as mesmas propriedades físico-químicas tais como: índice de refração, ponto de fusão, ponto de ebulição e solubilidade. Entretanto, diferem quanto à sua estrutura tridimensional e com a interação com uma luz plano-polarizada que apresenta um ângulo de rotação diferente para os diferentes enantiômeros (MORI, 2011). Essa diferença na estrutura tridimensional destes compostos pode ocasionar diferenças bioquímicas significativas no organismo dos seres vivos uma vez que macromoléculas biológicas tais como enzimas e receptores podem apresentar seletividade e reconhecimento quiral a um determinado enantiômero (MISLANOVÁ et al., 2003).

Muitos medicamentos são comercializados na forma de racematos (mistura em igual proporção dos dois enantiômeros), contudo os enantiômeros de determinado fármaco podem apresentar acentuadas diferenças na atividade farmacológica, seja na sua farmacocinética (absorção, distribuição, metabolismo e excreção) seja na sua farmacodinâmica (interação dos enantiômeros com os sítios alvos de ação). Dessa forma, um estudo detalhado com os enantiômeros individuais deve ser realizado antes de sua comercialização para que suas propriedades farmacológicas e toxicológicas sejam caracterizadas e bem estabelecidas (NATARAJAN; BASAK, 2011).

Devido o reconhecimento da grande importância em se estudar as propriedades dos enantiômeros individualmente, foram estabelecidas algumas mudanças na legislação referentes ao desenvolvimento de fármacos (SILVA JÚNIOR et al., 2006; SMITH, 2009). Órgãos regulamentadores internacionais tornaram as legislações mais rígidas no controle de qualidade de fármacos quirais. Nos Estados Unidos, o FDA ("Food and Drug Administration"), tem colocado exigências mais rigorosas quanto à concessão de novas patentes de fármacos racêmicos, exigindo uma documentação completa quanto o perfil farmacológico e farmacocinético dos enantiômeros individuais e de suas combinações (SILVA JÚNIOR et al., 2006). A importância do fator racemato versus enantiômeros também possibilitou uma nova estratégia de mercado na 
indústria farmacêutica denominada "chiral switch" que viabiliza a produção de "novos" medicamentos na forma de enantiômeros puros, o que reforça ainda mais o desenvolvimento de técnicas analíticas capazes de quantificar precisamente os enantiômeros (ISAKE, 2007).

Dessa forma, técnicas que possibilitam a análise e discriminação dos enantiômeros vêm se tornando importantes em química analítica, especialmente no desenvolvimento de novos medicamentos. Entre as maneiras utilizadas para o entendimento da estereoquímica nas propriedades farmacocinéticas de fármacos quirais estão: o desenvolvimento de métodos de análise com possibilidade de separação; identificação e quantificação de isômeros isolados (BONATO; JABOR; GAITANI, 2005).

\subsection{Fármaco SELECIONADO PARA OS ESTUdos}

O fármaco selecionado para este projeto foi a risperidona (RISP). A RISP é um agente antipsicótico usado no tratamento de distúrbios psiquiátricos como déficit de atenção; hiperatividade em crianças e esquizofrenia (FRAGOSO et al., 2012). Ele age bloqueando os receptores de serotonina 5$\mathrm{HT}_{2}$ e de dopamina $\mathrm{D}_{2}$ (MEULDER et al., 2008).

Essa nova classe terapêutica, muitas vezes referida como antipsicóticos atípicos, difere dos antipsicóticos convencionais no perfil de ligação com os receptores de serotonina e dopamina. A melhor tolerabilidade dos antipisicóticos atípicos está ligada ao bloqueio reduzido do receptor dopamina $\left(D_{2}\right)$ responsável em grande parte pelos efeitos colaterais de antipsicóticos (STAHL et al., 2003).

Após sua administração via oral, a RISP é rapidamente e completamente absorvida pelo trato gastrointestinal e sofre um extenso metabolismo mediado pelas enzimas do citocromo P450 isoforma 2D6, resultando em metabólitos provenientes de reações de hidroxilação (HEYKANT et al., 1994). Os metabólitos formados destas reações são a 9hidroxirisperidona (9-RispOH) e com menor predominância, a 7hidroxirisperidona (7-RispOH) (HUANG et al., 1993; MANNENS et al., 1994) (Figura 1). Os metabólitos 9-RispOH e 7-RispOH possuem um centro quiral, 
sendo possível a presença de dois enantiômeros para cada metabólito. O principal metabólito, 9-RispOH, apresenta as mesmas atividades farmacológicas que a RISP (VAN et al., 1994) e por isso já é comercializado como fármaco com o nome genérico de paliperidona.

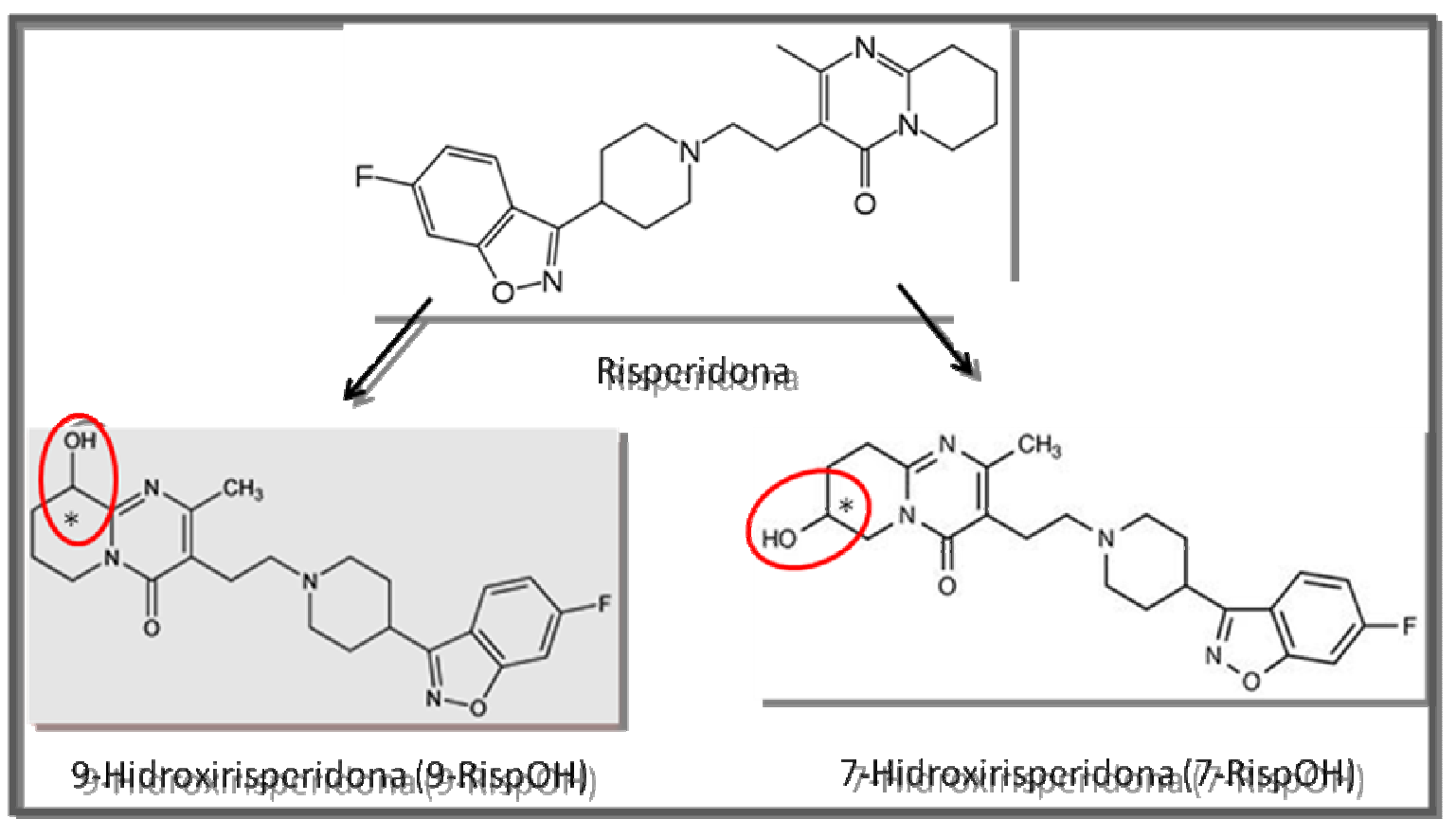

Figura 1 - Esquema de metabolismo da risperidona pelas enzimas do CYP 450 com formação majoritária da 9-RispOH

\subsubsection{ANÁLISE DA RISPERIDONA E SEUS METABÓLITOS QUIRAIS EM MATRIZES} BIOLÓGICAS: REVISÃO DA LITERATURA

Alguns métodos bioanalíticos estereosseletivos foram desenvolvidos para quantificação da RISP e 9-RispOH (CABOVSKA et al., 2007; MEULDER et al., 2008; LOCATELLI et al., 2009; DE JESUS et al., 2011) em fluidos biológicos. Tais métodos utilizam como instrumentos de determinação: HPLC, LC-MS e eletroforese capilar, sendo que a maioria dos métodos descritos utiliza como matriz biológica plasma humano. Um estudo do perfil farmacocinético da RISP e 9-RispOH empregando plasma de pacientes pediátricos que usam RISP, foi realizado por LC-MS/MS pelo grupo de 
Cabovska et al (2007). Nesse estudo os autores empregaram como técnica de preparação de amostras a extração líquido-líquido. Os resultados mostraram uma maior prevalência do enantiômero (+)-9-RispOH em plasma. Outro estudo em plasma humano e urina na determinação da RISP e 9-RispOH empregando LC-MS/MS foi realizado por Meulder et al (2008). Nesse estudo os autores empregaram como técnica de preparação de amostras a extração em fase sólida. Os resultados mostraram uma maior prevalência do enantiômero (+)-9RispOH tanto em plasma como em urina. Já, Locatelli et al (2009), empregaram HPLC com detector eletroquímico para estudos de quantificação da RISP e 9-RispOH em plasma humano. Nesse estudo os autores empregaram como técnica de preparação de amostras a extração em fase sólida. Os resultados mostraram também uma maior prevalência do enantiômero (+)-9-RispOH em plasma. Estudos de biotransformação estereosseletiva da RISP empregando fungos e eletroforese capilar foram realizados por Jesus et al (2011). Nesse estudo a biotransformação foi realizada pelo fungo de solo Mucor rouxii. Os estudos mostraram um favorecimento em formação do enantiômero (-)-9-RispOH.

\subsection{RESOLUÇÃo de ENANTIÔMEROS POR HPLC}

A separação cromatográfica de enantiômeros empregando a cromatografia líquida de alta eficiência pode ser feita de duas formas: (i) empregando métodos indiretos e (ii) métodos diretos. Os métodos indiretos são raramente utilizados devido a algumas dificuldades operacionais encontradas e a grande eficiência apresentada pelos métodos diretos, empregando colunas com fases estacionárias quirais (CSPs). No método direto, ocorre a formação de diastereoisômeros transitórios entre os enantiômeros e o seletor quiral presente na CSP. Esses diastereoisômeros podem apresentar constantes de interação diferentes, possibilitando assim a separação dos enantiômeros, que consequentemente, terão tempos de retenção diferentes (QIU et al., 2011). 


\subsubsection{FASES ESTACIONÁRIAS QUIRAIS}

O uso de métodos diretos com fases estacionárias quirais é preferido devido à facilidade de desenvolvimento do método, menor custo, robustez, maior praticidade e, também, devido à aplicabilidade em separações em escala analítica e preparativa (QIU et al., 2011).

As fases estacionárias quirais que são frequentemente utilizadas na resolução de enantiômeros são baseadas em derivados de polissacarídeos, proteínas e antibióticos macrocíclicos. Nesse trabalho serão discutidas apenas as CSP avaliadas durante o desenvolvimento do projeto: (i) baseadas em polissacarídeos e (ii) antibióticos macrocíclicos. Maiores detalhes sobre as CSP baseadas em proteínas podem ser encontrados na revisão descrita por HAGINAKA (2011).

\subsubsection{FASES ESTACIONÁRIAS DERIVADAS DE POLISSACARÍDEOS}

Entre as diversas CSP utilizadas na separação de enantiômeros, as derivadas de polissacarídeos são as mais utilizadas. Essas CSP são sintetizadas a partir de amilose ou celulose como polímero. Esses polissacarídeos são facilmente encontrados in natura e, embora sejam capazes de discriminar enantiômeros e resolver misturas racêmicas, o seu reconhecimento quiral é limitado e derivados podem ser obtidos por modificações químicas nos polímeros dos polissacarídeos (QIU et al., 2011). Estes polissacarídeos podem ser facilmente convertidos em derivados de fenilcarbamatos e triésteres suportados ou ligados em sílica criando, desta forma, novos sítios de reconhecimento quiral além de aumentar a estabilidade mecânica da fase estacionária resultante (QIU et al., 2011).

O mecanismo de interação entre os enantiômeros e as CSP depende do polissacarídeo empregado (amilose ou celulose) e da forma com que os enantiômeros irão se encaixar nas cavidades formadas na estrutura da fase estacionária. Além disso, as interações intermoleculares como as ligações hidrogênio, interações dipolo-dipolo e interações m-ா (LAMMERHOFER, 2010) 
contribuem de forma significativa para o mecanismo de interação, principalmente na interação com os resíduos de carbamatos e benzoatos presentes nos polímeros derivados. A Tabela 1 mostra alguns tipos de seletores quirais de colunas derivadas de polissacarídeos. Estudos têm mostrado que estas fases estacionárias derivadas de polissacarídeos podem ser empregadas nos modos de eluição normal, reverso e polar-orgânico desde que um pré-condicionamento da coluna seja realizado antes da conversão (CASS et al., 2000; QIU et al., 2011) evitando assim possíveis danos à CSP.

Tabela 1 - Alguns tipos de colunas quirais baseadas em polissacarídeos (http://www.daicelchiral.com/appguide/index/column_table.htm; http://www.allcrom.com.br/colunas-hplc/lux. Acessado em 11/06/2012)

\begin{tabular}{|c|c|}
\hline Derivados de polissacarídeos & Nome Comercial \\
\hline \multirow{2}{*}{ Celulose tris (4-metilbenzoato) } & Chiralcel OJ / Chiralcel OJ-H / Chiralcel OJ- \\
\hline & RH / Lux Cellulose 3 \\
\hline Celulose tribenzoato & Chiralcel OB / Chiralcel OB-H \\
\hline Celulose tricinamato & Chiralcel OK \\
\hline Celulose microcristalina triacetato & Chiralcel CA-1 \\
\hline Celulose triacetato & Chiralcel OA \\
\hline \multirow{2}{*}{ Celulose tris (3,5-dimetilfenilcarbamato) } & Chiralcel OD / Chiralcel OD-H / Chiralcel \\
\hline & OD-R / Lux Cellulose 1 \\
\hline \multirow{2}{*}{ Amilose tris (3,5-dimetilfenilcarbamato) } & Chiralpak AD / Chiralpak AD-H / Chiralpak \\
\hline & AD-R \\
\hline \multirow{2}{*}{ Amilose tris [(S)-1-feniletilcarbamato] } & Chiralpak AS / Chiralpak AS-H / Chiralpak \\
\hline & AS-R \\
\hline Celulose tris (4-cloro-3-metilfenilcarbamato) & Lux Cellulose 4 \\
\hline Amilose tris (5-cloro-2-metilfenilcarbamato) & Lux Amylose 2 \\
\hline
\end{tabular}




\subsubsection{FASES DERIVADAS DE ANTIBIÓTICOS MACROCÍ́CLICOS}

As CSP derivadas de antibióticos macrocíclicos para uso em HPLC foram introduzidas por Armstrong et al em 1994. Essas CSP são sintetizadas pela imobilização covalente de glicopeptídeos macrocíclicos como a vancomicina, rifamicina $B$, teicoplanina, tiostreptona, ristocetina $A$ e outros em um suporte de sílica (LOURENÇO; CASSIANO; CASS, 2010). Os antibióticos macrocíclicos apresentam diversas cavidades quirais e diversos tipos de grupos funcionais de caráter ácido, básico ou neutro, o que lhes proporcionam a possibilidade de diferentes interações com os analitos como: $\Pi$ - $\pi$, ligações de hidrogênio, interações dipolo-dipolo, interações estéreas, formação de complexos de inclusão e interações eletrostáticas. O tipo de interação dependerá das condições da fase móvel empregada, tais como $\mathrm{pH}$ e presença de aditivos. Como exemplo da complexidade e da diversidade de interações que uma CSP deste tipo possui, pode-se citar a vancomicina. Esse antibiótico macrocíclico possui 18 centros quirais, 3 cavidades macrocíclicas contendo 5 anéis aromáticos e 2 cadeias laterais; uma delas é um carboidrato dímero e a outra, um $\mathrm{N}$-metil aminoácido. Em sua estrutura está presente também diversos grupos funcionais como 9 grupos hidroxila, 2 grupos amino, 7 grupos amidas e 2 átomos de cloro substituintes de anéis aromáticos (ARMSTRONG et al., 1994; ILISZ et al., 2006; ILISZ et al., 2009).

As principais vantagens no uso destas CSP são: possibilidade do uso nos três modos de eluição, alta estabilidade mecânica, moderada relação custo/benefício e alta capacidade de amostra podendo ser usada também em escala preparativa (WARD et al., 2001). A Tabela 2 mostra a principais CSP baseadas em antibióticos macrocíclicos, suas dimensões e seletor quiral presente. 
Tabela 2 - Principais tipos de colunas quirais baseadas em antibióticos macrocíclicos. http://www.sigmaaldrich.com/analytical-chromatography/hplc/columns/chiral/chirobiotic-r.html. Acessado em 12/06/2012.

\begin{tabular}{llcc}
\hline Nome comercial & Seletor quiral & Tamanho de poro & Tamanho de partícula \\
\hline Chirobiotic V & Vancomicina & $100 \AA$ & $5 \mu \mathrm{m}$ \\
Chirobiotic V2 & Vancomicina & $200 \AA$ & $5 \mu \mathrm{m}$ \\
Chirobiotic T & Teicoplanina & $100 \AA$ & $5 \mu \mathrm{m}$ \\
Chirobiotic T2 & Teicoplanina & $200 \AA$ & $5 \mu \mathrm{m}$ \\
Chirobiotic TAG & teicoplanina aglicona & $100 \AA$ & $5 \mu \mathrm{m}$ \\
Chirobiotic R & ristocetina A & $100 \AA$ & $5 \mu \mathrm{m}$ \\
\hline
\end{tabular}

\subsubsection{MOdOS DE ELUIÇÃO EMPREGADOS EM CROMATOGRAFIA QUIRAL}

A escolha do solvente utilizado na fase móvel precisa respeitar algumas características impostas pelo método analítico. A principal característica é que a fase móvel dissolva a amostra e não decomponha seus componentes ou a fase estacionária. Em cromatografia líquida quiral pode-se classificar os modos de eluição baseado na polaridade dos solventes utilizados, sendo estes: (i) modo normal cuja fase móvel é composta predominantemente por solventes apolares, como hexano; (ii) modo reverso, onde a fase móvel é composta predominantemente por misturas aquosas de solventes polares e, mais recentemente o (iii) modo polar-orgânico cuja fase móvel é composta somente por solventes orgânicos polares ou mistura destes (MATTHIJS et al., 2006). No desenvolvimento desse projeto foi enfatizado o uso do modo polar-orgânico de eluição, principalmente devido sua alta compatibilidade com o espectrômetro de massas. Dessa forma, somente esse modo de eluição será descrito na seção seguinte. 


\subsubsection{MOdO POLAR-ORgÂNICO}

O modo polar orgânico é um modo em cromatografia líquida quiral que ainda é pouco explorado. Este tipo de fase móvel faz o emprego somente de solventes orgânicos polares puros ou misturas destes, como, por exemplo, metanol, etanol, acetonitrila e isopropanol.

Esse modo possui diversas vantagens. $\mathrm{O}$ uso de solventes orgânicos puros pode oferecer mecanismos alternativos de reconhecimento quiral e solubilizar melhor alguns analitos pouco solúveis em água. Além disso, a quantidade de solventes orgânicos usada é baixa devido à baixa vazão empregada; os solventes orgânicos polares empregados neste modo são potencialmente capazes de serem reciclados e, os analitos podem ser facilmente concentrados quando analisados em escala preparativa já que neste modo os solventes são facilmente evaporados (CHANKVETADZE et al., 2002; MATTHIJS et al., 2006).

No emprego deste modo de eluição em análises por espectrometria de massas, o uso de solventes orgânicos puros é vantajoso se comparado ao uso de fases móveis contendo grande quantidade de água como no modo reverso. Embora a água suporte a formação de íons, sua tensão superficial e energia de solvatação são maiores, e torna mais difícil a dessolvatação dos analitos alvo no processo de ionização se comparado aos solventes orgânicos polares como etanol e metanol (VOYKSNER, 1997). Por outro lado, o uso de fases móveis contendo solventes altamente apolares, como hexano acarreta problemas de segurança, necessitando muitas vezes, da diluição desse solvente na entrada da fonte de ionização, levando a problemas de detectabilidade (PĖREZ; BACELÓ, 2008).

\subsection{Cromatografia Líquida de Alta Eficiência Acoplada À ESPECTROMETRIA DE MASSAS SEQUENCIAL (LC-MS/MS)}

Embora a cromatografia líquida de alta eficiência seja extensivamente utilizada empregando-se detectores convencionais como detector UV-Vis e 
fluorescência, essa é uma técnica de excelente desempenho que pode ser combinada a outros sistemas de detecção.

O acoplamento da cromatografia líquida com espectrometria de massas soma as vantagens da cromatografia como a alta versatilidade e poder de resolução, com as do espectrômetro de massas como alta seletividade, informações estruturais dos analitos e alta sensibilidade (CHIRADIA; COLLINS; JARDIM, 2008). Durante o acoplamento das duas técnicas, é necessário que as características das duas sejam consideradas e respeitadas (CHIRADIA; COLLINS; JARDIM, 2008).

O acoplamento da cromatografia líquida com o espectrômetro de massas é complicado, pois quando há a vaporização da fase líquida, há a produção de uma grande quantidade de gás que não é facilmente eliminado pelo sistema de vácuo do espectrômetro de massas (THONSON, 1998). Assim, o sucesso deste acoplamento só foi possível com o desenvolvimento de interfaces para ionização à pressão atmosférica (API, atmospheric pressure ionization) (GATES et al., 2006). Tais interfaces possibilitaram a eliminação da fase móvel e promoveram a ionização das moléculas gerando íons que podem ser analisados pelo espectrômetro de massas. Além disso, as técnicas de API também são chamadas de técnicas de ionização branda, pois possibilitam gerar/transferir os íons dos analitos de forma suave, permitindo que as moléculas mais frágeis atinjam a fase gasosa de forma intacta.

\subsubsection{MODOS DE IONIZAÇÃO}

Várias fontes de ionização surgiram de maneira a otimizar o processo de acoplamento das duas técnicas. Entretanto, as mais importantes para análise de fármacos são a ionização por eletronebulização (Electrospray Ionization, ESI), a ionização química à pressão atmosférica (Atmospheric Pressure Chemical lonization, $\mathrm{APCl}$ ) e a fotoionização à pressão atmosférica (Atmospheric Pressure Photoionization, APPI). No desenvolvimento deste trabalho foi empregada a ESI a qual será discutida mais detalhadamente adiante. 
Em espectrometria de massas, três tipos de íons podem ser gerados no processo de ionização dos analitos: os íons moleculares, as moléculas cationizadas ou anionizadas e as moléculas protonadas ou desprotonadas.

Os íons moleculares $\left[\mathrm{M}^{+\bullet}\right]$ ou $\left[\mathrm{M}^{-\bullet}\right]$ são provenientes de reações de oxidação e de redução. Já, as moléculas cationizadas $[\mathrm{M}+\mathrm{Na}]^{+}$ou anionizadas $[\mathrm{M}+\mathrm{Cl}]^{-}$surgem de uma coordenação com cátions ou ânions. E, por último, as moléculas protonadas $[\mathrm{M}+\mathrm{H}]^{+}$ou desprotonadas $[\mathrm{M}+\mathrm{H}]^{-}$, são oriundas de reações ácidas ou básicas (CROTTI et al., 2006). Todas essas reações ocorrem em fase gasosa, entre a interface de ionização e a entrada do espectrômetro de massas. $\mathrm{O}$ tipo de ionização que irá ocorrer é dependente da fonte de ionização e das características redox dos analitos em questão (CROTTI et al., 2006).

\subsubsection{ELETRONEBULIZAÇÃo (ESI - "ELECTROSPRAY”)}

A ionização dos analitos empregando a eletronebulização (ESI) é a técnica mais utilizada atualmente (THEODORIDIS, 2012). O estado de comportamento de líquidos frente a campos elétricos carregados é de extrema importância para a compreensão dessa técnica. Os primeiros estudos teóricos sobre o comportamento de uma gota aplicando-se um campo elétrico foi realizado em 1882 por Lord Rayleigh que descreveu o aumento de densidade de carga originado pela evaporação da gota que aumenta até que a tensão superficial da gota seja superada pela repulsão coulômbica dos íons e faz com que a gota gere um spray (gotículas menores). Dessa forma, os estudos de Rayleigh deram nome à máxima densidade de carga que uma gota pode atingir e esta densidade foi conhecida como Limite de Rayleigh (RAYLEIGH, 1882). A ESI se inicia quando o fluxo da fase móvel proveniente da cromatografia líquida entra em um capilar de diâmetro muito pequeno que é alimentado por uma diferença de potencial. Esta diferença de potencial induz o acúmulo de carga na superfície do líquido no final do capilar formando uma espécie de cone, conhecido como o cone de Taylor. Essa deformação do líquido (o cone de Taylor) atinge o máximo de densidade de carga até que a repulsão coulômbica se torne maior que a tensão superficial deste líquido que, então, produz 
pequenas gotículas carregadas gerando o spray eletrolítico que segue em direção a um contra eletrodo interno ao equipamento (Figura 2). A formação dos íons é dependente da evaporação do solvente por um gás inerte como o nitrogênio. Por ser uma técnica branda, quase não ocorre fragmentação das moléculas em ESI, pois a diferença de potencial aplicada para a formação do spray é pequena (WRIGHT, 2011).

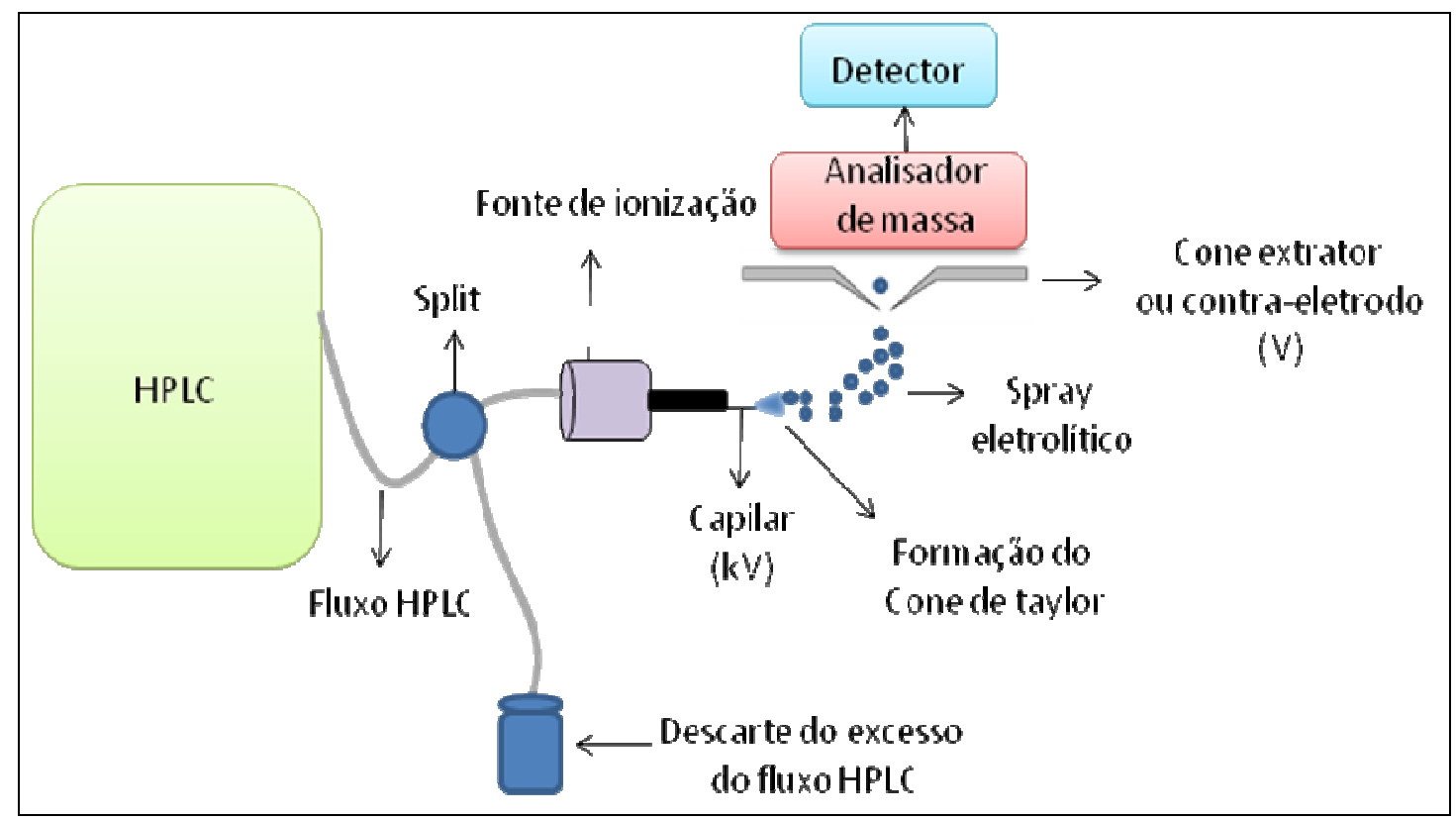

Figura 2 - Esquema da fonte de ionização por eletronebulização (ESI)

\subsubsection{ANALISADORES DE MASSA}

Após serem ionizados, os íons de diferentes $\mathrm{m} / \mathrm{z}$ formados na fonte de ionização são direcionados para um analisador onde são separados. Existe uma grande variedade de analisadores em espectrometria de massas, que são escolhidos de acordo com as características da amostra e da aplicação desejada. Os principais analisadores de massas são:

Quadrupolo (Q): um analisador de baixa resolução formado por hastes em paralelo, conectadas eletricamente. A tensão e a radiofrequência aplicada a essas hastes são responsáveis por determinar quais íons de razão $\mathrm{m} / \mathrm{z}$ atravessarão o quadrupolo em uma trajetória estável sendo então 
detectados pelo detector (GATES et al., 2006; CHIARADIA; COLLINS; JARDIM, 2008).

Tempo de vôo ("Time-of-Flight", ToF): se baseia no princípio que as velocidades dos íons serão diferentes de acordo com sua massa molecular. Os íons produzidos na fonte de ionização são acelerados através de um tubo que serão detectados pelo tempo que levam para atravessá-lo em função da razão $\mathrm{m} / \mathrm{z}$ de cada íon. Esse analisador possui alta resolução e grande exatidão de massas (CHIARADIA; COLLINS; JARDIM, 2008).

* Aprisionador de íons 2D e 3D ("Ion trap"): é um analisador de baixa resolução que corresponde a um quadrupolo tridimensional que armazena e aprisiona todos os íons que são introduzidos em seu interior. Em seguida, após a aplicação de determinada radiofrequência os íons de certa razão m/z estáveis são liberados e detectados (CHIARADIA; COLLINS; JARDIM, 2008). Semelhante ao "Ion trap", o analisador do tipo "Orbtrap" também é um aprisionador de íons. Este difere do "Ion trap", pois a trajetória destes íns de razão $\mathrm{m} / \mathrm{z}$ é em formato de órbitas que faz com que a exatidão das massas seja superior ao "Ion trap" Além disso, esse analisador apresenta uma maior resolução, quando comparado ao "Ion trap" (MARAKOV, 2000).

Além destes analisadores, há a possibilidade do acoplamento de mais de um analisador, o que possibilita a análise de massas sequencial no espaço (tandem), podendo ser do mesmo tipo, como no caso do triplo quadrupolo (QqQ) que veremos com maior detalhes já que foi o analisador utilizado para a realização deste trabalho ou, então, com equipamentos híbridos como no caso do quadrupolo acoplado ao ToF (Q-ToF) (VEKEY, 2001).

\subsubsection{TRIPLO QUADRUPOLO (QqQ) E MODOS DE AQUISIÇÃO EM QqQ}

Em cromatografia líquida acoplada à espectrometria de massas sequencial (LC-MS/MS) para a análise e quantificação de fármacos e metabólitos em matrizes biológicas, uma boa opção de analisador de equipamento é o triplo quadrupolo empregando o modo de aquisição denominado "Monitoramento de Reações Múltiplas" (MRM). O modo de aquisição MRM é muito utilizado na determinação e quantificação de 
compostos conhecidos e de interesse, pois oferece maior seletividade e detectabilidade, reduzindo o ruído da linha de base e elevando o sinal analítico (TRAPP, 2010).

$\mathrm{O}$ analisador do tipo $\mathrm{QqQ}$ permite que as varreduras sejam feitas em diferentes modos de aquisição dos íons produtos ou íons filhos; desta forma, a escolha do modo de varredura utilizado é importante para a determinação do perfil de fragmentação dos analitos de interesse.

Existem quatro principais modos de aquisição em QqQ sequencial: monitoramento de reações múltiplas (MRM, Multiple Reaction Monitoring) que é conhecido também como monitoramento de reações selecionadas (SRM, Selected Reaction Monitoring); varredura do íon produto ou íon "filho" (Product Ion Scan); varredura do íon precursor (Precursor Ion Scan) e varredura de perda neutra (Neutral Loss). Porém, o funcionamento do triplo quadrupolo será explicado apenas para o modo MRM de varredura já que foi o modo utilizado neste trabalho (Figura 3).

O funcionamento do QqQ depende da participação concomitante dos quadrupolos. O primeiro quadrupolo tem a função de isolar o íon de interesse dentre vários íons gerados na fonte de ionização. O segundo quadrupolo (na verdade um hexapolo), preenchido por um gás inerte (geralmente argônio), é chamado de cela de colisão. Neste segundo quadrupolo, os íons selecionados no primeiro quadrupolo são acelerados com energia suficiente para colidirem com as moléculas de gás inerte, e então, fragmentados e selecionados pelo terceiro quadrupolo (o terceiro quadrupolo seleciona um dos fragmentos formados). Esta técnica fornece alta seletividade já que para ser detectado, o analito precisa ter massa molecular do íon selecionado no primeiro quadrupolo e precisa ser fragmentado formando o íon específico selecionado no terceiro quadrupolo.

Como este tipo de analisador monitora massas específicas, é uma técnica muito sensível que possibilita limites de quantificação da ordem de pg. $\mathrm{mL}^{-1}$ (CHIARADIA; COLLINS; JARDIM, 2008). 


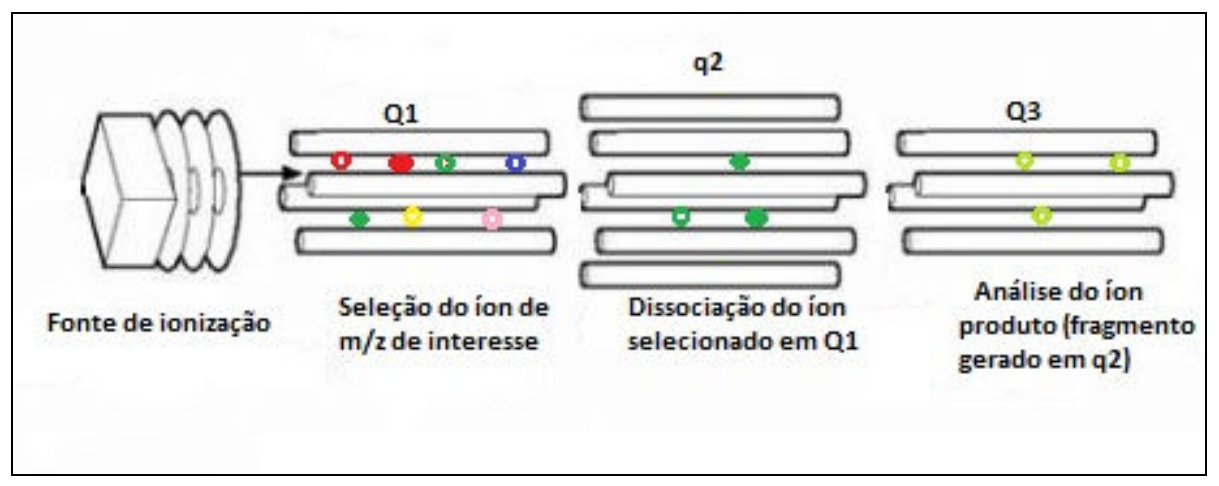

Figura 3 - Esquema de funcionamento do analisador triplo quadrupolo por monitoramento de reações múltiplas

\subsection{Preparação de amostras}

Tratando-se de análises instrumentais realizadas utilizando matrizes biológicas complexas, faz-se necessário uma prévia preparação da amostra a fim de eliminar possíveis interferentes e concentrar os analitos, que muitas vezes estão presentes ao nível de traços. No caso de matrizes biológicas como urina, plasma, sangue total, soro e resíduos microbiológicos, uma grande variedade de compostos orgânicos pode interferir na eficiência de extração dos analitos (DE OLIVEIRA et al., 2008).

Em LC-MS/MS, o preparo de amostras é muito importante para prevenir possíveis efeitos da matriz na ionização dos analitos causado por componentes endógenos como sais, compostos altamente polares e várias moléculas orgânicas como lipídeos, peptídeos, carboidratos e aminas (TRUFELLI et al., 2011). Assim, procedimentos de pré-tratamento das amostras são requeridos antes da extração de fármacos e metabólitos em amostras biológicas (DE OLIVEIRA et al., 2008; HADLEY; CAMILLERI; HUTT, 2000). As técnicas de extração mais comumente empregadas são: (i) extração líquido-líquido (LLE) e a (ii) extração em fase sólida (SPE). Entretanto, tais técnicas apresentam algumas desvantagens como alto consumo de solventes orgânicos em ambos os casos ou, no caso da SPE, quando utilizada em LC-MS, pode contribuir para o efeito de matriz causado por resíduos dos materiais utilizados na confecção dos cartuchos empregados neste tipo de extração (TRUFELLI et al., 2011). 
Assim, técnicas miniaturizadas e mais seletivas de preparação de amostras vêm sendo desenvolvidas. Entre essas, podemos destacar: a microextração em fase líquida empregando membranas cilíndricas ocas (HFLPME); a microextração em fase sólida (SPME), a microextração líquido-líquido dispersiva (DLLME), a microextração sortiva em barras de agitação (SBSE) e outras (DE OLIVEIRA et al., 2008).

Estas técnicas de microextração empregam quantidades mínimas de solventes orgânicos para o desenvolvimento dos métodos corroborando assim com as tendências atuais na geração de resíduos químicos. Além disso, são técnicas altamente seletivas, de custo moderado, compatíveis com a maioria dos sistemas de análise e algumas, como no caso da SPME e HF-LPME, já são passíveis de automação (DE OLIVEIRA et al., 2008; WILLE; LAMBERT, 2007; VUCKOVIC et al., 2010).

Nesse projeto, com o objetivo de empregar uma técnica com mínima geração de resíduo químico, foi empregado a SPME como técnica de preparação de amostras.

\subsubsection{MicroeXtração em FASE SÓLIDA (SPME)}

SPME foi desenvolvida pelo grupo de Pawliszyn em 1990 (ARTHUR; PAWLISZYN, 1990) com o objetivo de extrair os analitos com maior uma seletividade e maior rapidez. Além disso, desenvolver um sistema simples e prover uma forma de levar o sistema de extração ao local onde se encontra a amostra para a realização da extração "in situ" dos analitos de interesse. A aplicabilidade da técnica vem sendo extensivamente explorada e seu emprego é variado, desde determinação de poluentes em amostras ambientais como ar, água, solo; determinação de drogas e fármacos em fluidos biológicos como urina, sangue, cabelos; até mesmo na determinação de compostos aromáticos ou tóxicos presentes em alimentos (BOJKO et al., 2011).

A SPME é uma técnica de extração e pré-concentração não-exaustiva com base nas condições de equilíbrio ou pré-equilíbrio dos analitos após um determinado tempo de contato entre os analitos e a fase extratora. As extrações são realizadas por polímeros (fase extratora) que estão suportados 
por fibras de sílica fundida. Quanto maior a afinidade do analito pela fase extratora, maior a quantidade de analito extraído (VUCKOVIC et al., 2010). Assim, o processo de extração é controlado pelas características físicoquímicas do analito, da amostra e do polímero extrator.

As extrações podem ser feitas por dois modos: o modo de extração direta onde a fibra é mergulhada diretamente na amostra ou pelo modo indireto ("headspace") de extração onde a fibra extrai os analitos voláteis gerados no interior de um frasco hermeticamente fechado. Assim que o equilíbrio de extração é atingido, a extração é encerrada e após, a fibra pode ser introduzida diretamente no instrumento analítico e os analitos serem dessorvidos termicamente (quando as análises são realizadas por CG) ou então mergulhar a fibra contendo os analitos em um solvente apropriado, que posteriormente pode ser analisado por HPLC ou CE (THEODORIDIS et al., 2000). Em SPME, existem diversos tipos de revestimentos extratores nas fibras. A escolha das fibras é baseada na compatibilidade da fibra com as propriedades físicoquímicas do analito a ser extraído. Como um dos objetivos deste trabalho é extrair analitos de matrizes complexas para posterior análise utilizando cromatografia líquida, na Tabela 3 há um resumo das principais fibras para SPME disponíveis comercialmente e compatíveis com HPLC.

Tabela 3 - Fibras de SPME disponíveis comercialmente para HPLC. http://www.sigmaaldrich.com/analyticalchromatography/analyticalproducts.html?TablePage=9645337. Acessado em 12/06/2012.

\begin{tabular}{lcl}
\hline Composição Química & $\begin{array}{c}\text { Espessura } \\
(\boldsymbol{\mu m})\end{array}$ & $\begin{array}{l}\text { Descrição da } \\
\text { fase estacionária }\end{array}$ \\
\hline Poliacrilato (PA) & 85 & Parcialmente ligada \\
PDMS-DVB (polidimetilsiloxano- divinilbenzeno) & 60 & Parcialmente ligada \\
PDMS (polidimetilsiloxano) & 100 & Não-ligada \\
C18 & 45 & Ligada \\
Carbowax-TPR (carbowax-templated resin) & 50 & Ligada \\
\hline
\end{tabular}




\subsubsection{EXTRAÇÃo}

Para uma melhor condição na extração dos analitos de interesse pelo procedimento de SPME, é necessário avaliar e otimizar alguns parâmetros que afetam na extração. Os principais parâmetros que podem ser modificados quando as análises são realizadas por HPLC são: tipos de revestimento da fibra, tempo de extração, agitação da amostra, volume de amostra, pH, força iônica da amostra, temperatura de extração e tempo e solvente de dessorção (RISTECEVIC et al., 2010).

Tipos de fibras: como já dito anteriormente, o revestimento polimérico da fibra deve ser compatível com as características físico-químicas do analito e vice-versa. Baseado nesta afirmação, analitos polares devem ser mais facilmente extraídos por revestimentos polares assim como analitos apolares serão mais bem extraídos por polímeros apolares.

* Tempo de extração: o melhor tempo de extração do analito é o tempo necessário para o sistema entrar em equilíbrio e, desta forma, obter o máximo de recuperação do analito. Entretanto, diversos fatores afetam este processo de equilíbrio como, espessura da fibra utilizada, coeficiente de difusão do soluto, agitação e temperatura do sistema.

Agitação: a agitação do sistema tem como objetivo alcançar o máximo de recuperação dos analitos em um menor tempo de extração, favorecendo o equilíbrio do sistema em um menor tempo.

Volume da amostra: o volume da amostra influencia na recuperação dos analitos, pois pode modificar a viscosidade da matriz em análise. A modificação da viscosidade da matriz influencia no processo de transferência de massa do analito e, consequentemente, o tempo para atingir o equilíbrio.

pH da amostra: o processo de extração por SPME tem como objetivo extrair os analitos de interesse em sua forma molecular, por isso, o pH deve ser ajustado para que se garanta esta condição. $\mathrm{Na}$ análise de ácidos ou bases o controle do $\mathrm{pH}$ é essencial para garantir a neutralidade dos analitos. Além disso, quando o modo direto é empregado o $\mathrm{pH}$ da amostra deve ser compatível com a faixa adequada para o tipo de fibra extratora uma vez que muitos revestimentos podem ser deteriorados com valores extremos de $\mathrm{pH}$. 
Temperatura: um aumento de temperatura no procedimento da extração pode melhorar a recuperação dos analitos favorecendo que o sistema atinja o equilíbrio mais rapidamente. Por outro lado, um aumento da temperatura também é capaz de diminuir a constante de distribuição do analito entre a matriz e o polímero (em termos termodinâmicos, há um aumento de entropia com o aumento da temperatura, o que torna a distribuição dos analitos mais caótica e, consequentemente, menos eficiente).

Força iônica: a recuperação de determinados analitos pode ser melhorada pelo efeito "salting out" com a adição de um eletrólito inerte no meio. A melhor condição de adição de eletrólito é verificada com uma concentração ótima deste eletrólito já que, a partir de uma determinada concentração, há uma saturação do sistema o que pode levar a uma diminuição da recuperação dos analitos.

Tempo de dessorção e efeito memória: é o tempo necessário para que todo o analito retido na fibra extratora no processo de extração seja liberado no solvente de dessorção. Este parâmetro é importante porque a fibra de SPME é reutilizável podendo haver contaminações entre as análises sucessivas se os analitos não forem completamente dessorvidos da fibra, levando a uma falsa interpretação dos resultados, principalmente quando as amostras apresentam concentrações variadas. O efeito memória ou "carryover" é a quantidade de analito que não foi totalmente liberada no processo de dessorção. Esse efeito deve ser avaliado, fazendo-se sucessivas dessorções e avaliando a presença ou ausência do(s) analito(s) nesses extratos.

\subsubsection{DESSORÇÃO}

O processo de dessorção, como já dito anteriormente, é o processo de liberação dos analitos retidos na fibra para posterior análise. Em cromatografia líquida, a dessorção pode ocorrer de dois modos distintos:

1 - Modo "on-line": este modo faz o uso de uma interface acoplada ao injetor do cromatógrafo onde os analitos são dessorvidos diretamente e já seguem para a coluna para serem analisados. Somente a cromatografia no modo 
reverso é indicada para o modo on-line, pois os solventes orgânicos apolares empregados no modo normal podem danificar os polímeros presentes na fibra. 2- Modo "off-line": neste modo, a etapa de dessorção dos analitos é feita logo após a etapa de extração e fora do equipamento de análise. Um frasco

contendo a fase móvel ou um solvente compatível é usado para mergulhar a fibra onde ocorrerá a dessorção. No caso do uso da fase móvel pode-se injetar o extrato diretamente no equipamento. Porém, se o solvente for diferente dos constituintes da fase móvel, deve-se evaporar este solvente após o processo de dessorção e em seguida, dissolver o resíduo da evaporação na fase móvel.

\subsection{BIOTRANSFORMAÇÃo MEdiAda POR MiCRO-ORgANISMOS}

Biotransformação são reações de compostos orgânicos feitas por células microbianas intactas, células vegetais ou enzimas isoladas. O uso de microorganismos na biotransformação de compostos orgânicos é muito antigo, desde o século XIX. Nesse período, Louis Pasteur já descrevia a capacidade de espécies microbianas em modificar substratos específicos (FARAMARZI et al., 2008).

Reações de biotransformação provenientes de micro-organismos são capazes de catalisar seletivamente produtos em suaves condições (PUPO et al., 2008). O procedimento de biotransformação tem grande importância na produção de novos fármacos, metabólitos de fármacos, intermediários agroquímicos, ingredientes alimentares, e outros. Já é considerado um modelo com grande potencial para o desenvolvimento de tecnologias sustentáveis para estes tipos de produtos (SCHNEIDER et al., 2008).

O potencial de biotransformação a novos produtos fez com que aumentasse a busca por novos catalisadores para o desenvolvimento da biocatálise em escala industrial e então, micro-organismos, especialmente fungos, têm sido extensivamente empregados para este tipo de estudo (SCHNEIDER et al., 2008). Os fungos são micro-organismos de fácil cultivo, rápido crescimento e são capazes de produzir enzimas extracelulares que facilitam sua recuperação do meio de fermentação. Dessa forma, são os micro-organismos mais empregados em biocatálise. 


\subsubsection{BIOTRANSFORMAÇÃo ESTEREOSSELETIVA MEDIADA POR FUNGOS}

Biotransformação empregando micro-organismos como fungos têm grande aplicabilidade em diversas áreas da ciência como, por exemplo, na medicina e na química agrícola. Na medicina, o propósito do emprego de microorganismos para gerar novos fármacos é fascinante e baseia-se na capacidade dos micro-organismos em metabolizar fármacos similarmente ao sistema dos mamíferos como, por exemplo, reproduzir a ação de enzimas do citocromo P450 e, assim, produzir metabólitos semelhantes ao encontrado em mamíferos e que muitas vezes apresentam atividade farmacológica. Além disso, a assimetria desse meio é favorável a biotransformação estereosseletiva de substratos, levando a possibilidade de produção de metabólitos na sua forma enantiomericamente pura (ASHA et al., 2009).

Entre os fungos que podem ser usados no processo de biotransformação destacam-se os fungos filamentosos do gênero Cunninghamella que contém espécies capazes de metabolizar uma grande variedade de xenobióticos de maneira régio- e estereosseletiva similarmente ao sistema dos mamíferos (DAVIS, 1988). Outra classe de fungos pouco explorados e presentes em grande abundância no Brasil são os fungos endofíticos. Os fungos endofíticos são fungos que podem estar presentes em todos os órgãos de uma planta hospedeira e sua interação com a planta pode ser associada ao mutualismo já que esta interação pode ser benéfica para ambos (MACIÁ-VICENT et al., 2008). A Tabela 4 mostra alguns tipos de fungos capazes de metabolizar estereosseletivamente fármacos. 
Tabela 4 - Alguns estudos de biotransformação estereosseletiva com fungos.

\begin{tabular}{|c|c|c|}
\hline Espécie de fungo & Fármaco metabolizado & Referência \\
\hline Mucor rouxii & Risperidona & DE JESUS et al., 2011 \\
\hline Nigospora sphaerica (Sacc.) E.W. & & \\
\hline $\begin{array}{l}\text { Mason (SS67), Pestalotiopsis } \\
\text { foedans (VR8), Papulaspora } \\
\text { immersa Hotson (SS13) }\end{array}$ & Albendazol & HILÁRIO et al., 2012 \\
\hline Chaetomium globosum (VR10), & & \\
\hline $\begin{array}{l}\text { Nigospora sphaerica (Sacc.) E.W. } \\
\text { Mason (SS67), }\end{array}$ & Ibuprofeno & BORGES et al.,2011 \\
\hline Phomopsis sp. (TD2) & Midodrina & BARTH et al., 2010 \\
\hline Cunninghamella elegans & Mirtazapina & MOODY et al., 2002 \\
\hline
\end{tabular}

\subsection{CATÁlise OXIDATIVA de FÁRMACOS}

Outra forma de obtenção de metabólito oxidado de fármacos é a catálise empregando compostos sintéticos que mimetizem sistemas de mamíferos. Porém, a descoberta de catalisadores eficientes para a oxidação seletiva de moléculas orgânicas em condições suaves ainda é um grande desafio. Uma possível estratégia para esta síntese é a construção de catalisadores biomiméticos ou bioinspirados com base no conhecimento detalhado da oxidação seletiva do sistema enzimático dos organismos vivos. Neste contexto, foram realizados muitos estudos nos últimos 30 anos sobre o uso de modelos químicos para melhor compreensão e com objetivo de imitar uma determinada classe de metaloenzimas mono-oxigenases dependentes do citocromo P450 (MANSUY, 2007).

Estas enzimas têm atraído interesses químicos por duas razões principais:

1. São capazes de catalisar a mono-oxigenação seletiva por $\mathrm{O}_{2}$ de quase todo substrato orgânico, incluindo alcanos (equação 1) e, 


$$
\mathrm{RH}+\mathrm{O}_{2}+2 \mathrm{e}^{-}+2 \mathrm{H}^{+} \rightarrow \mathrm{ROH}+\mathrm{H}_{2} \mathrm{O}
$$

2. Desempenham um papel chave no metabolismo oxidativo de fármacos e xenobióticos.

\subsubsection{CatÁlise ASSimÉtrica empregando compleXos de SALEN}

Complexos de Salen (ou Jacobsen) são complexos sintéticos que mimetizam metaloenzimas do CYP450 utilizados para catálise oxidativa de diversos compostos. Entretanto, tais complexos possuem em sua estrutura sítios ativos quirais (Figura 4) capazes de produzir reações assimétricas.

As primeiras reações enantiosseletivas utilizando complexos de SalenMn-(III) foram relatadas por Jacobsen e Katsuki (JACOBSEN et al., 1991) que verificaram catálises altamente enantiosseletiva para a epoxidação assimétrica de alcenos simples (BALEIZ̃̃O; GARCIA, 2006). Portanto, os complexos de Salen também são conhecidos como complexos de Jacobsen.

Os complexos de Salen, como dito anteriormente, possuem sítios-ativos quirais e são comercialmente disponíveis em forma de enantiômeros puros (R,R-Jacobsen; S, S-Jacobsen ou R, S-Jacobsen).

Uma desvantagem neste tipo de catálise está no custo elevado dos catalisadores enantiomericamente puros, porém a grande importância dos ligantes quirais de Salen em catálise enantiosseletiva é vantajosa devido ao excesso enantiomérico elevado que pode ser alcançado e também sua ampla aplicabilidade.

Dessa forma, complexos de Salen tornam-se compostos potenciais para o uso na tentativa de produção de metabólitos oxidados de fármacos enantiomericamente puros. 


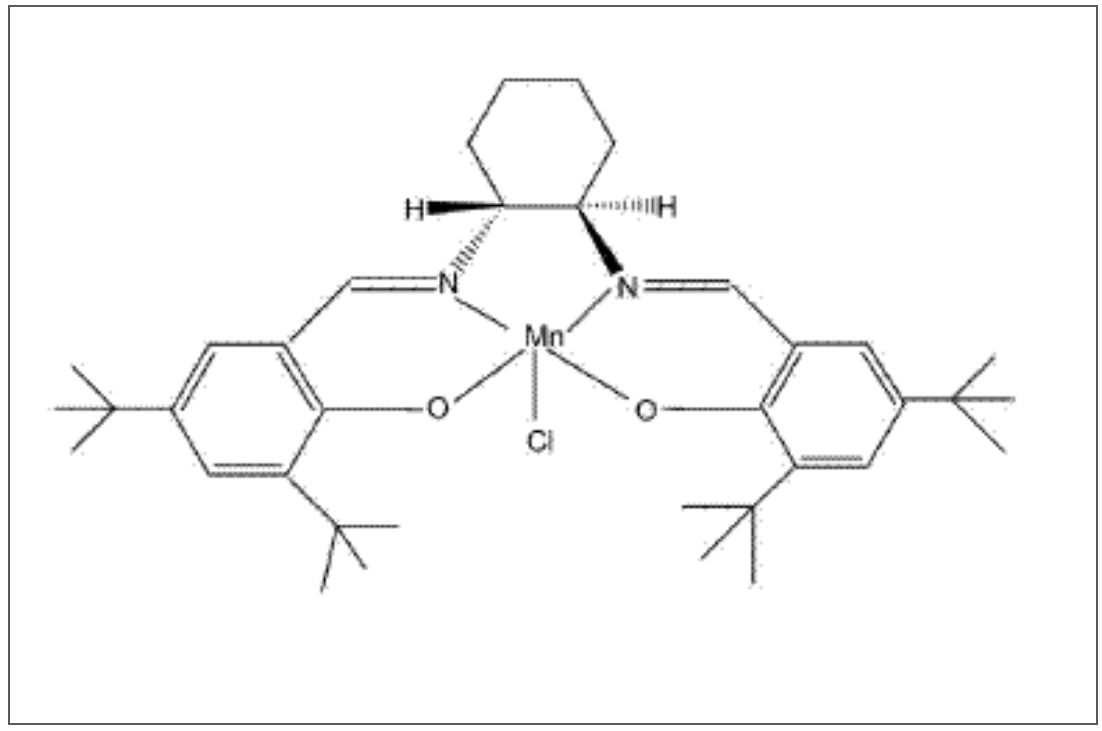

Figura 4 - Estrutura planar do catalisador $(R, R)$-Jacobsen 


\section{2 - OBJETIVOS}

O objetivo desse projeto foi avaliar modelos microbiológicos (fungos) e modelos químicos (complexo de Salen) na (bio)transformação enantiosseletiva da risperidona em seu metabólito quiral e ativo, 9-hidroxirisperidona. Para tanto, foram desenvolvidas as seguintes etapas:

* Desenvolvimento de um método cromatográfico para análise da risperidona e seus metabólitos quirais 7-RispOH e 9-RispOH por LC-MS/MS;

Desenvolvimento de uma microtécnica de preparação de amostra para extração da risperidona e seus metabólitos em meio de cultura;

Validação do método para análise da risperidona e seus metabólitos em meio de cultura;

Aplicação do método validado em estudos de biotransformação enantiosseletiva com fungos;

Aplicação do método de separação desenvolvido em estudos preliminares de catálise assimétrica empregando os catalisadores de Jacobsen. 


\section{3- MATERIAIS E MÉTODOS}

\subsection{MATERIAIS}

\subsubsection{EQUIPAMENTOS E ACESSÓRIOS}

A separação dos analitos foi realizada empregando cromatografia líquida de alta eficiência. O equipamento utilizado foi da marca Shimadzu ${ }^{\circledR}$ (Kyoto, Japão), composto por duas bombas LC 10AS, um detector por absorção no UV-Vis, modelo SPD 10A operando em $280 \mathrm{~nm}$, um forno para coluna modelo CTO 10AS, e um injetor Rheodyne ${ }^{\circledR}$ modelo 7125 (Cotati, EUA) com amostrador de $20 \mu \mathrm{L}$. Os dados foram monitorados usando uma controladora modelo SCL 10A e o software utilizado para aquisição dos dados foi o ClassVP (Shimadzu ${ }^{\circledR}$, Kyoto, Japão).

A validação da metodologia e os estudos de biotransformação foram realizados empregando um sistema de LC-MS/MS. O sistema cromatográfico utilizado (Shimadzu ${ }^{\circledR}$, Kyoto, Japão) foi constituído por duas bombas LC 10AD, um sistema controlador modelo SLC 10A, um forno modelo CTO 10AS e um injetor Rheodyne ${ }^{\circledR}$ modelo 7125 (Cotati, CA, EUA) com amostrador de $20 \mu \mathrm{L}$. O espectrômetro de massas utilizado foi um triplo quadrupolo (QuatroLC, Micromass $^{\circledR}$, Manchester, UK) com interface ESI, operando no modo positivo. A aquisição e processamento dos dados foram efetuados pelo software Micromass MassLynx, versão 4.1.

As temperaturas da fonte de ionização e de dessolvatação foram mantidas em $100^{\circ} \mathrm{C}$ e $250^{\circ} \mathrm{C}$, respectivamente. Nitrogênio foi utilizado como gás de secagem e nebulização na vazão de $265 \mathrm{~L} \mathrm{~h}^{-1}$. Argônio foi usado como gás de colisão. O efluente da coluna foi dividido por uma válvula Valco (Restek ${ }^{\circledR}$, Pensilvânia, PA, EUA) e aproximadamente $0,1 \mathrm{~mL} \mathrm{~min}^{-1}$ foram introduzidos na fonte de ionização.

Para o processo de microextração em fase sólida foram utilizadas fibras de extração compostas pelos polímeros C18, polidimetilsiloxano-divinilbenzeno (PDMS-DVB), e carbowax-templated resin (CW-TPR), com espessuras, respectivamente, de $45 \mu \mathrm{m}, 60 \mu \mathrm{m}$, e $50 \mu \mathrm{m}$, todas da marca Supelco ${ }^{\circledR}$ (Bellefonte, PA, EUA). As fibras PDMS-DVB e CW-TPR foram utilizadas 
empregando um amostrador também da marca Supelco ${ }^{\circledR}$, preso a um agitador magnético/aquecedor (Fisher Scientific, Pittsburgh, EUA) (Figura 5), enquanto que para as fibras $\mathrm{C} 18$ foi utilizado um agitador Vibrax modelo VRX (IKA ${ }^{\circledR}$, Staufen, Alemanha) (Figura 6). Também foi empregada para centrifugação das amostras de fungos uma centrífuga CF-15 (Hitachi Koki ${ }^{\circledR}$, Kyoto, Japão).
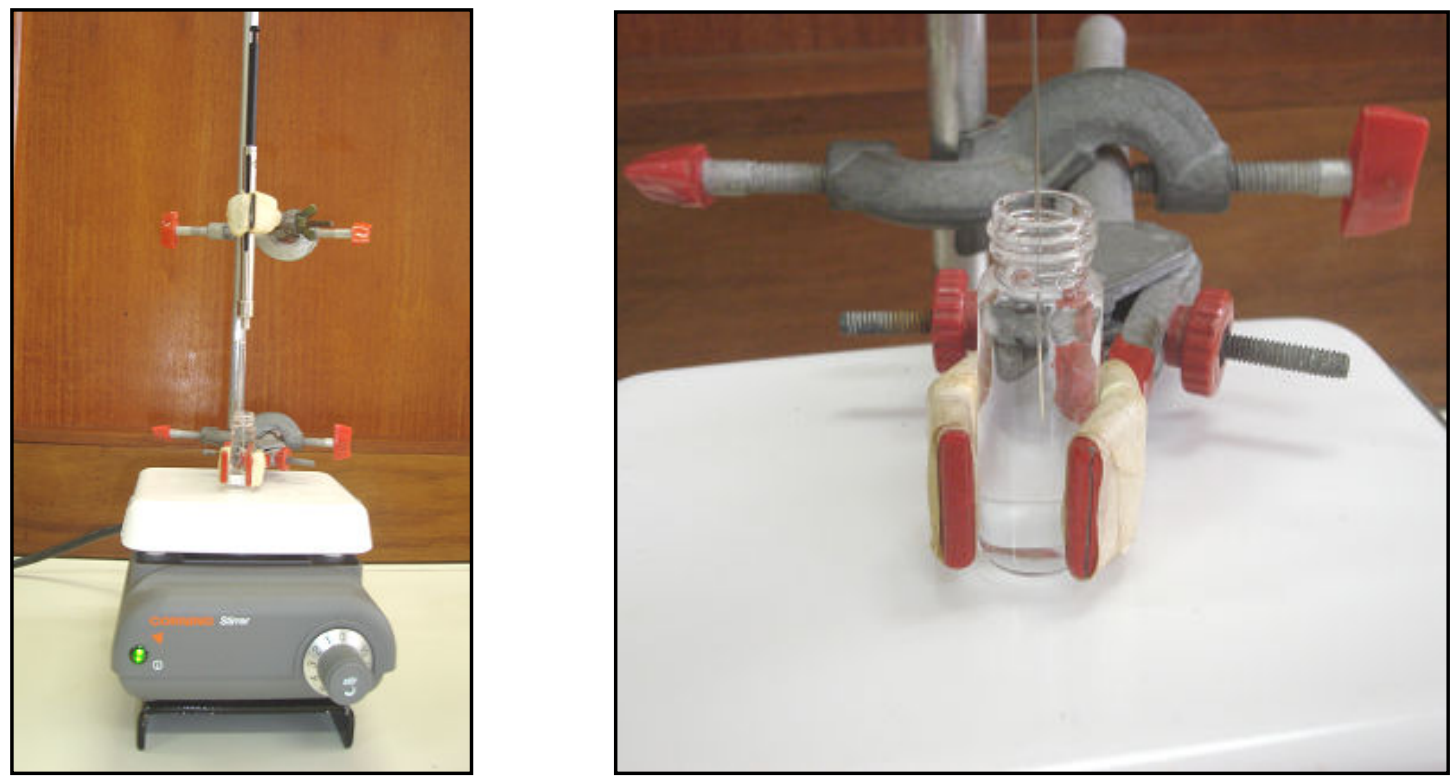

Figura 5 - Amostrador da Supelco ${ }^{\circledR}$ sobre um agitador magnético simulando a extração de uma amostra.
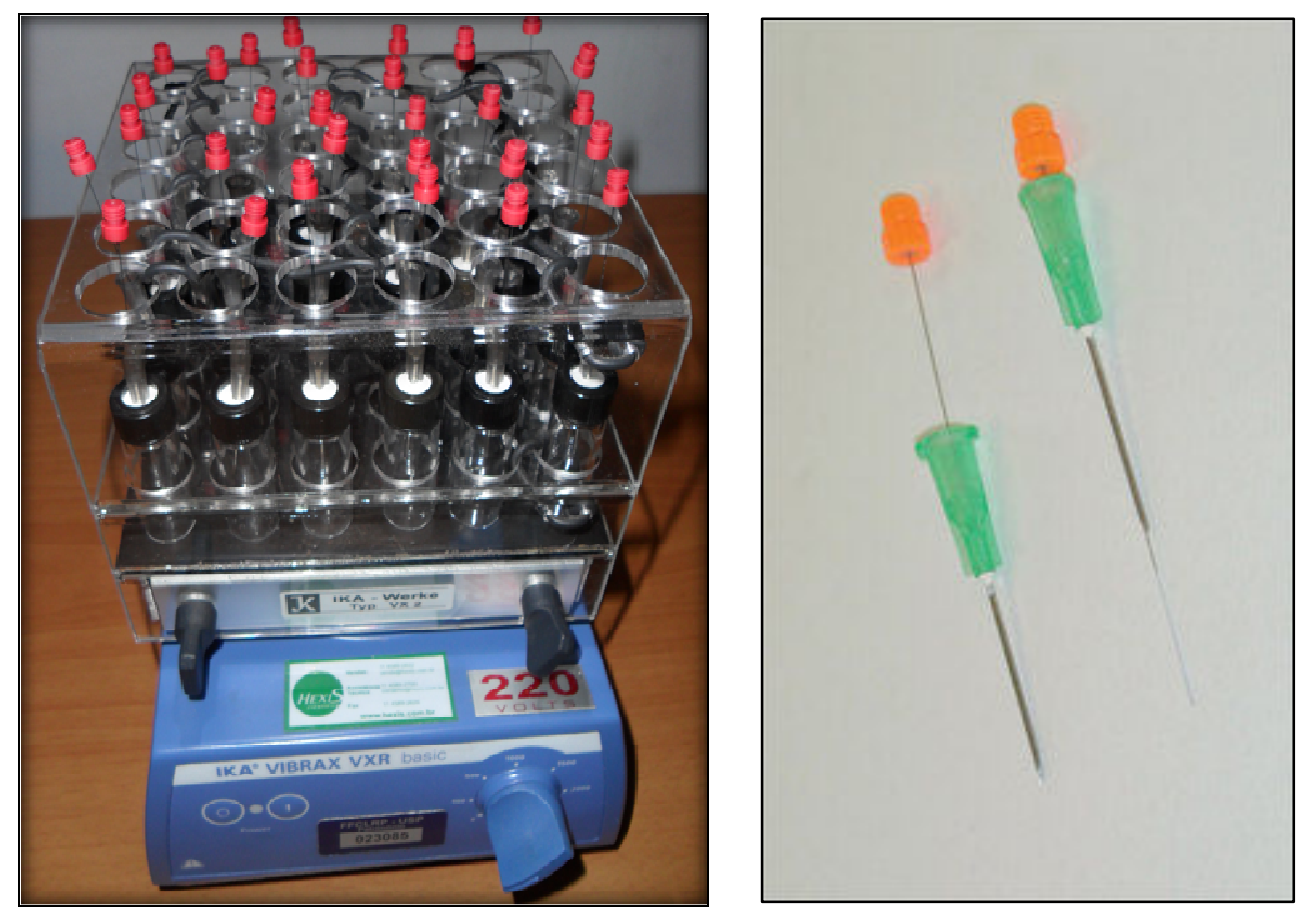

Figura 6 - Sistema Vibrax ${ }^{\circledR}$ empregado nas extrações com as fibras C18. 
No preparo das soluções-padrão empregou-se balança analítica Sartorius ${ }^{\circledR}$ AG Germany modelo CP225D (Sartorius, Santo André, SP, Brasil) e agitador de soluções modelo AP56 (Phoenix ${ }^{\circledR}$, Araraquara, SP, Brasil) que também foi utilizado para a homogeneização das amostras do processo de microextração em fase sólida. Para medida do $\mathrm{pH}$ das soluções-tampão foi utilizado um peagâmetro Orion modelo 420A+ (Thermo Electron Corporation ${ }^{\circledR}$, Waltham, MA, EUA). Um sistema Direct-Q 3 UV Ultrapure Water Systems ${ }^{\circledR}$ Millipore / Millipore Corporation (Bedford, MA, EUA) forneceu água purificada para o preparo das amostras e da solução-tampão.

Os equipamentos utilizados para cultivo dos fungos e reações de biotransformação foram: estufa de incubação bacteriológica modelo SL 101, marca Solab ${ }^{\circledR}$ (Piracicaba, SP, Brasil) e uma autoclave vertical Phoenix ${ }^{\circledR}$ modelo AV 75 (Araraquara, SP, Brasil). Empregou-se também, capela de fluxo laminar vertical, modelo PCR $\mathrm{T}_{2}$ Echo, Pachane ${ }^{\circledR}$ (Piracicaba, SP, Brasil), e mesa agitadora (tipo "shaker") com controle de temperatura da marca CIENTEC ${ }^{\circledR}$, modelo CT-712RN (Piracicaba, SP, Brasil).

\subsubsection{ReAGentes e Solventes}

Os reagentes utilizados (grau HPLC) foram: acetonitrila, diclorometano, etanol e metanol obtidos da Merck ${ }^{\circledR}$ (Darmstadt, Alemanha); hexano obtido da EM Science (Gibbstown, EUA) e isopropanol obtido da Fisher Scientific ${ }^{\circledR}$ (Fair Lawn, NJ, EUA). Ácido acético glacial e trietilamina (TEA) foram obtidos da J.T. Baker $^{\circledR}$ (Phillipsburg, NJ, EUA).

Os reagentes, grau analítico, utilizados foram: fosfato de sódio dibásico $\left(\mathrm{Na}_{2} \mathrm{PO}_{4} \cdot 2 \mathrm{H}_{2} \mathrm{O}\right)$, fosfato de sódio monobásico $\left(\mathrm{NaH}_{2} \mathrm{PO}_{4} \cdot \mathrm{H}_{2} \mathrm{O}\right)$ e cloreto de sódio obtidos da Merck $^{\circledR}$ (Darmstadt, Alemanha). N,N-dimetilformamida (DMF) foi obtido da Vetec $^{\circledR}$ (Rio de Janeiro, RJ, Brasil).

Os reagentes utilizados no preparo dos meios de cultura foram: sulfato de magnésio heptaidratado $\left(\mathrm{MgSO}_{4} \cdot 7 \mathrm{H}_{2} \mathrm{O}\right)$ e sulfato de ferro heptaidratado $\left(\mathrm{FeSO}_{4} .7 \mathrm{H}_{2} \mathrm{O}\right.$ ) obtidos da $\mathrm{Merck}^{\circledR}$ (Darmstadt, Alemanha); hidróxido de sódio obtido da Nuclear ${ }^{\circledR}$ (Diadema, SP, Brasil); ácido acético obtido da Zilquímica ${ }^{\circledR}$ (Ribeirão Preto, SP, Brasil). Potato dextrose agar (PDA), sacarose, extrato de 
malte, dextrose, triptona e extrato de levedura foram obtidos da Acumedia ${ }^{\circledR}$ (Lansing, EUA).

Para as reações de catálise assimétrica foram utilizados catalisadores de Jacobsen: $(R, R)$-Jacobsen (100\% de pureza), $(S, S)$-Jacobsen $(98 \%$ de pureza). Os oxidantes empregados nas reações foram: ácido metacloroperbenzóico ( $m$-CPBA) obtido da Acros $\operatorname{Organics}^{\circledR}$ (Nova Jersey, EUA), peróxido de hidrogênio obtido da Fluka ${ }^{\circledR}$ (Buchs, Suíça) e iodozilbenzeno (PhIO) sintetizado segundo o método descrito por SHAREFKIN (1973). Essa síntese foi realizada pela hidrólise do iodobenzenodiacetato, e sua pureza de 95\% foi determinada por titulação iodométrica segundo técnica descrita por LUCAS et al. (1963).

\subsubsection{Colunas Quirais e Coluna de Guarda}

Para separação dos metabólitos, sete tipos de colunas quirais foram avaliadas:

Coluna Chiralcel OD-H ${ }^{\circledR}(150 \times 4,6 \mathrm{~mm}$, Chiral Technologies, Exton, EUA), constituída pelo derivado celulose tris (3,5-dimetilfenilcarbamato) recobrindo partículas de sílica de $5 \mu \mathrm{m}$ de diâmetro.

Coluna Chiralcel $O J^{\circledR}(250 \times 4,6 \mathrm{~mm}$, Chiral Technologies, Exton, EUA), constituída de derivado de celulose tris (4-metilbenzoato) recobrindo partículas de sílica de $10 \mu \mathrm{m}$ de diâmetro.

Coluna Chiralpak $A D^{\circledR}(250 \times 4,6 \mathrm{~mm}$, Chiral Technologies, Exton, EUA), constituída pelo derivado de amilose tris (3,5-dimetilfenilcarbamato) recobrindo partículas de sílica de 10 m de diâmetro.

Coluna Chiralpak AD-RH ${ }^{\circledR}(150 \times 4,6 \mathrm{~mm}$, Chiral Technologies, Exton, EUA), constituída pelo derivado de amilose tris (3,5-dimetilfenilcarbamato) recobrindo partículas de sílica de $5 \mu \mathrm{m}$ de diâmetro 
Coluna Chiralcel OD- $R^{\circledR}(250 \times 4,6 \mathrm{~mm}$, Chiral Technologies, Exton, EUA), constituída pelo derivado de celulose tris (3,5-dimetilfenilcarbamato) recobrindo partículas de sílica de 10 um de diâmetro.

Coluna Chiralcel OJ-H ${ }^{\circledR}(150 \times 4,6 \mathrm{~mm}$, Chiral Technologies, Exton, EUA), constituída de derivado de celulose tris (4-metilbenzoato) recobrindo partículas de sílica de $5 \mu \mathrm{m}$ de diâmetro.

Coluna Chirobiotic $T^{\circledR}(250 \times 4,6 \mathrm{~mm}$, Astec Inc., Whippany, EUA), constituída de derivado de antibiótico macrocíclico Teiclopanina, recobrindo partículas de sílica de $5 \mu \mathrm{m}$ de diâmetro.

Em todos os experimentos realizados durante o projeto foi empregada uma coluna de guarda C18 (4,6 x 12,5 mm, Merck ${ }^{\circledR}$, Darmstadt, Alemanha) com partículas de sílica de $5 \mu \mathrm{m}$ de diâmetro.

\subsubsection{SOLUÇõES-PADRÃO DE RISPERIDONA, SEUS METABÓLITOS E PADRÃO} INTERNO

A risperidona e seus metabólitos foram adquiridos da Toronto Research Chemicals $^{\circledR}$ (Toronto, Canadá). Soluções padrão de risperidona foram preparadas no intervalo de concentrações de $4-300 \mu \mathrm{g} \mathrm{mL}^{-1}$ a partir de uma solução estoque $400 \mu \mathrm{g} \mathrm{mL}^{-1}$. As soluções dos metabólitos, rac-7-RispOH e rac-9-RispOH, foram preparadas também em metanol no intervalo de concentrações de 4 - $80 \mu \mathrm{g} \mathrm{mL}^{-1}$ a partir de uma solução estoque $400 \mu \mathrm{g} \mathrm{mL}^{-1}$. Todas essas soluções foram utilizadas na otimização das condições de separação, extração e no desenvolvimento e validação do método. Ranolazina, adquirida de Sigma Aldrich ${ }^{\circledR}$ (Steinhem, Alemanha) foi utilizada como padrão interno. Para tanto, foi preparada uma solução em metanol na concentração de $60 \mu \mathrm{g} \mathrm{m}^{-1}$. As soluções foram estocadas em tubos de vidro à $-20^{\circ} \mathrm{C}$, e assim, permaneceram estáveis por pelo menos seis meses. 


\subsection{MÉTODOS}

\subsubsection{Preparação das fases Móveis}

As soluções empregadas como fase móvel na separação dos analitos no modo polar-orgânico foram preparadas por simples misturas dos componentes com posterior homogeneização. $\mathrm{O}$ aditivo orgânico trietilamina foi adicionado na fase móvel com o objetivo de melhorar a simetria dos picos e a resolução da separação.

\subsubsection{Preparo da solução-Tampão}

A solução-tampão empregada para o processo de microextração foi preparada na concentração desejada e o pH foi ajustado com adição de ácido clorídrico ou hidróxido de sódio.

\subsubsection{Avaliação da Separação Quiral}

A avaliação da separação dos analitos foi realizada injetando as soluções-padrão solubilizadas em $100 \mu \mathrm{L}$ da fase móvel. O parâmetro usado para avaliação da separação foi a resolução (Rs), calculada segundo a equação 2 (SNYDER; KIRKLAND; GLAJCH, 1997):

$$
\mathrm{RS}=\frac{2\left(t_{R_{\mathrm{n}}}-t_{\mathrm{R}_{1}}\right)}{w_{\mathrm{h} 1}+w_{\mathrm{n}}}
$$

Onde, $t_{R 2}$ é o tempo de retenção do analito mais retido $t_{R 1}$ do menos retido. $w_{b 1}$ e $w_{b 2}$ são as respectivas larguras das bases dos picos, calculadas pelo método da tangente.

A vazão da fase móvel empregada foi ajustada conforme a viscosidade da mesma, respeitando a pressão máxima permitida para cada tipo de coluna, 
resolução entre os analitos e tempo de análise. As análises foram efetuadas a em $25^{\circ} \mathrm{C}$.

3.3. OtimizaçÃo da Detecção dos Analitos por Espectrometria de MASSAS SEQUENCIAL (MS/MS)

A otimização da detecção por espectrometria de massas foi feita através da infusão direta de soluções-padrão dos analitos $\left(100 \mu \mathrm{g} \mathrm{mL}^{-1}\right)$ preparadas na fase móvel. Para tanto, foi empregado uma bomba de infusão na vazão de 10 $\mu \mathrm{L} \min ^{-1}$ e a detecção foi feita no modo positivo (ES+). Primeiramente foi empregado o modo Full Scan para determinar as condições de fragmentação adequadas. O espectrômetro de massas foi programado para operar em uma varredura de 100-400 amu. A energia do cone foi definida em $35 \mathrm{~V}$ para a risperidona, $35 \mathrm{~V}$ para os metabólitos 9-RispOH e 7-RispOH e $25 \mathrm{~V}$ para o padrão interno, ranolazina. A energia de colisão foi de 27 eV para risperidona, 26 eV para a ranolazina e 27 eV para os metabólitos.

Após os espectros de massas serem obtidos e as melhores condições de fragmentação definidas no modo Full Scan, o íon com maior intensidade (íon precursor, $[\mathrm{M}+\mathrm{H}]^{+}$) foi selecionado. Após, o íon "filho" foi selecionado para cada analito empregando o modo de varredura por monitoramento de reações múltiplas (MRM) operando entre 100-400 amu em um tempo de permanência de $0,4 \mathrm{~s}$. As transições de massas monitoradas foram: $\mathrm{m} / \mathrm{z} 411 \rightarrow 191$ para risperidona; $\mathrm{m} / \mathrm{z} 427 \rightarrow 207$ para 9-RispOH e 7-RispOH e m/z 428 $\rightarrow 279$ para a ranolazina. A Tabela 5 mostra as condições definidas para análise dos analitos por espectrometria de massas sequencial. 
Tabela 5 - Resumo das condições MS/MS para análise dos analitos.

\begin{tabular}{lccc} 
Analitos & Transição (m/z) & Cone (V) & Energia de colisão $(\mathbf{e V})$ \\
\hline 7-RispOH e 9-RispOH & $427>207$ & 35 & 27 \\
Risperidona & $411>191$ & 35 & 27 \\
Ranolazina (PI) & $428>279$ & 25 & 26 \\
\hline
\end{tabular}

\subsection{ORdem de ElUIÇÃo dA 9-RISPOH}

Depois de otimizadas as condições de separação dos enantiômeros, a ordem de eluição do metabólito ativo, 9-RispOH, foi determinada baseada no trabalho de Danel et al. (2007). A mistura racêmica da 9-RispOH foi injetada nas condições cromatográficas descrita por Danel et al. (2007). Em seguida, os eluatos correspondentes a cada enantiômero foram coletados, concentrados e injetados nas condições determinadas nesse estudo. Posteriormente os tempos de retenção de cada pico em cada estudo foram comparados e a ordem de eluição estabelecida.

\subsection{Procedimento de preparação das amostras para anÁlise dos} ANALITOS EM MEIO DE CULTURA EMPREGANDO A SPME

O desenvolvimento e a otimização do procedimento de extração foi realizado de acordo com o esquema apresentado na Figura 7. Os principais parâmetros que pudessem afetar no processo de extração foram avaliados empregando alíquotas de meio de cultura líquido Czapeck (descrito na seção 3.7.4.) acrescidas com alíquotas de solução-tampão e fortificadas com solução padrão de risperidona e seus metabólitos nas concentrações de $500 \mathrm{ng} \mathrm{mL}^{-1} \mathrm{e}$ $250 \mathrm{ng} \mathrm{mL}^{-1}$, respectivamente. Para cada parâmetro analisado foi construído um gráfico que representa a quantidade extraída (representada pela área dos picos nos cromatogramas) frente à modificação empregada. Todo procedimento foi realizado em triplicata. 
O meio de cultura Czapeck foi preparado para realização de todas as etapas do procedimento de otimização da extração e armazenado em tubos Falcon a $-20^{\circ} \mathrm{C}$. Antes do uso, o meio foi descongelado à temperatura ambiente $\left(23^{\circ} \mathrm{C} \pm 2^{\circ} \mathrm{C}\right)$, e agitado por 30 segundos. Alíquotas de $2 \mathrm{~mL}$ de meio de cultura foram transferidas para recipientes de $4 \mathrm{~mL}$, fortificadas com $25 \mu \mathrm{L}$ das soluções-padrão e agitadas em agitador de bancada do tipo "mixer" por 30 segundos. Feito isso, $2 \mathrm{~mL}$ de solução-tampão fosfato $0,25 \mathrm{~mol} \mathrm{~L}^{-1} \mathrm{pH} 7,0$ foi adicionado para manter $\mathrm{opH}$ constante durante o processo de extração. $\mathrm{O}$ procedimento de extração por SPME foi realizado por imersão direta da fibra nas amostras. A agitação foi realizada empregando um agitador orbital do tipo Vibrax, pois o formato desta fibra não permite o uso de amostradores. Após a extração, a fibra foi recolhida para dentro da agulha, removida do recipiente de extração e inserida em um micro-recipiente contendo $120 \mu \mathrm{L}$ da fase móvel. Nesse momento a dessorção dos analitos foi realizada. Após a dessorção, as fibras foram lavadas por 30 minutos com metanol para evitar a presença de interferentes e o efeito memória ("carryover") nas fibras. 


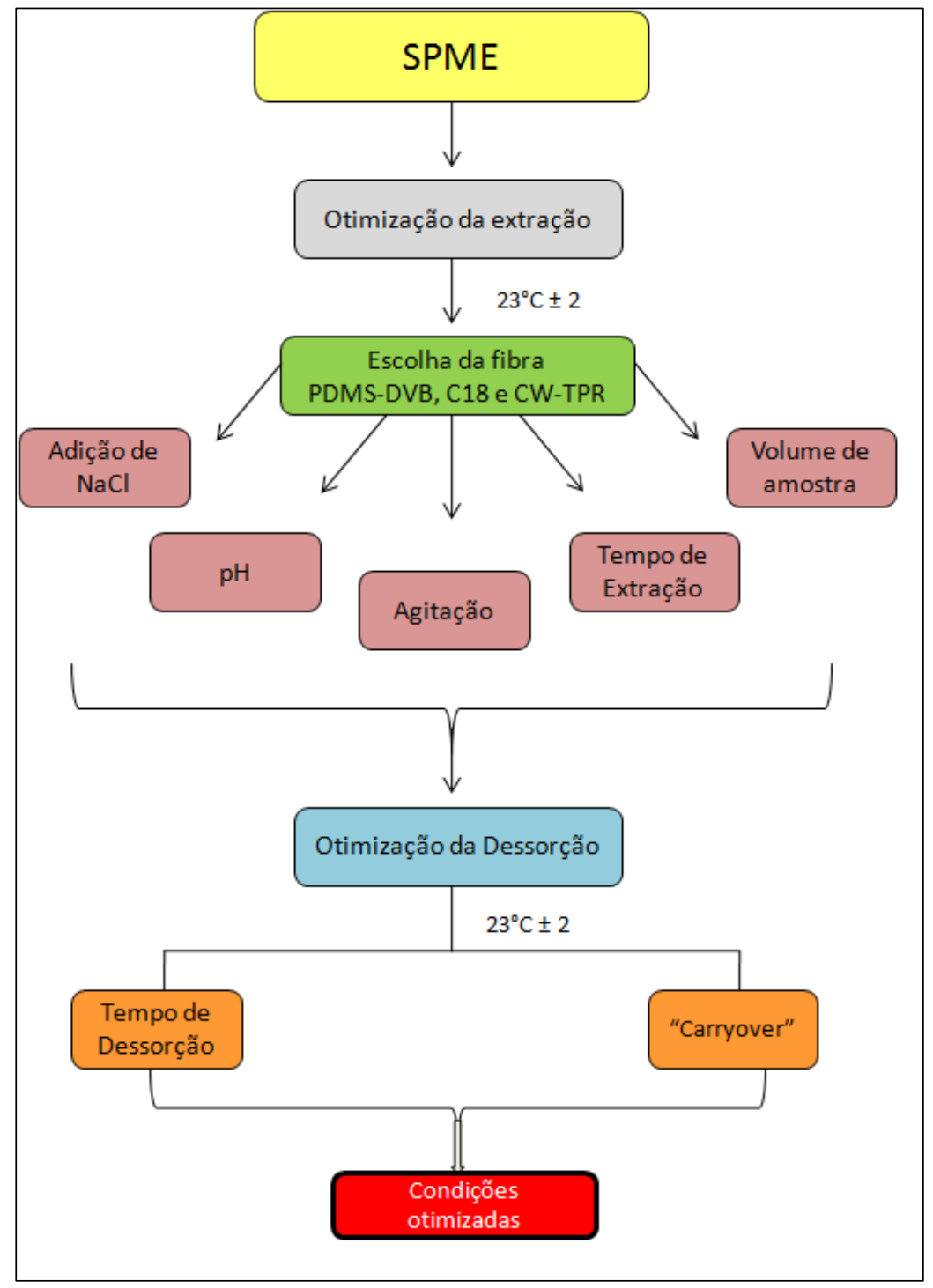

Figura 7 - Esquema de otimização das condições para SPME. Todo o procedimento foi realizado utilizando meio de cultura líquido Czapeck em temperatura ambiente $\left(23^{\circ} \mathrm{C} \pm 2^{\circ} \mathrm{C}\right)$. As condições foram avaliadas em triplicata $(n=3)$.

\subsection{VALIDAÇÃo da METOdOLOGIA ANALÍtica}

O método foi validado realizando-se os principais parâmetros propostos por algumas agências regulamentadoras (FDA, 2001 e ANVISA, 2003) para análise de fármacos em fluidos biológicos. $O$ uso da padronização interna é frequentemente utilizada em análises cromatográficas, portanto, para a análise 
da risperidona e seus metabólitos em meio de cultura empregando a SPME, a ranolazina foi utilizada como padrão interno.

\subsubsection{Curva Analítica e Linearidade}

A linearidade é determinada pela análise de soluções de diferentes concentrações, abrangendo a faixa de concentração de interesse de trabalho.

Embora a otimização completa da SPME tenha sido realizada em meio Czapeck, sabe-se que após a biotransformação, o meio contendo fungos pode apresentar características diferentes quanto à viscosidade (devido à formação de metabólitos secundários provenientes dos fungos) podendo, portanto, afetar o processo de microextração em fase sólida. Para tanto, a linearidade foi avaliada em dois tipos diferentes de matrizes. Dessa forma, as curvas analíticas foram construídas em meio de cultura líquido Czapeck (2 mL) previamente fortificadas com $25 \mu \mathrm{L}$ das soluções-padrão de risperidona, seus metabólitos e o padrão interno, e também em amostras construídas por um pool de fungos do gênero Cunninghamella (2 mL) (descrito na seção 3.7.5) que também foram previamente fortificadas com $25 \mu \mathrm{L}$ dos analitos. A linearidade nas diferentes matrizes foi realizada fortificando as amostras com risperidona no intervalo de 50-3750 ng mL ${ }^{-1}$. Na análise dos metabólitos as amostras foram fortificadas no intervalo de $25-500 \mathrm{ng} \mathrm{mL}^{-1}$ para cada enantiômero. A concentração do padrão interno foi de $750 \mathrm{ng} \mathrm{mL}^{-1}$. A linearidade $(n=5)$ do método foi ponderada utilizando $1 / x^{2}$. Os resultados da linearidade foram ponderados porque a análise residual da curva analítica mostrou um comportamento heterocedástico.

A razão dos slopes das curvas analíticas foi determinada e analisada (MATUSZEWSKI, 2006). Foram consideradas como semelhantes as curvas que apresentavam uma razão de slope não estatisticamente diferente de 1. Além disso, para garantir que a matriz não influenciava o processo de extração, amostras de pool de fungos foram fortificadas com os analitos em três diferentes concentrações $\left(75,500\right.$ e $2000 \mathrm{ng} \mathrm{mL}^{-1}$ para risperidona, 37, 187 e $500 \mathrm{ng} \mathrm{mL}^{-1}$ para cada enantiômero da 9-RispOH e 45, 187 e $500 \mathrm{ng} \mathrm{mL}^{-1}$ para cada enantiômero da 7-RispOH, $n=5$ para cada concentração) e quantificadas empregando a curva analítica preparada em meio Czapeck. Após, o erro 
relativo de cada concentração e o desvio padrão relativo foram calculados. Depois de verificar que as curvas analíticas das diferentes matrizes não apresentavam diferenças significativas, optou-se por continuar a validação analítica utilizando meio de cultura líquido Czapeck uma vez que este é ecologicamente mais viável por não gerar resíduos biológicos. Dessa forma, toda validação analítica foi realizada em meio de cultura Czapeck.

\subsubsection{LIMITE de QUANTIFICAÇÃo (LOQ)}

O limite de quantificação é definido como a menor concentração que pode ser quantificada com precisão e erro relativo inferior a $20 \%$. O LOQ foi determinado avaliando amostras de $2 \mathrm{~mL}$ de meio de cultura $(n=5)$ nas concentrações de $25 \mathrm{ng} \mathrm{mL}^{-1}$ de cada enantiômero da 9-RispOH e 7-RispOH e $50 \mathrm{ng} \mathrm{mL}^{-1}$ de risperidona. Essas amostras foram analisadas com base em uma curva analítica preparada com amostras de meio de cultura nas concentrações de 25-500 $\mathrm{ng} \mathrm{mL}^{-1}$ de cada enantiômero dos metabólitos e na concentração de $50-3750 \mathrm{ng} \mathrm{mL}^{-1}$ de risperidona. A curva analítica foi construída em triplicata $(n=3)$ para cada concentração.

\subsubsection{RECUPERAÇÃo}

A recuperação é a medida da eficiência no processo de extração utilizado. A recuperação dos analitos frente ao método de extração da SPME foi avaliada empregando a equação 3 :

$$
\text { Recuperação }=\frac{\text { Concentrapăo calculada }}{\text { Conemtrạtio nominal }} \times 100
$$

A "concentração calculada" na equação acima é a concentração das amostras que foram submetidas ao processo de extração por SPME e a "concentração nominal" corresponde aos dados resultantes da análise direta das mesmas soluções-padrão sem passar pelo processo de extração. A 
recuperação foi avaliada fortificando $2 \mathrm{~mL}$ de meio de cultura cuja concentração final foi de 100, 1000 e $2000 \mathrm{ng} \mathrm{mL}^{-1}$ para risperidona e 50, 200 e $400 \mathrm{ng} \mathrm{mL}^{-1}$ para cada enantiômero dos metabólitos. Os dados foram expressos em porcentagem de recuperação e desvio padrão relativo.

\subsubsection{Precisão e Exatidão}

A precisão é o parâmetro que avalia a proximidade de várias medidas efetuadas em uma mesma amostra. As medidas devem ser simultâneas (precisão intraensaios) e também efetuadas em corridas diferentes (precisão interensaios). Esse parâmetro é avaliado pelo coeficiente de variação (CV\%) de acordo com a equação 4:

$$
C V=\frac{S D}{M} \quad x 100
$$

Onde, SD, é o desvio padrão e, $\bar{M}$, a média dos valores de concentrações obtidas das amostras analisadas em replicatas.

A exatidão é a diferença entre o valor nominal presente na amostra e o valor obtido na análise. É avaliada pelo afastamento entre os valores esperado e obtido, e pode ser representada pela equação 5 :

$$
E(\%)=\frac{\text { valor obtido }- \text { valor real }}{\text { Valor real }} \times 100
$$

A precisão e exatidão intraensaio foram avaliadas analisando-se frações $(n=5)$ de $2 \mathrm{~mL}$ de meio de cultura líquido Czapeck, fortificadas nas concentrações de 100, 1000 e $2000 \mathrm{ng} \mathrm{mL}^{-1}$ para análise da risperidona e 50, 200 e $400 \mathrm{ng} \mathrm{mL}^{-1}$ para análise de cada enantiômero dos seus metabólitos. Neste experimento, todas as frações foram analisadas no mesmo dia. Essas amostras foram quantificadas construindo, no mesmo dia, uma curva analítica em duplicata $(n=2)$ da risperidona e de seus metabólitos. 
A precisão e exatidão interensaio foram avaliadas fortificando amostras de $2 \mathrm{~mL}$ de meio de cultura líquido Czapeck com risperidona e seus metabólitos nas mesmas concentrações descritas para análise intraensaio $(n=$ 5) durante 3 dias consecutivos. Novamente, para cada dia de análise, uma curva analítica foi feita de modo idêntico ao descrito no experimento de avaliação da precisão e exatidão intraensaio.

\subsubsection{ESTABILIDADE}

A estabilidade da risperidona e seus principais metabólitos no meio de cultura foi avaliada de duas formas: (i) estabilidade em ciclos de congelamento/descongelamento e (ii) estabilidade em curto prazo.

Este estudo foi realizado empregando amostras $(n=6)$ de $2 \mathrm{~mL}$ de meios de cultura fortificados com rac-7-RispOH e rac-9-RispOH em duas concentrações: uma concentração baixa $\left(50 \mathrm{ng} \mathrm{mL}^{-1}\right.$ para cada enantiômero dos metabólitos e $100 \mathrm{ng} \mathrm{mL}^{-1}$ para a risperidona) e uma concentração alta (400 $\mathrm{ng} \mathrm{mL}^{-1}$ para cada enantiômero dos metabólitos e $800 \mathrm{ng} \mathrm{mL}^{-1}$ para a risperidona). Os resultados obtidos foram comparados aos resultados obtidos de amostras frescas (recém-preparadas). A comparação entre os parâmetros de estabilidade foram realizadas empregando o teste "One-way ANOVA", sendo que valores de $p \leq 0,05$ foram considerados estatisticamente significativos.

Para o estudo da estabilidade em ciclos de congelamento/descongelamento, o estudo foi realizado nas seguintes condições: as amostras foram congeladas a $-20^{\circ} \mathrm{C}$ por 24 horas e então submetidas ao descongelamento à temperatura ambiente $\left(23^{\circ} \mathrm{C} \pm 2^{\circ} \mathrm{C}\right)$. Estes ciclos de congelamento/descongelamento foram repetidos por mais duas vezes, sendo que as amostras foram quantificadas no final do terceiro ciclo. Os resultados (áreas dos picos) foram comparados com aqueles obtidos das análises de amostras frescas.

A estabilidade em curto prazo foi realizada deixando as amostras em temperatura ambiente $\left(23^{\circ} \mathrm{C} \pm 2^{\circ} \mathrm{C}\right)$ sobre a bancada por 8 horas e, 
posteriormente analisadas. Os resultados (áreas dos picos) foram comparados com aqueles obtidos das análises das amostras frescas.

\subsubsection{EFEITo da Matriz na lonização dos Analitos}

Para verificar se houve interferências da matriz na ionização dos analitos foi realizado um estudo de efeito da matriz empregando dois tipos de matrizes: (1) pool de fungos e (2) meio de cultura Czapeck. Neste estudo, brancos de pool de fungos e brancos de meio de cultura líquido Czapeck foram extraídos $(n=4)$ por SPME. Após, o extrato foi levado à secura e o resíduo foi fortificado com $25 \mu \mathrm{L}$ de cada uma das soluções-padrão de risperidona e seus metabólitos nas seguintes concentrações: 100, 1000 e $2000 \mathrm{ng} \mathrm{mL}^{-1}$ para análise da risperidona; 50, 200, $400 \mathrm{ng} \mathrm{mL}^{-1}$ para análise da 9-RispOH e 7RispOH e $750 \mathrm{ng} \mathrm{mL}^{-1}$ para análise do padrão interno, ranolazina. Essas amostras foram injetadas no LC-MS/MS e suas áreas monitoradas. Simultaneamente, soluções-padrão de mesma concentração e na mesma quantidade foram dissolvidas na fase móvel $(n=4)$ e as áreas de seus picos monitoradas. Os dados foram comparados para a verificação de possível interferência de matriz na ionização. Os resultados deste estudo foram expressos como porcentagem de erro relativo (considerando as áreas das soluções-padrão como 100\%) e coeficiente de variação.

\subsection{ESTUdOS DE BIOTRANSFORMAÇÃo}

\subsubsection{FUNGOS}

Os fungos endofíticos utilizados no processo de biotransformação foram: Penicillium crustosum (VR4), Chaetomium globusum (VR10) e Aspergillus fumigatus (VR12), isolados de Viguiera robusta. Papulaspora immersa Hotson (SS13), Nigrospora sphaerica (Sacc.) E.W. Mason (SS67) e Fusarium oxysporum (SS50), isolados de Smallanthus sonchifolius e Glomerella cingulata (VA1) isolado de Viguiera arenaria. Os fungos endofíticos foram gentilmente 
cedidos pela Prof Farmacêuticas de Ribeirão Preto. Os fungos Cunninghamella echinulata var. elegans ATCC 8688A e Cunninghamella elegans NRRL 1393 ATCC 10028B foram adquiridos da American Type Culture Collection $\left(A T C C^{\circledR}\right.$, Universidade Boulevard, Manassas, VA, EUA). Os fungos foram cedidos na forma de "plugs de ágar" e foram mantidos em meio de glicerol:água $(8: 2, \mathrm{v} / \mathrm{v}) \mathrm{a}-20^{\circ} \mathrm{C}$.

Os estudos de biotransformação com fungos baseiam-se em três etapas: (i) incubação das espécies de fungos em meio sólido para seu crescimento em placa; (ii) transferência de três plugs do fungo do meio sólido para um meio líquido rico em nutrientes (meio de malte) e (iii) transferência da massa micelial formada na etapa anterior para um segundo meio líquido juntamente com o fármaco em estudo (Figura 8).

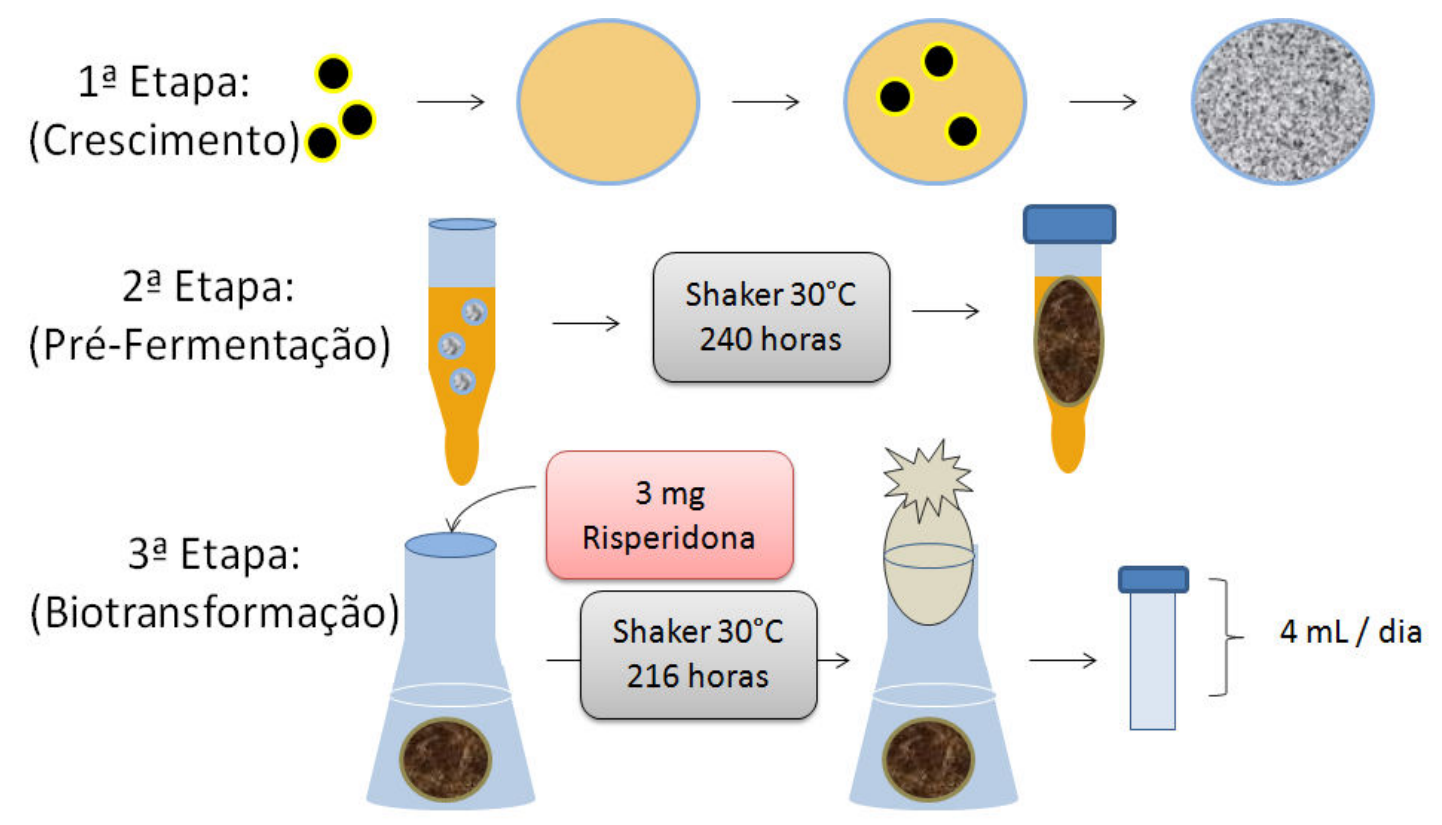

Figura 8 - Esquema do processo de biotransformação com fungos.

\subsubsection{Preparo do Meio de cultura PDA}

O meio de cultura Batata (Potato) Dextrose agar, PDA, é o meio sólido utilizado para a primeira etapa do crescimento dos fungos. São pesadas 
massas suficientes para o preparo das quantidades $(\mathrm{mL})$ necessárias para tantos quantos forem o número de placas de Petri a serem utilizadas nesta primeira etapa. São necessários $15 \mathrm{~mL}$ de meio para cada placa de Petri. Após a pesagem, completa-se com a quantidade necessária de água ultra-pura e, em seguida, essa mistura é esterilizada em autoclave por cerca de 30 minutos para posterior distribuição do meio em cada placa.

\subsubsection{Preparo do Meio de cultura de Malte}

O meio de cultura de malte é o meio líquido pré-fermentativo, utilizado na segunda etapa do estudo. Nesta etapa, os fungos crescem e ganham massa. O meio de malte é preparado fazendo-se uma mistura dos reagentes: extrato de malte, dextrose, triptona e extrato de levedura nas concentrações de $10,0 \mathrm{~g} \mathrm{~L}^{-1}, 10,0 \mathrm{~g} \mathrm{~L}^{-1}, 5,0 \mathrm{~g} \mathrm{~L}^{-1}$ e $3,0 \mathrm{~g} \mathrm{~L}^{-1}$, respectivamente. Tal mistura gera uma solução líquida de $\mathrm{pH}$ próximo de 7 que é corrigido para $\mathrm{pH}$ 6,2 utilizandose ácido clorídrico $0,5 \mathrm{~mol} \mathrm{~L}^{-1}$. Em seguida, esse meio é também esterilizado em autoclave da mesma forma que para o meio PDA.

\subsubsection{Preparo do meio de cultura líquido Czapeck}

O meio de cultura Czapeck é o meio utilizado na terceira etapa do processo, onde os fungos serão mantidos por determinado número de dias juntamente com o fármaco empregado no estudo de biotransformação. Foi também, o meio empregado para todo o processo de validação deste trabalho. O meio Czapeck é preparado fazendo-se uma mistura em massa dos reagentes: sacarose, $\mathrm{NaNO}_{3}, \mathrm{~K}_{2} \mathrm{HPO}_{3}, \mathrm{MgSO}_{4} .7 \mathrm{H}_{2} \mathrm{O}, \mathrm{KCl}$ e $\mathrm{FeSO}_{4} .7 \mathrm{H}_{2} \mathrm{O}$ nas porcentagens de $2,5 \%, 0,2 \%, 0,1 \%, 0,05 \%, 0,05 \%, 0,001 \%$, respectivamente. Em seguida, adiciona-se água ultrapura no volume desejado desde que as concentrações em massa permaneçam as mesmas. A mistura gera uma solução líquida de $\mathrm{pH}$ próximo de 8 que deve ser corrigido para $\mathrm{pH}$ 5,0 utilizando-se $\mathrm{HCl}$ 1,0 mol L ${ }^{-1}$. Da mesma forma que para os outros meios de cultura, esta mistura é esterilizada em autoclave. 


\subsubsection{Preparo da Matriz Pool de Fungos}

Este meio de pool de fungos foi utilizado para verificar se havia efeito da matriz em etapas de otimização do procedimento de extração e na validação do método. É um meio que se faz uma mistura contendo mais de uma espécie de fungos (mistura dos brancos das espécies) cultivados sem adição do fármaco, e é preparado da mesma maneira que foi apresentado na terceira etapa do processo de biotransformação. Para este trabalho, foi feito um pool de fungos empregando as duas espécies dos fungos do gênero Cunninghamella (Figura 9) (Cunninghamella echinulata var. elegans ATCC 8688A e Cunninghamella elegans: NRRL 1393 ATCC 10028B) para serem aplicados em etapas da validação do método.

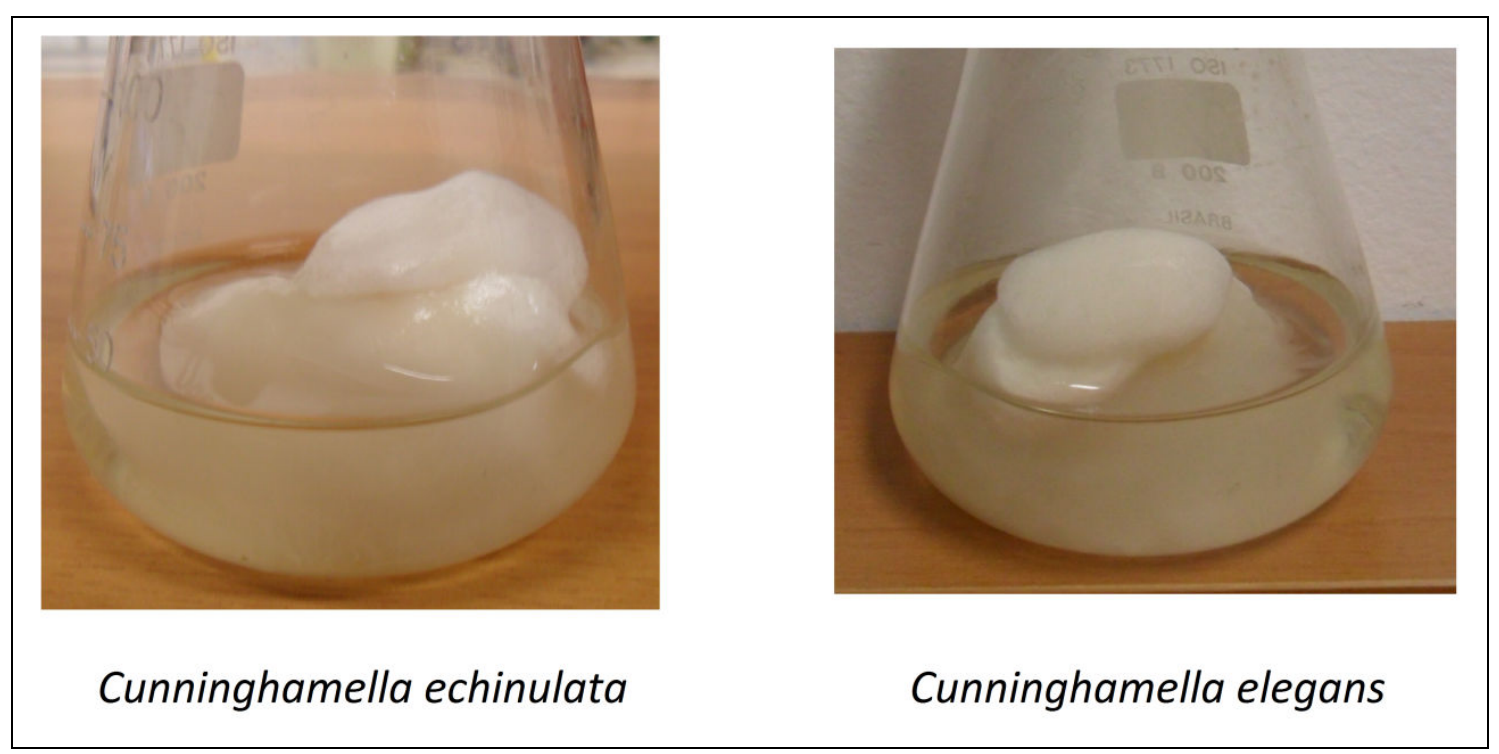

Figura 9 - Fotos dos brancos do gênero Cunninghamella utilizados como pool de fungos. 


\subsubsection{PROCEDIMENTO de BIOTRANSFORMAÇÃo dA RISPERIDONA}

Inicialmente, os plugs em ágar dos fungos cedidos foram transferidos com auxílio de uma alça de platina esterilizada para placas de Petri contendo meio PDA, em capela de fluxo laminar. Cada espécie do fungo foi cultivada em duplicata de forma a monitorar possíveis contaminações. As placas de Petri foram vedadas com PVC e, então, levadas à estufa bacteriológica e incubados a $30^{\circ} \mathrm{C} \mathrm{em}$ dias necessários para que cada espécie de fungo crescesse uniformemente nas placas (em média, os fungos eram mantidos por 5 dias na estufa).

Nesta segunda etapa, após o crescimento dos fungos, três discos (plugs) de $0,5 \mathrm{~cm}$ de diâmetro deste meio de cultura com os fungos foram retirados com o auxílio de um Transfer tube e inoculados assepticamente em $15 \mathrm{~mL}$ de meio de malte e colocados sob agitação no agitador orbital tipo "shaker" a $120 \mathrm{rpm}$ e a uma temperatura de $30^{\circ} \mathrm{C}$ por 5 dias, até que os fungos ganhassem massa. Nessa etapa, quase todo o meio de malte era consumido pelo micro-organismo.

Em seguida, na terceira etapa do procedimento, a massa micelial formada na segunda etapa foi transferida assepticamente com o auxílio de uma alça de platina, para $80 \mathrm{~mL}$ do meio fermentativo Czapeck. Após a transferência dos fungos para o meio Czapeck, foram adicionado $3 \mathrm{mg}$ de risperidona dissolvida em $200 \mu \mathrm{L}$ de DMF em somente uma das suas duplicatas e a mistura foi incubada no agitador orbital tipo "shaker" por 9 dias sob agitação de $120 \mathrm{rpm}$ a $30^{\circ} \mathrm{C}$. A outra replicata foi cultivada da mesma forma como "branco", sem a presença do fármaco. A cada dia, alíquotas de 4 $\mathrm{mL}$ eram coletadas assepticamente de cada espécie de fungo e seus respectivos brancos e armazenadas a $-20^{\circ} \mathrm{C}$ até o momento da análise, as quais foram realizadas em duplicata.

Todo o procedimento foi realizado utilizando capela de fluxo laminar e para todas as espécies de fungos as etapas foram feitas da mesma forma e em duplicata.

Os resultados positivos para a formação dos enantiômeros foram demonstrados em resultados e discussão e o excesso enantiomérico foi calculado pela equação 6 : 


$$
e e=\frac{(A-B)}{(A+B)} \times 100
$$

Onde, A é o enantiômero em maior concentração e $B$, o enantiômero em menor concentração.

\subsubsection{Estudos Preliminares de Catálise Assimétrica Empregando} Complexos de JACOBSEN

A fim de se avaliar a atividade catalítica enantiosseletiva dos catalisadores de Jacobsen, os catalisadores: $(R, R)$-Jacobsen e $(S, S)$-Jacobsen foram empregados em um estudo preliminar na oxidação da risperidona. Todas as reações foram realizadas à temperatura ambiente $\left(23^{\circ} \mathrm{C} \pm 2^{\circ} \mathrm{C}\right)$, sob agitação magnética, em frascos de $3 \mathrm{~mL}$ com tampa rosqueada.

O monitoramento da reação foi feito até 24 horas. A cada 4 horas uma alíquota de $25 \mu \mathrm{L}$ do meio reacional era retirada e analisada por HPLC.

A avaliação do efeito de diferentes oxidantes (m-CPBA, $\mathrm{H}_{2} \mathrm{O}_{2}$ e PhIO) na oxidação da risperidona foi realizada nas condições 1:100:50 e 1:50:50 (proporção em número de mols, catalisador:oxidante:substrato, nesta ordem), partindo-se de 9,74 $10^{-8} \mathrm{~mol}$ de catalisador Jacobsen, em um volume final de reação de $1500 \mu \mathrm{L}$ que eram completados usando-se diclorometano. 


\section{4 - $\quad$ RESULTADOS E DISCUSSÃO}

\subsection{OtimizaÇÃo da SeparaÇão Cromatográfica}

O objetivo principal desta etapa foi realizar a separação simultânea da RISP e dos enantiômeros da 7-RispOH e 9-RispOH utilizando uma mesma coluna e em condições ainda não descritas na literatura. Entre os métodos de separação enantiosseletivas existentes na literatura e já mencionados na introdução deste trabalho, poucos realizam a separação simultânea dos enantiômeros dos dois metabólitos: 7-RispOH e 9-RispOH. Os métodos descritos fazem o uso, em sua maioria, da coluna baseada em celulose, Chiralcel $O J^{\circledR}$, empregando fase normal ou, então, da coluna baseada em proteína, Chiral $A G P^{\circledR}$, empregando fase reversa. Até o momento, não há dados na literatura relatando o uso do modo polar-orgânico na separação quiral desses analitos. Dessa forma, nesse trabalho o modo polar-orgânico foi avaliado na separação dos analitos. Para tanto, foram avaliadas sete tipos de colunas quirais: Chirobiotic $T^{\circledR}$, Chiralpak $A D^{\circledR}$, Chiralpak $A D-R H^{\circledR}$, Chiralcel OD-R ${ }^{\circledR}$, Chiralcel OJ-H ${ }^{\circledR}$, Chiralcel OJ ${ }^{\circledR}$ e Chiralcel OD-H ${ }^{\circledR}$.

Além disso, o uso do aditivo orgânico trietilamina (TEA) também foi avaliado em diferentes proporções nas fases móveis empregadas.

\subsubsection{Coluna Chirobiotic T ${ }^{\circledR}$}

Embora a classe dos antibióticos macrocíclicos seja conhecida por separar diversos tipos de compostos quirais por terem vários centros estereogênicos capazes de inúmeras variedades de interações com reconhecimento quiral e, também, embora exista na literatura a separação de alguns compostos básicos (LIU et al., 2002) de características similares ao da RISP e seus metabólitos, nenhum indício de separação ocorreu durante a tentativa de separação com esta coluna.

As condições avaliadas na tentativa de separação com esta coluna foram utilizando como fase móvel os solventes: etanol, metanol, acetonitrila, isopropanol ou mistura dos mesmos. 


\subsubsection{Coluna ChiRALPaK $A D^{\circledR}$}

Esta coluna, derivada de amilose tris (3,5-dimetilfenilcarbamato) com partículas de sílica de $10 \mu \mathrm{m}$, tem uma grande capacidade de resolução de compostos quirais, da mesma forma que as colunas derivadas de celulose com o mesmo tipo de seletor quiral. Estas colunas possuem reconhecimento quiral para muitas classes de compostos como: aminoácidos, aminas, éteres e diversas classes de fármacos (OKAMOTO; YASHIMA, 1998). O que difere as classes de colunas derivadas de celulose das colunas derivadas de amilose é a estrutura diferenciada destes polissacarídeos que leva a diferenças na disposição espacial dos seletores quirais e, consequentemente, mudam a conformação do sítio de reconhecimento quiral. Este reconhecimento é possível uma vez que estudos demonstraram que os derivados de celulose e amilose apresentam estruturas helicoidais em formato de "calhas" onde os grupos benzoato e carbamato localizam-se no interior e os grupos aromáticos hidrofóbicos no exterior das "calhas" (BONATO et al., 2005; YASHIMA, 2001; YASHIMA; OKAMOTO, 1995)

$\mathrm{Na}$ otimização da separação da RISP e seus metabólitos com esta coluna foram empregados os solventes: etanol, metanol e acetonitrila em diferentes proporções. $O$ aditivo orgânico trietilamina também foi utilizado em diferentes proporções na tentativa de melhorar a qualidade da resolução cromatográfica.

Quaisquer das proporções de fase móvel empregadas não foram capazes de obter a separação de todos os compostos. Obteve-se uma separação efetiva apenas para os enantiômeros da 7-RispOH utilizando como fase móvel acetonitrila:metanol $(50: 50, v / v)+0,1 \%$ de TEA, sendo que houve coeluição com a RISP para os um dos enantiômeros da 9-RispOH (Figura 10). 


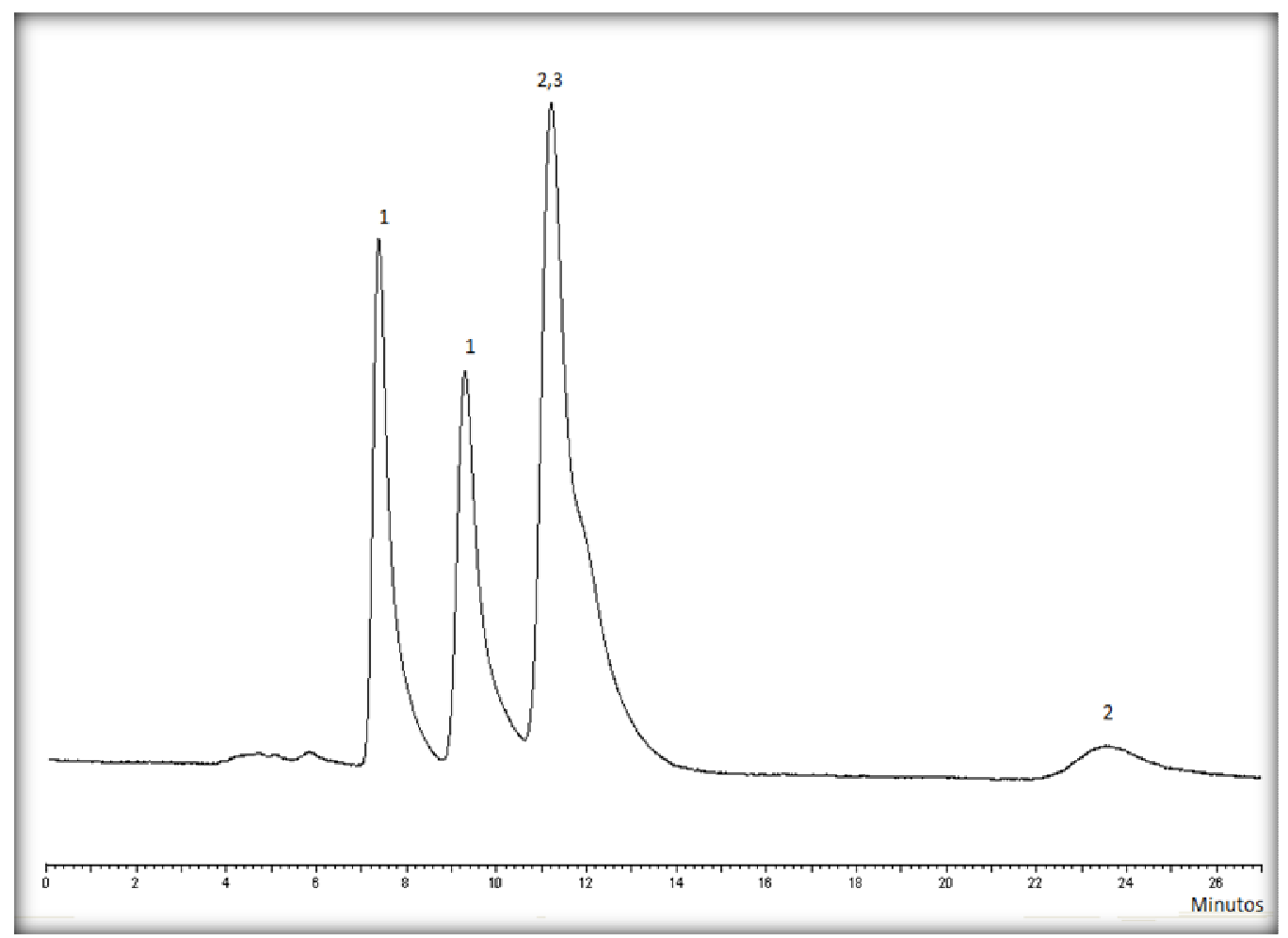

Figura 10 - Melhor condição obtida na tentativa de separação da RISP e seus metabólitos na coluna Chiralpak $A D^{\circledR}$. Enantiômeros da 7-RispOH (1), enantiômeros da 9-RispOH (2) e RISP (3). Fase móvel: acetonitrila:metanol $(50: 50, \mathrm{v} / \mathrm{v})+0,1 \%$ TEA, vazão: $0,6 \mathrm{~mL} \mathrm{~min}{ }^{-1}$, temperatura $25^{\circ} \mathrm{C}$, detecção em $280 \mathrm{~nm}$.

\subsubsection{Coluna ChIRALPAK AD-RH ${ }^{\circledR}$}

Esta coluna apresenta as mesmas características da coluna Chiralpak $A D^{\circledR}$ quanto ao derivado de amilose. Entretanto, esta coluna foi desenvolvida para o emprego preferencial de fase móvel no modo reverso, que faz o uso de soluções aquosas (TACHIBANA; OHNISHI, 2001). Outra diferença significativa quanto à coluna Chiralpak $A D^{\circledR}$ é o tamanho das partículas de sílica utilizadas, que, neste caso é de $5 \mu \mathrm{m}$. Esta característica faz com que a coluna seja, teoricamente, mais eficiente (GRITTI; GUIOCHON, 2012).

Embora a coluna seja produzida para ser empregada no modo reverso, esta coluna também pode ser utilizada nos demais modos de eluição. Por esta razão, e também por apresentar partículas menores, houve uma tentativa de separação dos compostos nas mesmas condições empregadas para a coluna 
Chiralpak $A D^{\circledR}$. Porém, o comportamento de ambas as colunas foi similar e não houve separação efetiva dos compostos (Figura 11). Além disso, não foi possível utilizar a mesma vazão empregada da primeira coluna, uma vez que em partículas de sílica menores, há um aumento significativo da pressão no sistema cromatográfico.

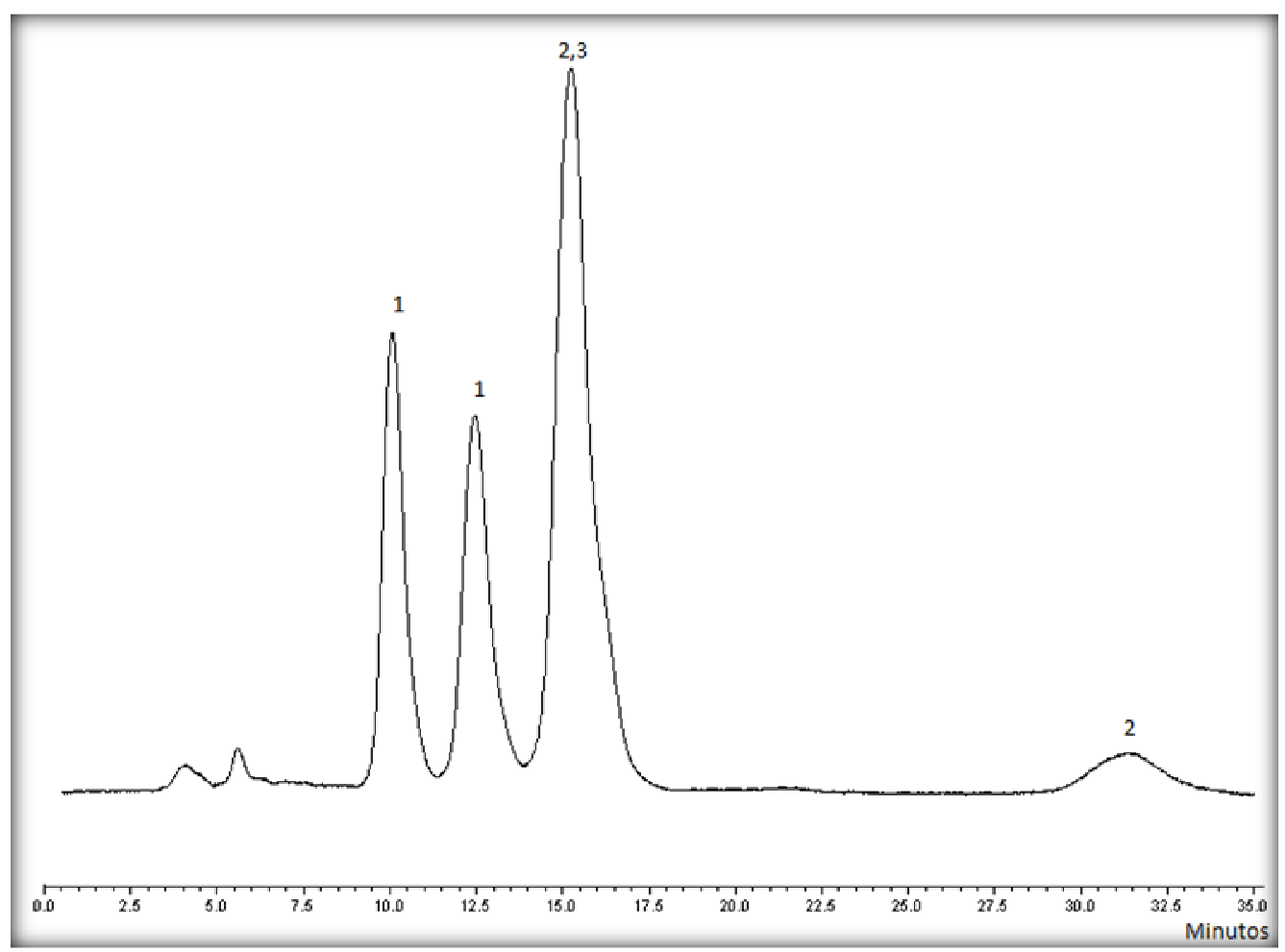

Figura 11 - Melhor condição obtida na tentativa de separação da RISP e seus metabólitos na coluna Chiralpak AD-RH ${ }^{\circledR}$. Enantiômeros da 7-RispOH (1), enantiômeros da 9-RispOH (2) e RISP (3). Fase móvel: acetonitrila:metanol (50:50, v/v) + 0,25\% TEA, vazão: 0,4 mL $\mathrm{min}^{-1}$, temperatura $25^{\circ} \mathrm{C}$, detecção em $280 \mathrm{~nm}$.

\subsubsection{ChIRALCEL OD-H ${ }^{\circledR}$}

A fase estacionária desta coluna de celulose também é constituída do seletor tris (3,5-dimetilfenilcarbamato) e também apresenta partículas de sílica de $5 \mu \mathrm{m}$. As condições avaliadas para esta coluna foram as mesmas empregadas para coluna Chiralpak $A D^{\circledR}$, portanto, como já dito anteriormente, a diferença das colunas derivadas de celulose e amilose está na conformação tridimensional das mesmas. Dessa forma, muitos compostos que não possuem 
um bom reconhecimento quiral nas colunas derivadas de amilose, podem ter separação efetiva em colunas derivadas de amilose e vice-versa.

De acordo com dados da literatura, racematos com grupamentos polares podem interagir com os resíduos carbamatos próximos às unidades de glicose presentes nesta coluna, através de ligações de hidrogênio (OKAMOTO; KAIDA, 1994). Os solventes empregados na tentativa de separação foram: etanol, metanol, isopropanol em diferentes proporções, acrescidos ou não de TEA. Entretanto, não houve separação neste modo de eluição utilizando a coluna Chiralcel OD-H ${ }^{\circledR}$.

\subsubsection{Coluna ChiRAlCel OD-R ${ }^{\circledR}$}

A coluna Chiralcel OD- $\mathrm{R}^{\circledR}$ apresenta as mesmas propriedades da coluna Chiralcel OD- $H^{\circledR}$, diferindo no tamanho de partícula de sílica que para a OD- ${ }^{\circledR}$ é de $10 \mu \mathrm{m}$ e no comprimento que é $25 \mathrm{~cm}$. Foram feitas tentativas de separação da RISP e seus principais metabólitos utilizando os seguintes solventes: metanol, etanol e isopropanol em diferentes proporções com adição de TEA ou não. Entretanto, em nenhuma das condições utilizadas houve início de separação para qualquer dos compostos.

\subsubsection{Coluna Chiralcel OJ ${ }^{\circledR}$}

A coluna Chiralcel $O J^{\circledR}$ é constituída por um derivado de celulose tris (4metilbenzoato) com partículas de sílica de $10 \mu \mathrm{m}$ de diâmetro. Segundo relatos da literatura, este derivado possui um reconhecimento quiral para uma grande variedade de compostos assimétricos (YASHIMA, 2001). Alguns métodos da literatura para separação concomitante e eficiente da RISP e 9-RispOH fazem o uso desta coluna em modo normal (MEULDER et al, 2008; DANEL et al., 2007) Entretanto, não há nenhum relato na literatura que emprega como fase móvel o modo polar-orgânico.

Novamente, várias proporções de misturas de solventes foram avaliadas tais como: metanol, etanol, isopropanol e acetonitrila. Poucas misturas foram 
estudadas empregando o modo polar-orgânico para esta coluna, pois, optou-se por prosseguir os estudos no modo polar-orgânico com a coluna, Chiralcel OJ$\mathrm{H}^{\circledR}$, que possui a mesma CSP da Chiralcel $O J^{\circledR}$, diferindo no tamanho da partícula de sílica $(5 \mu \mathrm{m})$ e no comprimento $(15 \mathrm{~cm})$.

\subsubsection{Coluna Chiralcel OJ-H ${ }^{\circledR}$}

A coluna Chiralcel OJ-H ${ }^{\circledR}$ é constituída também pelo derivado de celulose tris (4-metilbenzoato), porém com partículas de sílica de $5 \mu \mathrm{m}$ de diâmetro e comprimento de $15 \mathrm{~cm}$.

A separação da RISP e seus principais metabólitos, 7-RispOH e 9$\mathrm{RispOH}$, foi estudada neste coluna empregando os seguintes solventes orgânicos polares: metanol, etanol e isopropanol. O aditivo orgânico TEA também foi empregado na fase móvel em diferentes proporções.

Para esta coluna, três tipos de fases móveis foram capazes de separar os analitos de interesse. A fase móvel composta por metanol:isopropanol $(80: 20, v / v)+0,2 \%$ TEA; a fase móvel composta por $100 \%$ de etanol $+0,2 \%$ TEA (Figura 12) e a fase móvel composta por metanol:etanol $(50: 50, \mathrm{v} / \mathrm{v})+$ 0,2\% TEA (Figura 13).

Para prosseguir com os estudos, foi necessário escolher uma das separações obtidas. A fase móvel composta por metanol:isopropanol (80:20, $\mathrm{v} / \mathrm{v})+0,2 \%$ TEA foi excluída em relação às demais separações por apresentar valores de resolução mais baixos para os enantiômeros da 9-RispOH $\left(R_{\mathrm{S} 2} \mathrm{e}\right.$ $R_{S 4}$, disponível na Tabela 6) . Quanto às demais condições, a separação obtida empregando a fase móvel composta por metanol:etanol $(50: 50, \mathrm{v} / \mathrm{v})+0,2 \%$ TEA foi preferida porque apresentou uma melhor resolução cromatográfica, além de menor tempo de análise. A Tabela 6 faz uma comparação das condições obtidas para cada separação utilizando a coluna Chiralcel OJ-H ${ }^{\circledR}$.

Baseada nas estruturas da RISP e seus principais metabólitos (Figura 1) e em relatos da literatura, consegue-se fazer uma análise mais detalhada das possíveis interações que estes analitos podem fazer com a coluna Chiralcel OJ-H $\mathrm{H}^{\circledR}$ pela análise da estrutura do seu seletor quiral (Figura 14). 
A separação cromatográfica de enantiômeros em colunas quirais é baseada em mecanismos que envolvam a formação de complexos diastereoisoméricos transitórios destes compostos (LOURENÇO et al., 2010). Sabe-se que nas colunas derivadas de tris (4-metilbenzoato), os grupos carbonila dos ésteres, próximos aos resíduos de sílica, podem interagir com os enantiômeros por meio de ligações de hidrogênio e interações do tipo dipolodipolo. As ligações de hidrogênio podem ocorrer entre os grupos carbonila dos ésteres com as funções hidroxila dos metabólitos, ou então, entre o hidrogênio da função amida do seletor quiral com as carbonilas do grupo amida do anel pirimidinona, presentes tanto na estrutura da risperidona quanto nos metabólitos, ou com a amina secundária (do anel penta) e a amina terciária (do anel pirimidinona). Além disso, complexos de inclusão podem ser formados decorrentes do encaixe da porção aromática dos analitos nas cavidades quirais da fase estacionária (LOURENÇO et al., 2010).

É importante ressaltar que o mecanismo de interação entre os analitos e a fase estacionária, neste caso, é dependente também da fase móvel escolhida e da natureza dos compostos separados (BONATO et al., 2005; CHANKVETADZE et al., 2002). No modo polar-orgânico utilizado, a fase móvel é mais polar que a fase estacionária, sendo assim, os analitos mais polares serão mais facilmente eluídos pela fase móvel, interagindo menos com a coluna e, portanto, terão um tempo de retenção menor (MATTHIJS et al., 2006). A presença do aditivo orgânico TEA na fase móvel contribui com um mecanismo adicional de interação com os grupos silanóis residuais da sílica, deixando os analitos mais livres desta interação com os grupos silanóis. Isto proporciona uma melhor resolução cromatográfica, evitando possíveis interações secundárias com a sílica e assimetria caudal causada por este tipo de interação (MATTHIJS et al., 2006). 


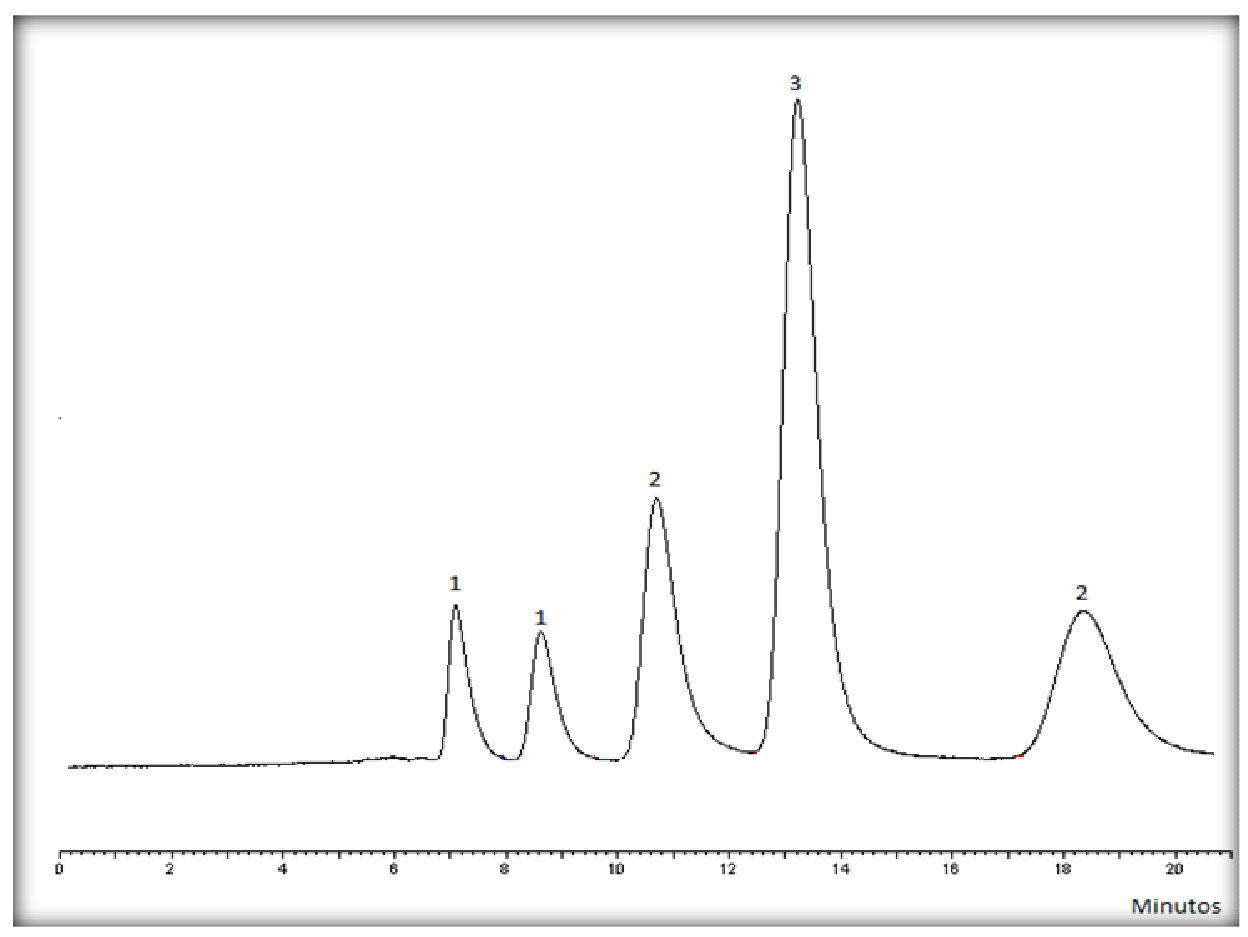

Figura 12 - Condição obtida na separação da RISP e seus metabólitos na coluna Chiralcel OJ$H^{\circledR}$ utilizando fase móvel no modo polar-orgânico. Enantiômeros da 7-RispOH (1), enantiômeros da 9-RispOH (2) e RISP (3). Fase móvel: etanol $100 \%+0,2 \%$ TEA, vazão: 0,4 $\mathrm{mL} \mathrm{min}^{-1}$, temperatura $25^{\circ} \mathrm{C}$, detecção em $280 \mathrm{~nm}$.

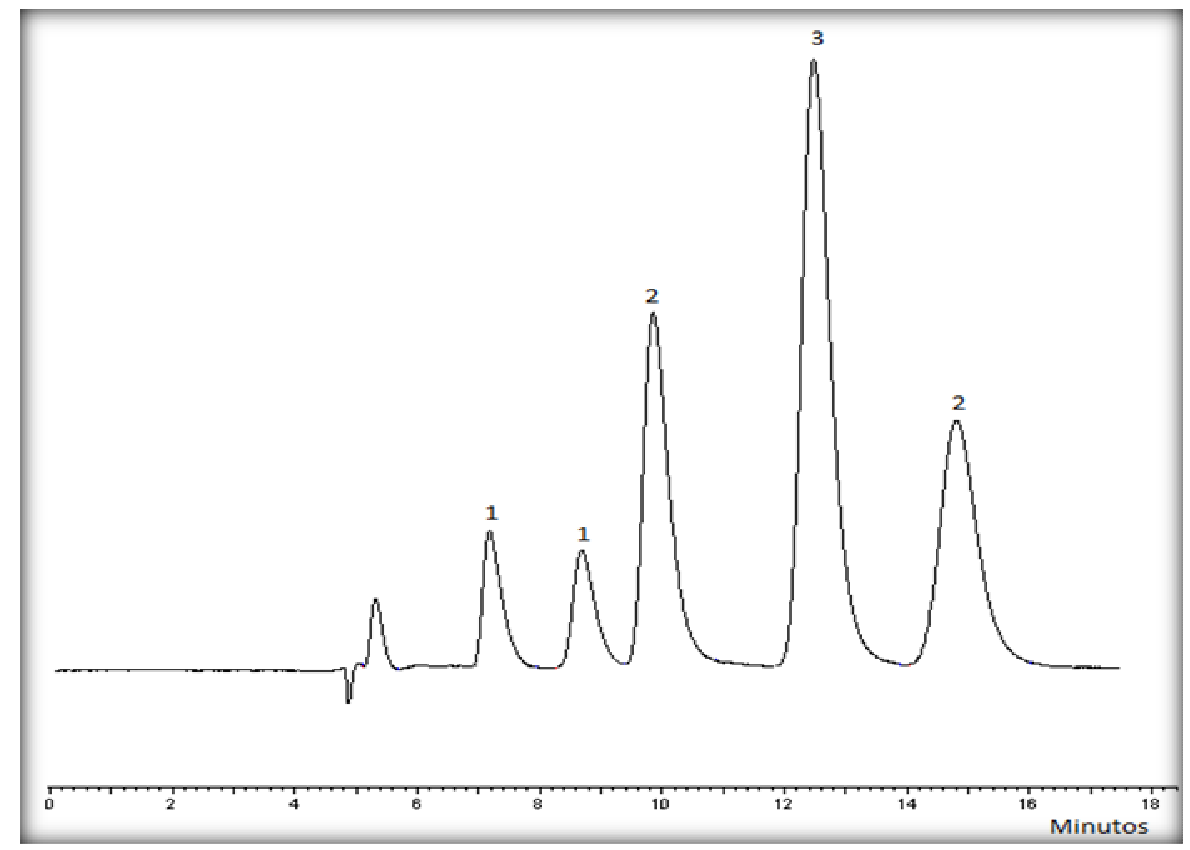

Figura 13 - Melhor condição obtida na separação da RISP e seus metabólitos na coluna Chiralcel OJ-H ${ }^{\circledast}$ utilizando fase móvel no modo polar-orgânico. Enantiômeros da 7-RispOH (1), enantiômeros da 9-RispOH (2) e RISP (3). Fase móvel: etanol:metanol (50:50, v/v) + 0,2\% TEA, vazão: $0,4 \mathrm{~mL} \mathrm{~min}{ }^{-1}$, temperatura $25^{\circ} \mathrm{C}$, detecção em $280 \mathrm{~nm}$. 


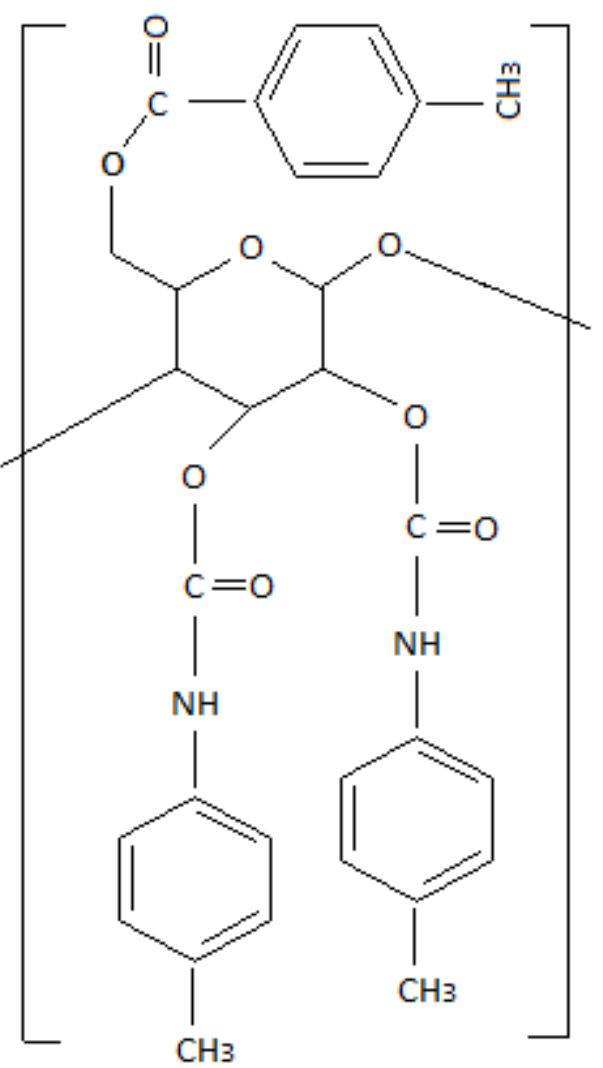

Figura 14 - Estrutura química planar do preenchimento da coluna Chiralcel OJ-H ${ }^{\circledR}$. Tris (4metilbenzoato) de celulose quimicamente ligado à sílica.

Portanto, a melhor condição cromatográfica encontrada para separação da RISP e metabólitos é a condição descrita na Figura 13. Além disso, devido a baixa viscosidade da fase móvel apresentada, o modo polar-orgânico permitiu o aumento da vazão da para $0,8 \mathrm{~mL} \mathrm{~min}^{-1}$ dentro da pressão permitida especificada pelo fabricante da coluna. Com isso, houve um ganho no tempo de análise e a corrida cromatográfica passou a terminar antes de 7 minutos. 
Tabela 6 - Comparação dos resultados obtidos com a coluna Chiralcel OJ-H $\mathrm{H}^{\circledR}$ para diferentes fases móveis.

\begin{tabular}{|c|c|c|c|c|c|c|c|}
\hline Coluna & Fase móvel & $\begin{array}{c}\text { Vazão } \\
\left(\mathrm{mL} \mathrm{min}^{-1}\right)\end{array}$ & $\begin{array}{c}t_{R} \\
(\min )\end{array}$ & $\mathbf{R}_{\mathrm{S} 1}$ & $\mathbf{R}_{\mathrm{S} 2}$ & $\mathbf{R}_{\mathrm{S} 3}$ & $\mathbf{R}_{\mathrm{S} 4}$ \\
\hline Chiralcel OJ-H ${ }^{\circledR}$ & $\begin{array}{l}\text { Metanol:isopropanol } \\
(80: 20, v / v)+0,2 \% \text { TEA }\end{array}$ & 0,4 & 16 & 2,6 & 1,4 & 3,5 & 1,9 \\
\hline Chiralcel OJ-H ${ }^{\circledR}$ & Etanol $100 \%+0,2 \%$ TEA & 0,4 & 20 & 2,0 & 2,1 & 2,2 & 3,3 \\
\hline Chiralcel OJ-H ${ }^{\circledR}$ & $\begin{array}{c}\text { Metanol:etanol } \\
(50: 50, v / v)+0,2 \% \text { TEA }\end{array}$ & 0,4 & 16 & 2,3 & 1,5 & 3,2 & 2,3 \\
\hline Chiralcel OJ-H ${ }^{\circledR}$ & $\begin{array}{c}\text { Metanol:etanol } \\
(50: 50, v / v)+0,2 \% \text { TEA }\end{array}$ & 0,8 & 6,9 & 2,2 & 1,6 & 3,2 & 2,4 \\
\hline
\end{tabular}

$t_{R}:$ Tempo de retenção do último analito a eluir

\subsubsection{ORDEM DE ELUIÇÃO DA 9-RISPOH}

A ordem de eluição foi estabelecida somente para os enantiômeros da 9RispOH na coluna Chiralcel OJ-H ${ }^{\circledR}$. Os enantiômeros puros da 9-RispOH foram obtidos por análise semipreparativa empregando o método descrito por DANEL et al., (2007) e posteriormente foram injetados nas condições estabelecidas neste trabalho. Os tempos de retenção foram comparados e a ordem de eluição estabelecida.

Não houve mudança na ordem de eluição dos metabólitos sendo que o primeiro pico da 9-RispOH, corresponde, então, ao enantiômero (+)-9-RispOH e o segundo pico, ao enantiômero (-)-9-RispOH. Não foi possível estabelecer a estereoquímica dos enantiômeros da 7-RispOH por falta de dados na literatura e insuficiência de padrão para a realização do procedimento de dicroísmo circular. Dessa forma, o primeiro enantiômero da 7-RispOH a eluir foi chamado de 7-RispOH (E1) e o segundo, de 7-RispOH (E2). 


\subsection{Preparação das amostras em MEIO de cultura empregando a SPME}

\subsubsection{OTIMIZAÇÃo dAS CONDIÇÕES PARA SPME}

A técnica da SPME é uma técnica que consiste em extrair de uma amostra analitos em sua forma neutra, durante um tempo pré-determinado, por um fino recobrimento polimérico presente em um capilar de sílica fundida (VUCKOVIC, et al., 2009). A extração inicia-se imediatamente após a fibra ser exposta à amostra e termina quando o equilíbrio entre a concentração dos analitos presentes no polímero e a concentração dos analitos presentes na amostra for atingido. Esta afirmação implica que quando o equilíbrio é atingido, a quantidade de analito extraído pela fibra é constante, por isso, o máximo de sensibilidade da técnica é atingido nas condições de equilíbrio (RISTICEVIC et al., 2010).

A equação (7) que demonstra as condições de equilíbrio entre a fibra e a matriz é expressa pela constante de distribuição $\mathrm{K}_{\mathrm{es}}$ :

$$
\mathrm{K}_{\mathrm{es}}=\frac{c_{e}^{\infty}}{c_{s}^{\infty}}
$$

Onde, $c_{e}^{\infty}$ é a concentração do analito presente na fibra extratora em condições de equilíbrio e, $C_{s}^{\infty}$ é a concentração do analito presente na amostra, no equilíbrio. As condições de extração que podem influenciar na constante de distribuição e, assim, afetar a SPME são: temperatura, agitação do sistema, espessura do filme polimérico, $\mathrm{pH}$, volume e força iônica da amostra. Por isso, estes fatores devem ser avaliados durante a técnica (RISTICEVIC et al., 2010). 


\subsubsection{TIPO DE FIBRA EXTRATORA}

A primeira etapa para o início da extração por SMPE é a escolha da fibra de extração. O tipo de recobrimento polimérico deve ser compatível em polaridade com os analitos que se deseja extrair, uma vez que a extração ocorre seguindo o conceito de "similar atrai similar". A espessura da fibra também é um fator determinante para que a extração ocorra com maior eficiência, já que se sabe que o número de mols de analito extraído da matriz (n) está relacionado com o volume do polímero, segundo a equação (8) (PAWLISZYN, 1997):

$$
\mathrm{n}=\frac{K e s, V e, V s, C o}{K e s, V e+V s}
$$

Onde, $V_{e}$ é o volume do polímero, $V_{s}$ é o volume da amostra e $C_{o}$ é a concentração inicial do analito na amostra.

O único fabricante das fibras para SPME, a Supelco ${ }^{\circledR}$, disponibiliza em sua página da web detalhes de espessura, polaridade, faixa de trabalho de $\mathrm{pH}$ e equipamento de análise compatível para cada tipo de recobrimento. Três tipos de fibras de polaridades diferentes e compatíveis com HPLC foram avaliadas neste trabalho: PDMS-DVB $(60 \mu \mathrm{m})$, CW-TPR $(50 \mu \mathrm{m})$ e C18 (45 $\mu \mathrm{m})$. Segundo o fabricante, a fibra mais polar é a fibra CW-TPR, de polaridade intermediária, a fibra PDMS-DVB e apolar, a C18 (SUPELCO, 2001; SUPELCO 2010).

O mecanismo de extração da PDMS-DVB e CW-TPR se dá através de adsorção e partição (KUMAZAWA et al., 2003; SPIETELUM et al., 2010). Na literatura, existem poucos estudos com a fibra C18, entretanto, com base em estudos de fibras C18 modificadas (MIRNAGHI et al., 2011), pode-se afirmar que o mecanismo de interação entre o analito e este tipo de recobrimento se dá através do processo de adsorção e também de absorção.

As fibras CW-TPR e PDMS-DVB são expostas na amostra através de um suporte apropriado que pode ser acoplado a um agitador magnético (como já demonstrado anteriormente). Porém, as fibras do tipo C18 apresentam formato diferenciado das outras fibras. É uma fibra interna a uma agulha 
hipodérmica e, desta forma, ela não é exposta por suporte apropriado como no caso das outras fibras. Entretanto, para que a extração pudesse ser da mesma forma para todas as fibras, no frasco de extração com as fibras C18 foi adicionada uma pequena barra magnética e, assim, todas as fibras puderam ser avaliadas da mesma maneira.

Deve-se conhecer as propriedades físico-químicas dos analitos para a escolha das fibras, uma vez que as fibras possuem faixas de $\mathrm{pH}$ adequadas de trabalho e também para se garantir que durante o processo de extração, os analitos sejam extraídos em sua forma neutra. Tanto a RISP, quanto seus metabólitos apresentam caráter básico com pKa próximo de 7,8 (DE JESUS et al., 2011). A eficiência na extração dos enantiômeros dos metabólitos da RISP e da RISP está representada na Figura 15.

Em um primeiro momento, era esperado que a fibra CW-TPR apresentasse um melhor desempenho de extração para a RISP e seus metabólitos, já que estes analitos apresentam polaridade intermediária da mesma forma que para o recobrimento CW-TPR. Além disso, na literatura, recomenda-se o emprego da CW-TPR para valores acima de pH 5,0 (LIN; SUNG; HUANG, 2003), o que representa condições de trabalho compatíveis com o pKa dos analitos. Entretanto, a fibra $\mathrm{C} 18$, que pode ser utilizada em uma ampla faixa de $\mathrm{pH}$ de trabalho de 1,0-9,0 (SUPELCO, 2010), apresentou uma melhor eficiência de extração para todos os analitos e foi então escolhida para efetuar os próximos experimentos. $O$ formato em agulha desta fibra, sem a necessidade de um suporte apropriado, possibilitou que várias fibras (36 unidades) pudessem ser utilizadas ao mesmo tempo, utilizando como agitador, um equipamento agitador do tipo Vibrax ${ }^{\circledR}$ (Figura 16). 


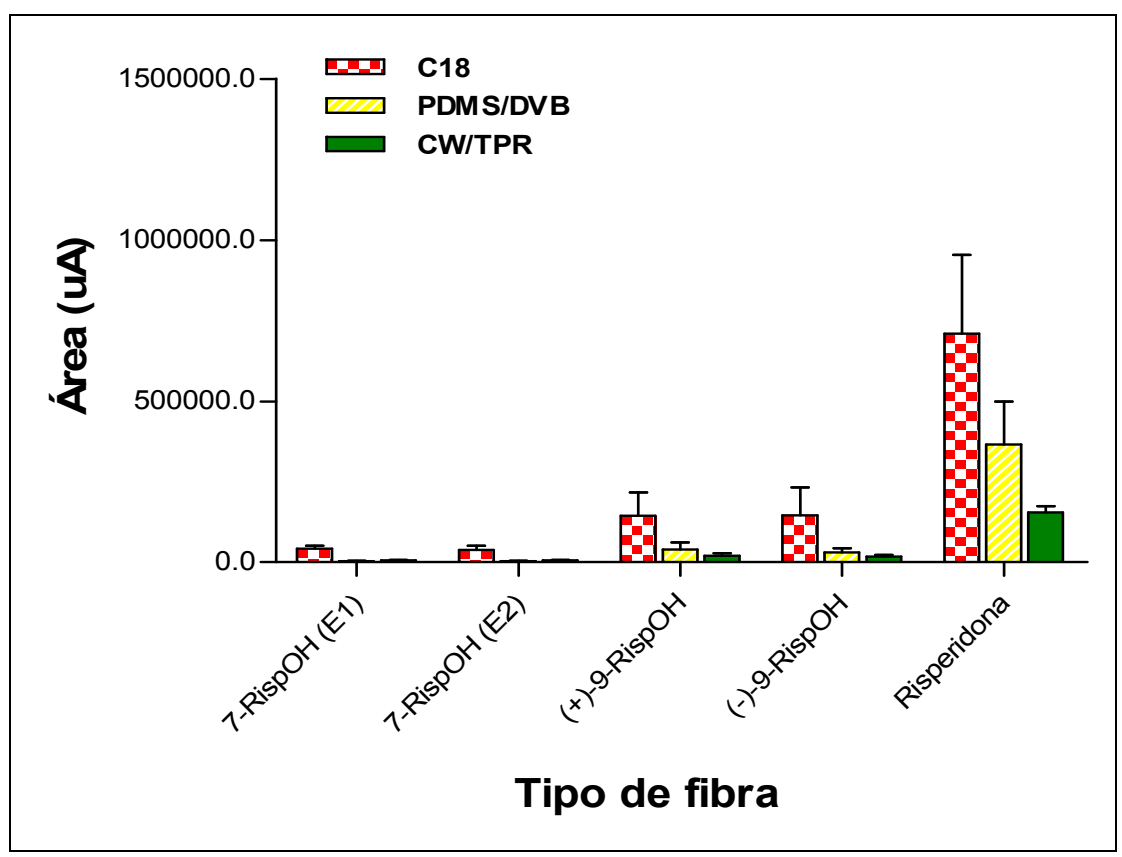

Figura 15 - Comparação da eficiência de extração da RISP e seus metabólitos (9-RispOH e 7RispOH) em meio de cultura Czapeck entre as fibras CW-TPR, C18 e PDMS-DVB. Extração 45 minutos a $23^{\circ} \mathrm{C} \pm 2^{\circ} \mathrm{C}$ e agitação de $900 \mathrm{rpm} ; 2 \mathrm{~mL}$ meio de cultura e $2 \mathrm{~mL}$ tampão fosfato $\mathrm{pH}$ $7,0,0,5 \mathrm{~mol} \mathrm{~L}^{-1}$, acrescidos de $30 \%(\mathrm{~m} / \mathrm{v})$ de $\mathrm{NaCl}$, dessorção em fase móvel etanol:metanol (50:50, v/v) $+0,2 \%$ TEA a $25^{\circ} \mathrm{C}$ por 5 minutos. Concentração $25 \mu \mathrm{g} \mathrm{mL} \mathrm{L}^{-1}$ de cada analito. $n=3$.

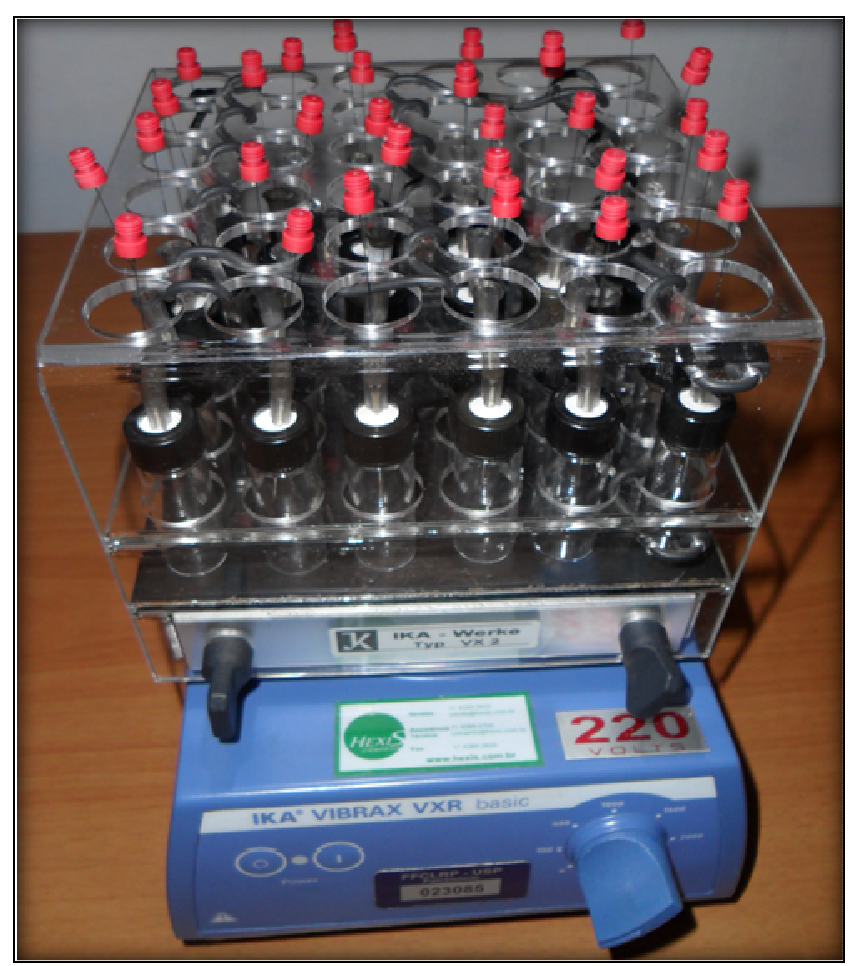

Figura 16 - Esquema de extração por SPME empregando fibras C18 e agitador tipo Vibrax®. Possibilidade de extrair 36 amostras ao mesmo tempo. 


\subsubsection{AdiçÃo de CLORETO de Sódio}

A adição de um sal solúvel inerte em amostras aquosas aumenta a força iônica destas mesmas. A maioria dos compostos orgânicos (exceto os compostos orgânicos muito polares) apresenta uma diminuição de solubilidade em soluções aquosas quando há um aumento da concentração salina, aumentando o valor da constante de distribuição, $K_{\mathrm{es}}$, (Equação 7 ) o que os torna mais "livres" no meio, possibilitando uma melhora na eficiência da extração (KUDLEJOVA et al., 2007).

Este efeito é chamado de efeito "salting ouf" e deve ser avaliado na técnica de SPME, uma vez que foi verificado experimentalmente que este efeito pode melhorar a sensibilidade do método e aumentar, dessa forma, a sua eficiência.

O efeito da adição de cloreto de sódio na extração da RISP e seus principais metabólitos em meio de cultura foi estudado preparando amostras com concentrações de $0-30 \%(\mathrm{~m} / \mathrm{v})$ do sal. Os estudos mostraram que a partir de $10 \%(\mathrm{~m} / \mathrm{v})$ de $\mathrm{NaCl}$ adicionado, a recuperação de todos os analitos se tornaram constantes (Figura 17). A concentração adequada para dar continuidade aos próximos experimentos seria então de $10 \%(\mathrm{~m} / \mathrm{v})$. Entretanto, foi escolhida a concentração de $20 \%(\mathrm{~m} / \mathrm{v})$. Este procedimento foi adotado visto que as matrizes de fungos estudadas são matrizes muito variáveis, assim, 20\% $(\mathrm{m} / \mathrm{v})$ foi escolhido a fim de tornar a força iônica do meio constante e realizar extrações mais eficientes. Outro fator que foi verificado durante os experimentos de adição de cloreto de sódio é que o tampão fosfato utilizado na concentração de 0,5 mol. L $^{-1}$ dificultava a solubilização do sal. Portanto, passouse a utilizar a mesma solução tampão fosfato em $\mathrm{pH} 7,0$, porém na concentração de $0,25 \mathrm{~mol} \cdot \mathrm{L}^{-1}$. 


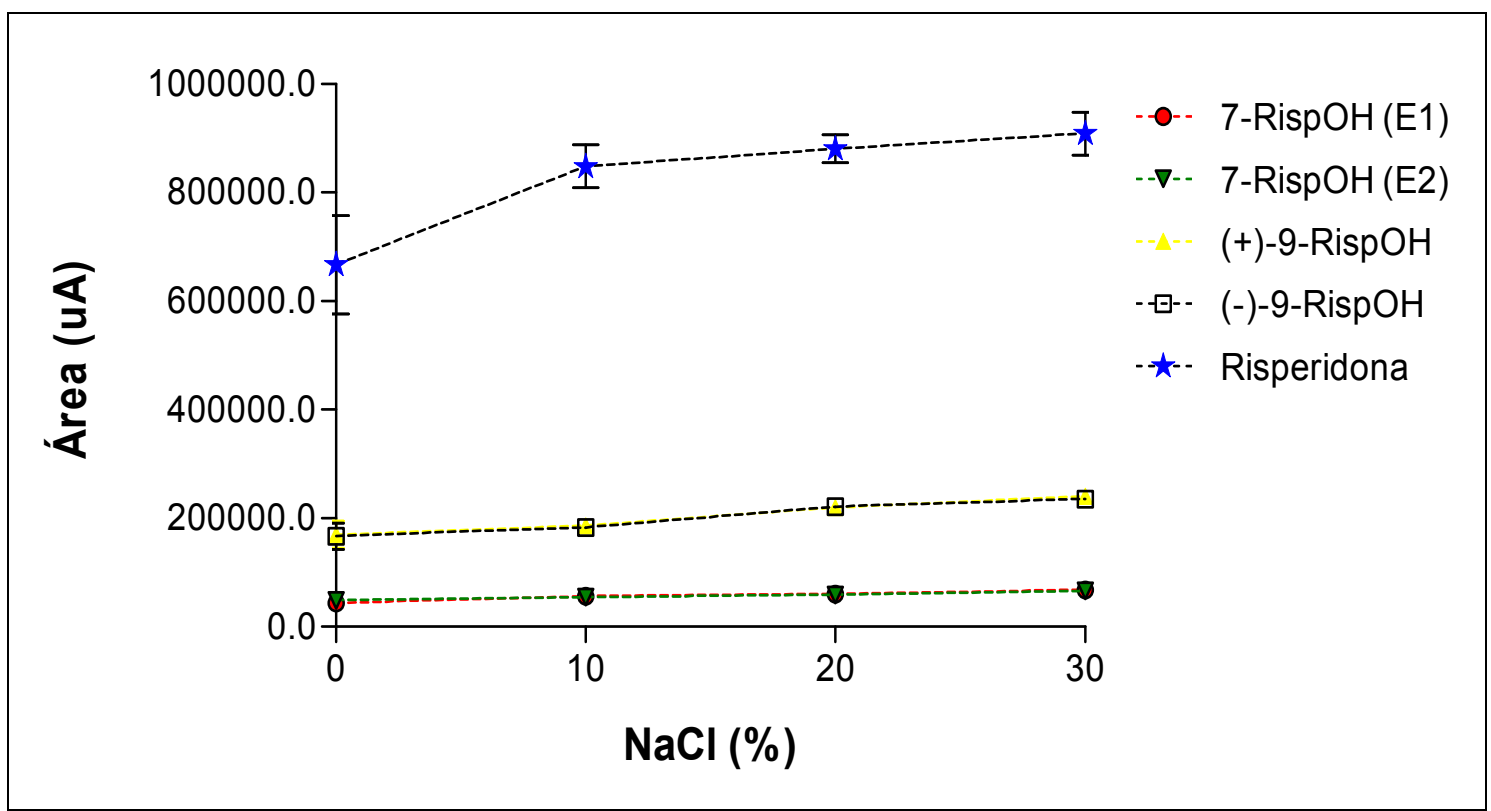

Figura 17 - Efeito da adição de $\mathrm{NaCl}$ na recuperação da RISP e dos enantiômeros de seus metabólitos (9-RispOH e 7-RispOH) em meio de cultura líquido Czapeck. Extração 45 minutos a $23^{\circ} \mathrm{C} \pm 2^{\circ} \mathrm{C}$ e agitação de $900 \mathrm{rpm} ; 2 \mathrm{~mL}$ meio de cultura e $2 \mathrm{~mL}$ tampão fosfato $\mathrm{pH} 7,0,0,25$ mol $\mathrm{L}^{-1}$, dessorção em fase móvel etanol:metanol $(50: 50, \mathrm{v} / \mathrm{v})+0,2 \%$ TEA a $25^{\circ} \mathrm{C}$ por 5 minutos. Concentração $25 \mu \mathrm{g} \mathrm{mL}^{-1}$ de cada analito. $n=3$.

Assim, os próximos parâmetros avaliados foram empregando as condições definidas nesta etapa do preparo de amostras.

\subsubsection{PH DA AMOSTRA}

Os polímeros de revestimento comercialmente disponíveis para SPME extraem apenas espécies neutras dos analitos presente na amostra (RISTICEVIC et al., 2010). Dessa forma, o ajuste do pH da amostra com adição de solução tampão pode melhorar a eficiência de extração do método e garantir que os analitos de interesse sejam extraídos na sua forma neutra.

O ajuste do $\mathrm{pH}$ deve, preferencialmente, obedecer aos valores fornecidos pelo fabricante que estão dentro do intervalo de estabilidade do revestimento polimérico para evitar que ocorra a degradação da fibra.

A fibra C18 possui uma ampla faixa de possibilidades de variação de $\mathrm{pH}$ $(1,0-9,0)$ (SUPELCO, 2010), assim, a eficiência na extração da RISP e seus principais metabólitos (9-RispOH e 7-RispOH) foi avaliada em um intervalo de 
pH de 3,0-9,0 com tampão fosfato $0,25 \mathrm{~mol} \mathrm{~L}^{-1}$. Os resultados obtidos estão apresentados na Figura 18.

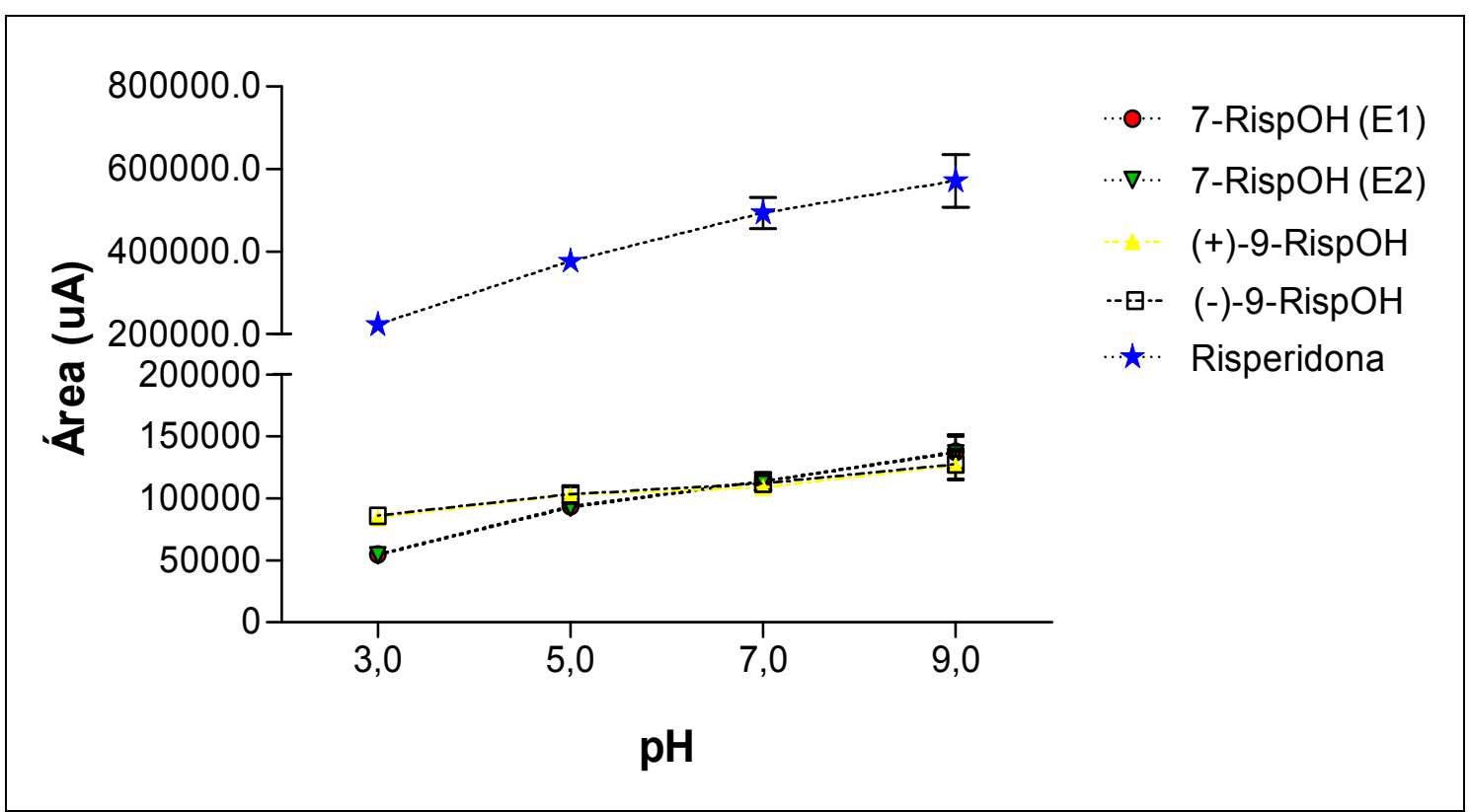

Figura 18 - Efeito da mudança de pH na recuperação da RISP e dos enantiômeros de seus metabólitos (9-RispOH e 7-RispOH) em meio de cultura líquido Czapeck. Extração 45 minutos a $23^{\circ} \mathrm{C} \pm 2^{\circ} \mathrm{C}$ e agitação de $900 \mathrm{rpm} ; 2 \mathrm{~mL}$ meio de cultura e $2 \mathrm{~mL}$ tampão fosfato ( $\mathrm{pH}$ variado), $0,25 \mathrm{~mol} \mathrm{~L}^{-1}+20 \% \mathrm{NaCl}(\mathrm{m} / \mathrm{v})$, dessorção em fase móvel etanol:metanol $(50: 50, \mathrm{v} / \mathrm{v})+0,2 \%$ TEA a $25^{\circ} \mathrm{C}$ por 5 minutos. Concentração $25 \mu \mathrm{g} \mathrm{mL} \mathrm{m}^{-1}$ de cada analito. $n=3$.

Como pôde ser observado na Figura 18, houve um aumento na eficiência de extração da RISP e seus principais metabólitos para pH's mais alcalinos. A melhor extração da RISP seria utilizando um tampão com pH 9,0, já, os metabólitos, não tiveram mudanças muito significativas acima de pH 7,0. Como a RISP estará presente em grande quantidade no meio reacional e o objetivo principal é extrair com maior eficiência os metabólitos, foi definido $\mathrm{pH}$ 7,0 como $\mathrm{pH}$ ótimo para a extração dos analitos. Além disso, como mencionado, a faixa de $\mathrm{pH}$ ideal de trabalho da fibra C18 é de 1,0-9,0 e, trabalhando em $\mathrm{pH} 7,0$, pode-se prolongar o tempo de uso da fibra, pois a mesma não estará sendo empregada em seu limite máximo estabelecido. 


\subsubsection{AGITAÇÃo dA AmOSTRA}

A agitação torna o processo de extração mais rápido. A agitação tem a capacidade de promover com maior facilidade a transferência de massa do analito presente na amostra para o revestimento da fibra. Dessa forma, o equilíbrio entre a concentração dos analitos na amostra e na fibra é atingido mais rapidamente e, consequentemente, o tempo de extração diminui.

O processo de agitação mais eficiente também fará com que seja maior a quantidade extraída nas condições de não-equilíbrio (RISTICEVIC et al., 2010). Existem várias maneiras de se realizar a agitação por SPME: movimento rápido da fibra, movimento do frasco, sonicação, movimento do fluxo da amostra (através de barra e agitador magnético, por exemplo) (RISTICEVIC et al., 2010). A eficiência da agitação na extração da RISP, 7RispOH e 9-RispOH foi avaliada por agitação do frasco através do equipamento agitador $\operatorname{Vibrax}^{\circledR}$, com rotações variando de 300-1200 rpm, utilizando as condições pré-estabelecidas nos parâmetros anteriores. Os resultados deste procedimento estão demonstrados na Figura 19.

Como pode ser observado na Figura 19, o equilíbrio de extração dos metabólitos 7-RispOH e 9-RispOH é atingido a uma agitação de 600 rpm. Já, para a RISP, há um aumento de extração com o aumento de agitação acima deste valor, entretanto, como já mencionado anteriormente, a RISP estará presente em grande quantidade no meio reacional e o objetivo principal é extrair os metabólitos com maior eficiência. Assim, a agitação foi definida como 600 rpm para os demais experimentos. Além disso, o aumento de extração gerado para a RISP acima de 600 rpm não foi tão significativo e muitas vezes o aumento da agitação leva a maiores erros na técnica, devido à formação de microbolhas que podem se aderir nas fibras de extração (KUDLEJOVA et al., 2007). 


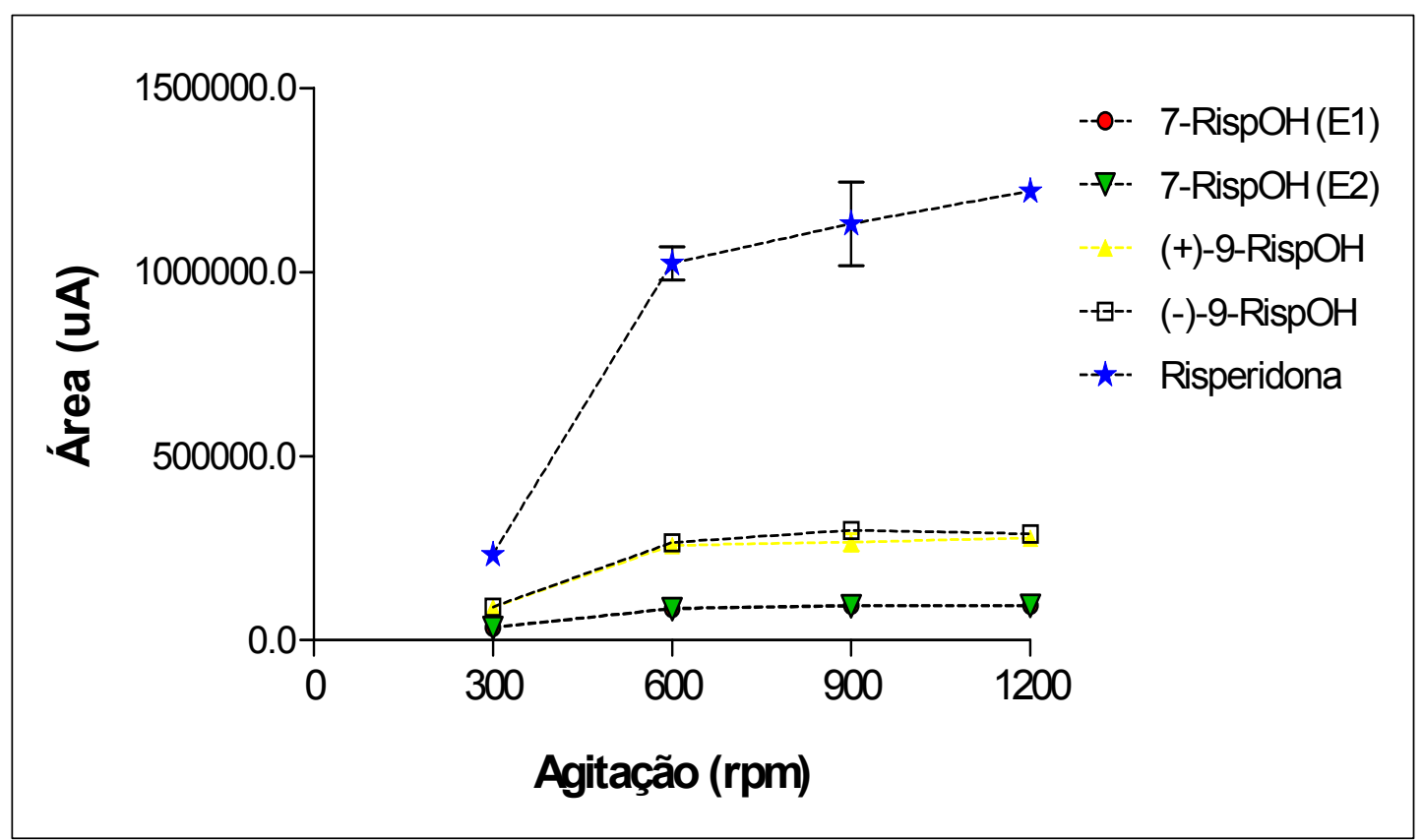

Figura 19 - Efeito da agitação na recuperação da RISP e dos enantiômeros de seus metabólitos (9-RispOH e 7-RispOH) em meio de cultura líquido Czapeck. Extração 45 minutos a $23^{\circ} \mathrm{C} \pm 2^{\circ} \mathrm{C} .2 \mathrm{~mL}$ meio de cultura e $2 \mathrm{~mL}$ tampão fosfato $(\mathrm{pH} 7,0), 0,25 \mathrm{~mol} \mathrm{~L}^{-1}+20 \% \mathrm{NaCl}$ $(\mathrm{m} / \mathrm{v})$, dessorção em fase móvel etanol:metanol $(50: 50, \mathrm{v} / \mathrm{v})+0,2 \%$ TEA a $25^{\circ} \mathrm{C}$ por 5 minutos. Concentração $25 \mu \mathrm{g} \mathrm{mL}^{-1}$ de cada analito. $n=3$.

\subsubsection{TEMPO de EXTRAÇÃo}

O transporte de massa dos analitos da matriz para a fibra inicia-se no exato momento em que a fibra é exposta à matriz (RISTICEVIC et al., 2010). O tempo de extração em SPME é o tempo necessário para que os analitos presentes na matriz entrem em equilíbrio com o revestimento da fibra. Assim, existe um tempo determinado no qual o equilíbrio é atingido e a extração dos analitos se torna constante.

O tempo de extração pode ser determinado através da equação (9):

$$
t_{e}=\frac{3 . \delta K e s(r o-r i)}{D w}
$$

Onde, $t_{e}$ é o tempo de equilíbrio, $r_{o}$ é o raio externo da fibra, $r_{i}$ o raio interno, $\delta$ é a camada estática formada ao redor da fibra durante a agitação e, 
$D_{w}$ o coeficiente de difusão do analito na matriz. De acordo com a expressão, o tempo para que o equilíbrio seja atingido será maior, quanto maior for $\mathrm{K}_{\mathrm{es}}$ e a espessura da fibra, dada por $\left(r_{o}-r_{i}\right)$ e menor, quando o coeficiente de difusão $\left(D_{w}\right)$ do analito na matriz for pequeno (ULRICH, 2000).

O tempo de extração necessário para que a RISP, 7-RispOH e 9$\mathrm{RispOH}$ entrem em equilíbrio com a fibra extratora foi avaliado em um intervalo de 15 a 90 minutos e os resultados foram expressos na Figura 20.

A quantidade de todos os analitos extraída aumenta com o aumento do tempo de extração. Porém, a partir de 30 minutos, o aumento não foi progressivo e significativo para os enantiômeros dos metabólitos 9-RispOH e 7RispOH. A RISP apresentou um aumento progressivo a partir de 45 minutos e um perfil de extração constante no intervalo de 30 a 45 minutos. Assim, como o foco principal é a extração dos metabólitos, 7-RispOH e 9-RispOH, o tempo de extração determinado para os próximos experimentos passou a ser de 30 minutos.

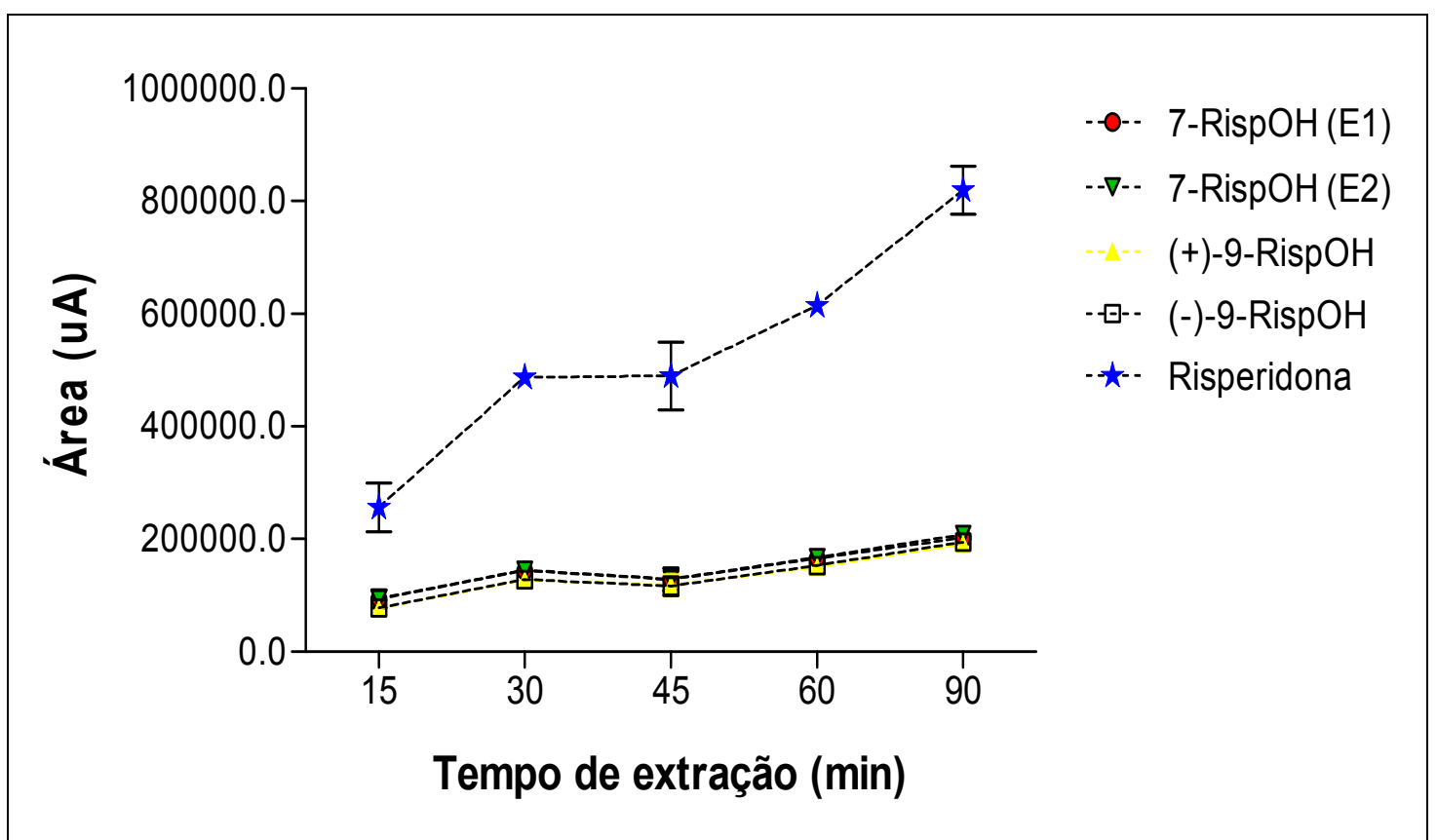

Figura 20 - Efeito do tempo de extração na recuperação da RISP e dos enantiômeros de seus metabólitos (9-RispOH e 7-RispOH) em meio de cultura líquido Czapeck. Extração a $23^{\circ} \mathrm{C} \pm$ $2^{\circ} \mathrm{C}$ com agitação a $600 \mathrm{rpm} .2 \mathrm{~mL}$ meio de cultura e $2 \mathrm{~mL}$ tampão fosfato $(\mathrm{pH} 7,0), 0,25 \mathrm{~mol} \mathrm{~L}^{-1}$ $+20 \% \mathrm{NaCl}(\mathrm{m} / \mathrm{v})$, dessorção em fase móvel etanol:metanol $(50: 50, \mathrm{v} / \mathrm{v})+0,2 \%$ TEA por 5 minutos. Concentração $25 \mu \mathrm{g} \mathrm{mL}^{-1}$ de cada analito. $n=3$. 


\subsubsection{VolUme dA AmOSTRA}

O volume da amostra pode afetar a eficiência na extração dos analitos segundo a equação 8 , descrita anteriormente:

Entretanto, é conhecido que a quantidade de analito extraído é independente do volume da amostra acima de um valor de volume crítico (RISTICEVIC et al., 2010). Nessas condições, o cálculo da quantidade de analito extraído se reduz a Equação 10, abaixo:

$$
\mathrm{n}=\mathrm{KeS}, \mathrm{Ve} \cdot \mathrm{Co}
$$

Assim, o volume de matriz foi avaliado em uma faixa de $0,5-3,0 \mathrm{~mL}$ para que se conseguisse alcançar o volume crítico. A eficiência da extração dos enantiômeros dos metabólitos 7-RispOH e 9-RispOH e também da RISP neste parâmetro, esta demonstrada na Figura 21.

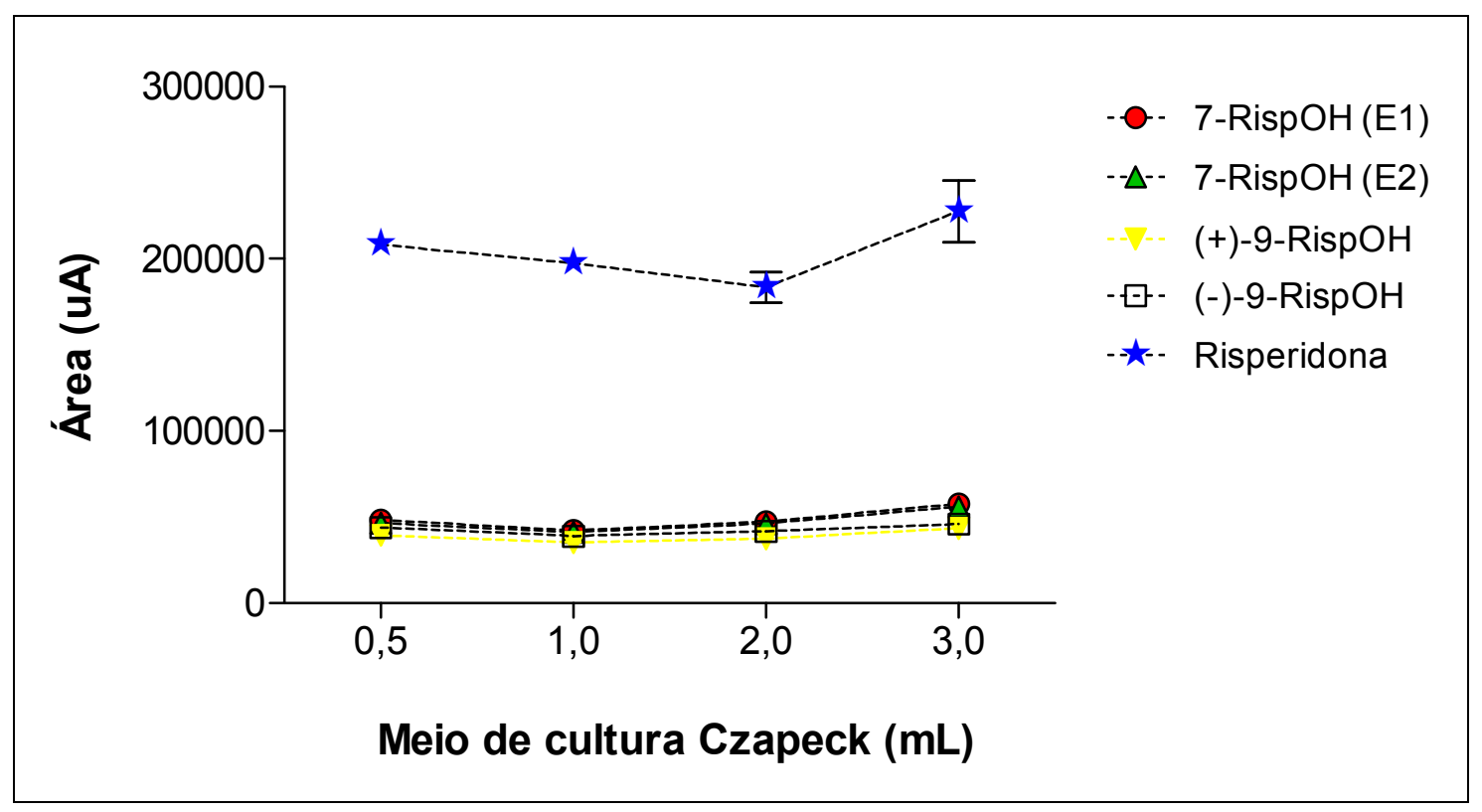

Figura 21 - Efeito do volume de matriz na recuperação da RISP e dos enantiômeros de seus metabólitos (9-RispOH e 7-RispOH) em meio de cultura líquido Czapeck. Extração em 30 min a $23^{\circ} \mathrm{C} \pm 2^{\circ} \mathrm{C}$ com agitação a $600 \mathrm{rpm}$. Meio de cultura (quantidade variada) completando-se com tampão fosfato $(\mathrm{pH} 7,0) 0,25 \mathrm{~mol} \mathrm{~L}^{-1}$ (em um volume final de $\left.4 \mathrm{~mL}\right)+20 \% \mathrm{NaCl}(\mathrm{m} / \mathrm{v})$, dessorção em fase móvel etanol:metanol $(50: 50, \mathrm{v} / \mathrm{v})+0,2 \%$ TEA a $25^{\circ} \mathrm{C}$ por 5 minutos. Concentração $25 \mu \mathrm{g} \mathrm{mL}^{-1}$ de cada analito. $n=3$. 
Analisando a Figura 21, não houve diferença significativa na extração dos metabólitos com a variação do volume do meio de cultura líquido, apenas a RISP apresentou um comportamento de melhora na extração com o aumento da matriz, mas, como dito anteriormente, a RISP estará presente em grande quantidade no meio reacional e por isso as conclusões recaem para a extração da 7-RispOH e 9-RispOH. Assim, a fim de obter uma amostra não muito diluída e que garanta que a viscosidade do meio de extração seja mais próxima possível da realidade das alíquotas de fungos analisadas neste projeto, estabeleceu-se $2 \mathrm{~mL}$ de meio de cultura para a realização dos experimentos.

\subsubsection{Tempo de Dessorção e "CarRyover"}

O tempo de dessorção é o tempo necessário para que toda a quantidade de analito retida na fibra pelo processo de extração seja dissolvida para o solvente de dessorção. Este parâmetro pode ser avaliado pelas áreas dos picos dos analitos que, a partir de um determinado tempo de dessorção, tornam-se constantes.

O "carryover" ou efeito memória é a quantidade de analito que pode ter ficado retido na fibra após o processo de dessorção. Este procedimento é avaliado fazendo-se sucessivas dessorções e comparando-se a área dos picos das dessorções sucessivas com a área do pico da primeira dessorção. $O$ efeito deve ser avaliado uma vez que as fibras de SPME são reutilizáveis, entretanto, o "carryover" pode ser um problema somente quando a concentração do analito na amostra seguinte é tão baixa que o equilíbrio na fibra é menor do que a concentração causada por "carryover" de análises anteriores (GORECKI, PAWLISZYN, 1995). Como é inevitável que se utilize uma mesma fibra em amostras de diferentes concentrações que serão analisadas em sequência, procedimentos de lavagem da fibra entre as extrações são recomendados. Por isso, em todo o processo de SPME realizado neste trabalho, entre uma extração e outra, as fibras eram lavadas com $100 \%$ de metanol.

O tempo de dessorção para a RISP e seus principais metabólitos foi avaliado em um intervalo de tempo de 1-10 minutos na mesma fase móvel 
empregada na separação dos analitos. Os resultados estão demonstrados na Figura 22.

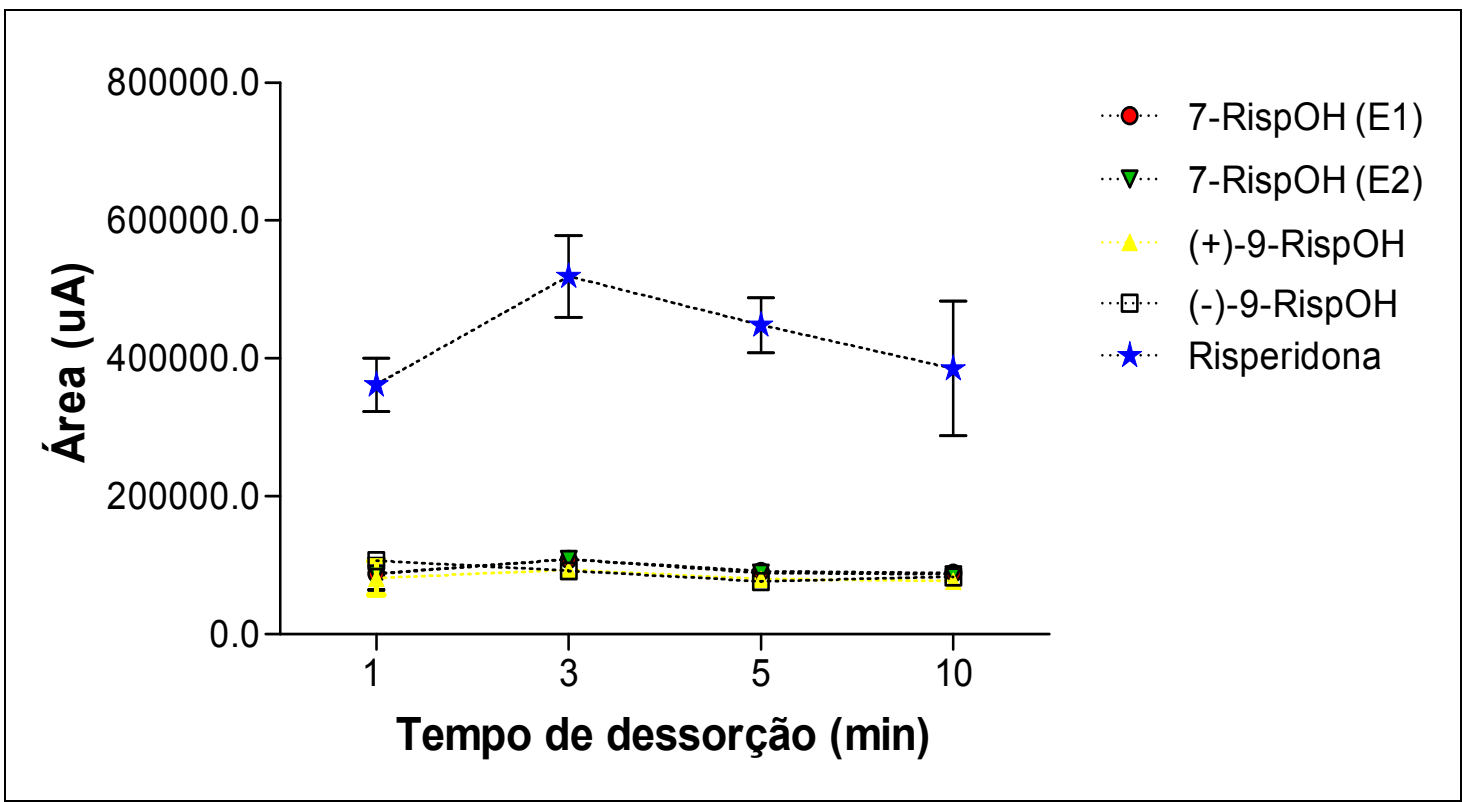

Figura 22 - Efeito do tempo de dessorção na análise da RISP e dos enantiômeros de seus metabólitos (9-RispOH e 7-RispOH) em meio de cultura líquido Czapeck. Extração em 30 min a $23^{\circ} \mathrm{C} \pm 2^{\circ} \mathrm{C}$ com agitação a $600 \mathrm{rpm} .2 \mathrm{~mL}$ de meio de cultura Czapeck acrescido de $2 \mathrm{~mL}$ tampão fosfato $(\mathrm{pH} 7,0), 0,25 \mathrm{~mol} \mathrm{~L}^{-1}+20 \% \mathrm{NaCl}(\mathrm{m} / \mathrm{v})$, dessorção em fase móvel etanol:metanol $(50: 50, \mathrm{v} / \mathrm{v})+0,2 \%$ TEA. Concentração $25 \mu \mathrm{gL}^{-1}$ de cada analito. $n=3$.

Na Figura 22, observa-se que para os enantiômeros da 7-RispOH e 9$\mathrm{RispOH}$, as áreas dos picos são constantes no intervalo de tempo avaliado. Já para a RISP as áreas dos picos começam a decair a partir de 3 minutos assim como os erros relativos (demonstrado pela barra de erro gráfico) tornam-se elevados em maiores tempos. Dessa forma, levando em consideração a barra de erros, a dessorção da RISP também é constante no período avaliado. Assim, foi definido um tempo de dessorção de 3 minutos para os demais experimentos.

Após definir o tempo de dessorção, o estudo de "carryover" foi realizado a fim de verificar se os analitos permaneciam na fibra após a dessorção. Para tanto, três dessorções sucessivas foram realizadas após o processo de dessorção na mesma faixa de tempo analisada para o parâmetro "tempo de dessorção" (1-10 minutos). Os resultados obtidos demonstraram que somente 
a lavagem com $100 \%$ de metanol entre uma e outra extração era insuficiente para eliminar o efeito memória, já que foi encontrado um valor "carryover" aproximadamente de $20 \%$ nesse estudo. A porcentagem de "carryover" é calculada tomando-se como $100 \%$ o valor da primeira dessorção.

Assim, seguindo-se recomendações do fabricante (SUPELCO, 2010), após o procedimento de dessorção um processo de lavagem com $100 \%$ de metanol por 30 minutos e um pré-condicionamento da fibra com metanol:água (50:50, v/v) era realizado antes de se iniciar uma nova extração. Este procedimento possibilitou um segundo estudo de "carryover" (que foi efetuado da mesma maneira que o primeiro) e seus resultados foram demonstrados na Figura 23.

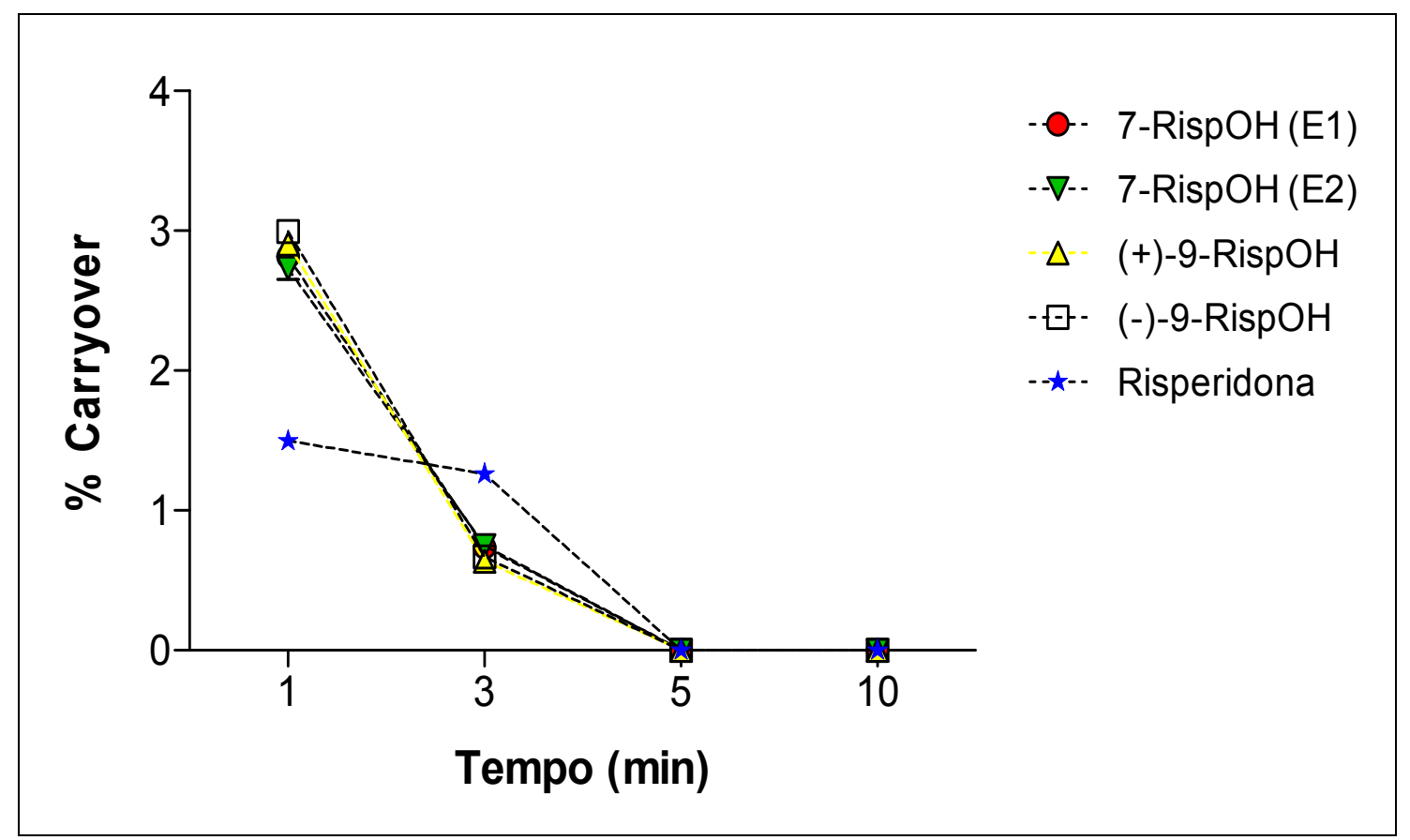

Figura 23 - Efeito "carryover" na dessorção da RISP e dos enantiômeros de seus metabólitos (9-RispOH e 7-RispOH) em meio de cultura líquido Czapeck. Extração em 30 min a $23^{\circ} \mathrm{C} \pm 2^{\circ} \mathrm{C}$ com agitação a $600 \mathrm{rpm} .2 \mathrm{~mL}$ de meio de cultura Czapeck acrescido de $2 \mathrm{~mL}$ tampão fosfato $\left(\mathrm{pH} \mathrm{7,0)}, 0,25 \mathrm{~mol} \mathrm{~L}^{-1}+20 \% \mathrm{NaCl}(\mathrm{m} / \mathrm{v})\right.$, dessorção em fase móvel etanol:metanol $(50: 50, \mathrm{v} / \mathrm{v})+$ $0,2 \%$ TEA. Concentração $25 \mu \mathrm{gL}^{-1}$ de cada analito. $n=3$. 
Como pode ser observado na Figura 23, após as duas etapas de lavagem em metanol $100 \%$ em 30 minutos e pré-condicionamento da fibra em metanol:água $(50: 50, \mathrm{v} / \mathrm{v})$ por mais 30 minutos, as fibras se tornaram livres do efeito memória a partir de 5 minutos de dessorção. Desta forma, o tempo estabelecido de dessorção foi de 5 minutos após estes dois procedimentos de lavagem.

\subsubsection{Condições OtimizadAs da SPME}

As condições otimizadas para SPME na análise da RISP, 7-RispOH e 9RispOH estão demonstradas em um resumo representado pela Figura 24.

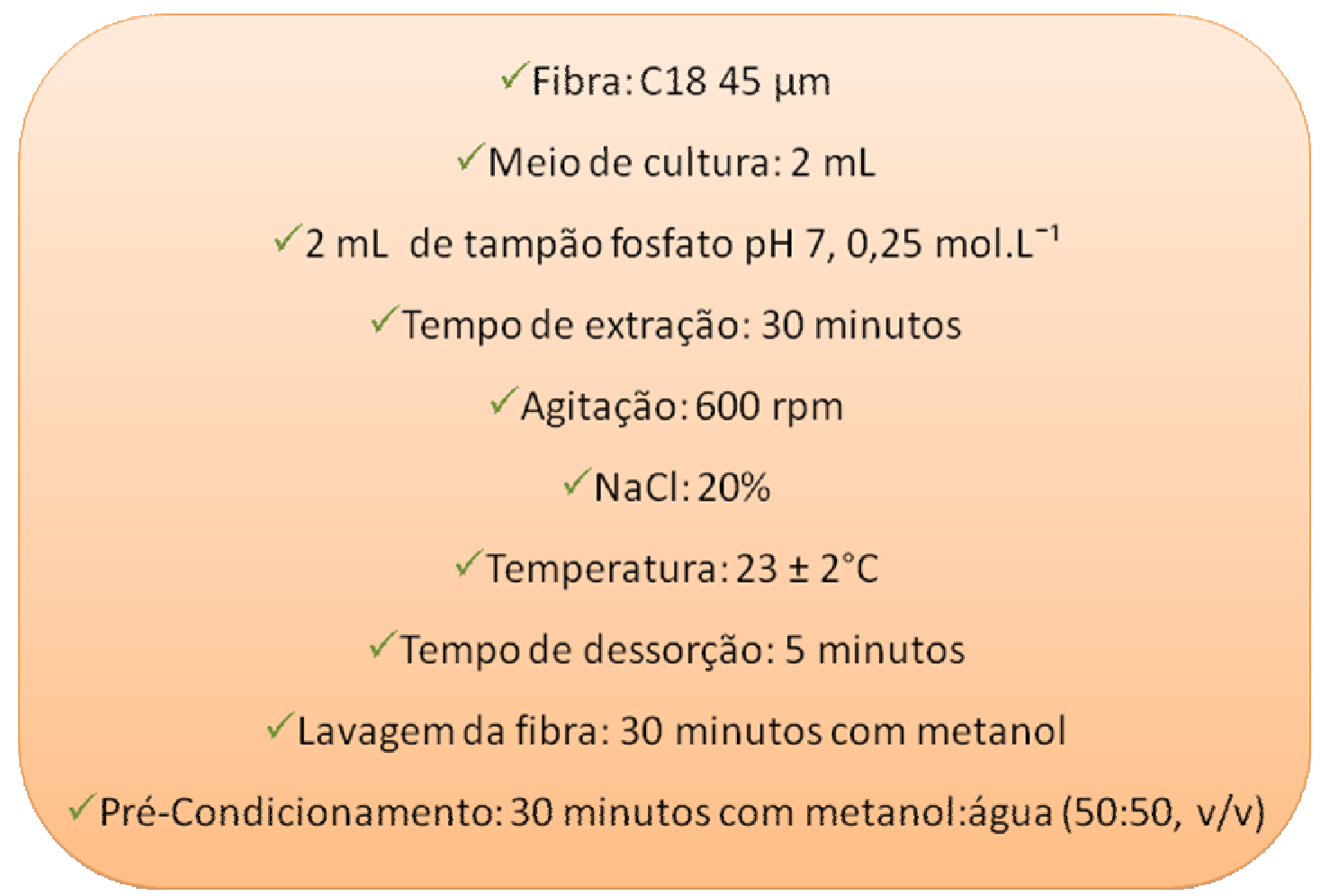

Figura 24 - Condições otimizadas para SPME para a análise da RISP, 7-RispOH e 9-RispOH em meio de cultura líquido Czapeck. 


\subsubsection{EFICIÊNCIA NA EXTRAÇÃO EMPREGANDO DIFERENTES MATRIZES}

Após o término da otimização da SPME em meio de cultura líquido Czapeck, para garantir que o meio Czapeck seria o meio mais adequado para validação da metodologia e próximo das condições do meio de biotransformação com fungos, um estudo comparativo de eficiência nas extrações da RISP, 7-RispOH e 9-RispOH foi realizado fazendo-se extrações nas condições estabelecidas para SPME, para um pool de fungos do gênero Cunninghamella (descrito no item 3.7.5.). Os fungos Cunninghamella foram escolhidos para este estudo porque, em um estudo prévio com amostras dos demais tipos de fungos, não foi verificada a presença de possíveis metabólitos da RISP, sendo assim, o pool foi preparado com matriz de fungos que forneceram resultados positivos no processo de biotransformação.

Os resultados deste estudo foram plotados em um gráfico de barras comparativo da quantidade de analito extraída nos dois tipos de meio: pool de fungos e Czapeck e demonstrado pela Figura 25. Além disso, uma análise estatística foi realizada comparando-se as duas populações. Para tanto, foi empregado o Student's t-test e adotando $p \leq 0,05$ sendo estatisticamente significativo.

A análise da Figura 25 demonstra que não há diferença de matriz de pool de fungos e o meio de cultura líquido Czapeck. Dessa forma, a validação foi iniciada empregando como matriz o meio de cultura líquido Czapeck. 


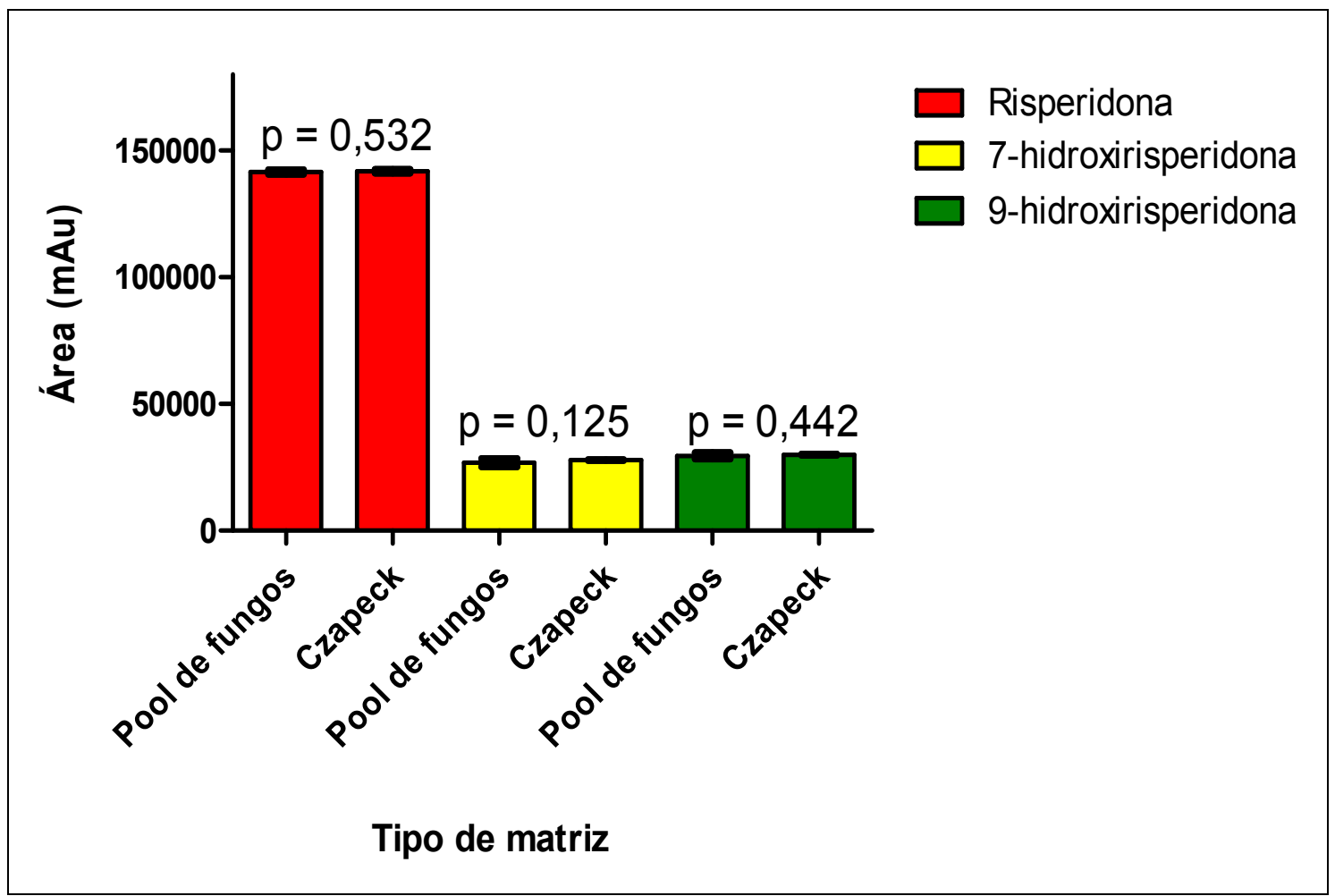

Figura 25 - Efeito da recuperação na extração dos analitos a partir do meio de cultura líquido Czapeck e do pool fungos empregando as condições estabelecidas na SPME. Concentrações de analito: risperidona $500 \mathrm{ng} \mathrm{mL}^{-1}$, metabólitos $187 \mathrm{ng} \mathrm{mL}^{-1}$. Nível de significância $\mathrm{p} \leq 0,05$ ( $n$ $=6)$.

\subsection{Validação da Metodologia Analítica}

Devido à complexidade da matriz, possível presença de metabólitos secundários dos fungos e a possibilidade formação de baixa quantidades dos metabólitos 9-RispOH e 7-RispOH, a validação da metodologia e o estudo de biotransformação foi realizado empregando uma técnica analítica mais seletiva e sensível. Dessa forma, foi empregado LC-MS/MS para os ensaios posteriores, conforme as condições descritas no item 3.3. em materiais e métodos. Sendo assim, as condições no espectrômetro de massas foram definidas e o cromatograma resultante da análise dos analitos esta representado na Figura 26 abaixo: 


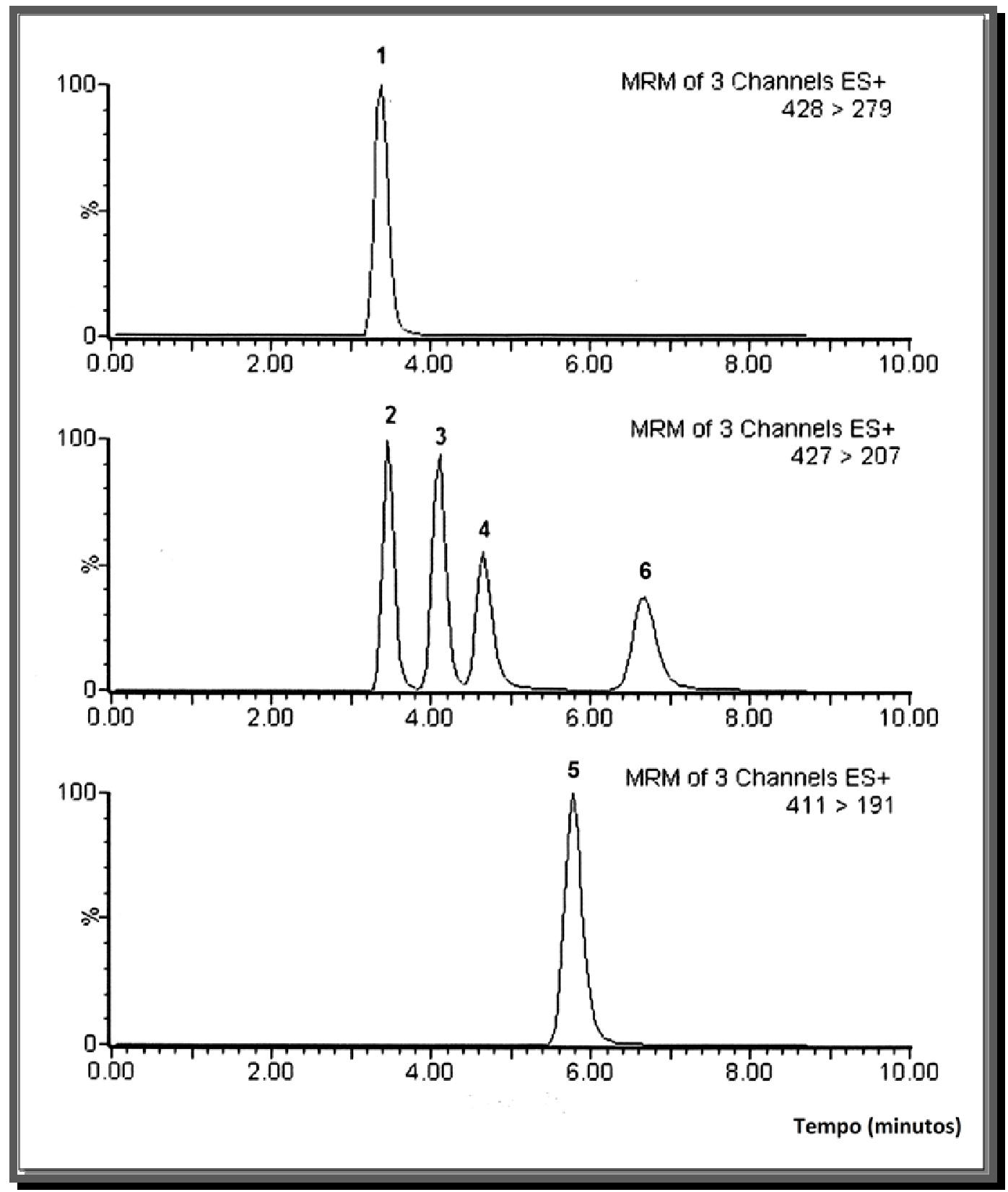

Figura 26 - Separação dos analitos na coluna Chiralcel OJ-H ${ }^{\circledR}$ e análise por LC-MS/MS. Cromatograma MRM de 3 canais; $1^{\circ}$ canal corresponde à transição de m/z 428 $\rightarrow 279$ para o padrão interno ranolazina; $2^{\circ}$ canal corresponde à transição de $\mathrm{m} / \mathrm{z} 427 \rightarrow 207$ para os metabólitos e o $3^{\circ}$ canal corresponde à transição de $\mathrm{m} / \mathrm{z} 411 \rightarrow 191$ para a risperidona. 1) Ranolazina 2) 7-RispOH (E1); 3) 7-RispOH (E2); 4) (+)-9-RispOH; 5) RISP e 6) (-)-9-RispOH. Fase móvel: etanol;metanol $(50: 50, \mathrm{v} / \mathrm{v})+0,2 \%$ TEA, vazão: $0,8 \mathrm{~mL} \mathrm{~min}^{-1}$, temperatura de análise $25^{\circ} \mathrm{C}$. 
Como não há um guia que recomende a análise de fármacos e metabólitos em meio de cultura, optou-se por seguir, mais próximo possível, as recomendações do FDA e ANVISA (FDA, 2001; ANVISA, 2003) para análise de fármacos e metabólitos em fluídos biológicos. Esta escolha foi devido à complexidade do meio de cultura líquido. Os parâmetros avaliados foram: linearidade, limite de quantificação, recuperação, precisão, exatidão, estabilidade e efeito da matriz.

A validação do método foi realizada por padronização interna empregando o fármaco ranolazina (figura 27-C) como padrão interno. Apesar de a ranolazina apresentar estrutura química diferente dos analitos analisados no presente trabalho, suas propriedades físico-químicas, tais como $\log P(2,7)$ e pKa $(7,2)$ são semelhantes às da RISP $(\log P 2,7$ e pKa 7,8$)$ e 9-RispOH $(\log P$ 2,2 e pKa 7,8) (Figura 27-A e 27-B, respectivamente) (JESUS et al., 2011; PUBCHEM, 2012).

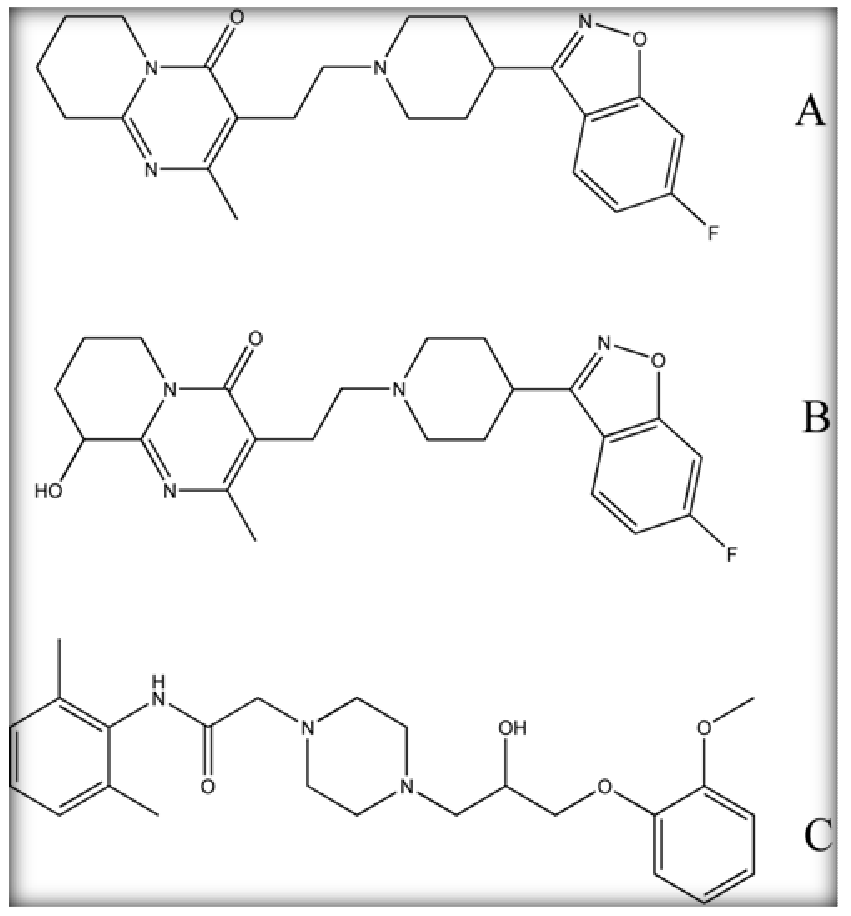

Figura 27 - Estruturas químicas da RISP (A), 9-RispOH (B) e Ranolazina (C). 


\subsubsection{LINEARIDADE}

O comportamento linear é avaliado através de uma curva analítica. Deve ser considerado na avaliação o coeficiente de correlação linear que deve ser estatisticamente semelhante a 1 e o erro relativo de cada ponto da curva analítica, que deve ser inferior a 15\%, exceto o primeiro ponto, cujo erro pode ser inferior a $20 \%$. A partir desta curva, verifica-se se existe relação linear entre a concentração do analito na amostra e a resposta do equipamento. A linearidade no presente trabalho foi avaliada em duas matrizes: a matriz de pool de fungos do gênero Cunninghamella e a matriz de meio de cultura líquido Czapeck. Após, a razão dos slopes das curvas analíticas foram determinadas e analisadas (MATUSZEWSKI, 2006). Foram consideradas como semelhantes, as curvas que apresentavam uma razão de slope não estatisticamente diferente de 1. Essa análise foi realizada na tentativa de reproduzir o meio de cultura após a fermentação dos fungos, ou seja, na presença dos metabólitos secundários dos mesmos.

$\mathrm{Na}$ avaliação da linearidade, devido o comportamento heterocedástico apresentado, a curva analítica foi ponderada, empregando o peso de $1 / x^{2}$. Os dados apresentados na Tabela 7 confirmam que a linearidade foi satisfatória para todos os analitos estudados e para os dois tipos de matrizes na faixa de concentração de $50-3750 \mathrm{ng} \mathrm{mL}^{-1}$ para a RISP e $25-500 \mathrm{ng} \mathrm{mL}^{-1}$ para os enantiômeros dos metabólitos. 
Tabela 7 - Linearidade do método desenvolvido para análise da RISP e seus metabólitos por SPME-LC-MS/MS em meio de cultura Czapeck e em pool de fungos

\begin{tabular}{|c|c|c|c|c|c|}
\hline Analitos & $\begin{array}{c}\text { Tipo de } \\
\text { Matriz }\end{array}$ & $\begin{array}{l}\text { Intervalo } \\
\text { (ng mL } \mathrm{mL}^{-1} \text { ) }\end{array}$ & Equação da reta & $\begin{array}{c}\text { Coeficiente } \\
\text { de } \\
\text { correlação }\end{array}$ & $\begin{array}{c}\text { Razão } \\
\text { dos } \\
\text { slopes }\end{array}$ \\
\hline \multirow[t]{2}{*}{ 7-RispOH (E1) } & Pool & $25-500$ & $y=0,01077 x+0,1021$ & 0,989 & \\
\hline & & & & & 1,01 \\
\hline 7-RispOH (E1) & Czapeck & $25-500$ & $y=0,01063 x+0,1242$ & 0,991 & \\
\hline \multirow[t]{2}{*}{ 7-RispOH (E2) } & Pool & $25-500$ & $y=0,01054 x+0,1067$ & 0,987 & \\
\hline & & & & & 0,994 \\
\hline 7-RispOH (E2) & Czapeck & $25-500$ & $y=0,01060 x+0,1227$ & 0,991 & \\
\hline \multirow[t]{2}{*}{ (+)-9-RispOH } & Pool & $25-500$ & $y=0,01217 x-0,1189$ & 0,996 & \\
\hline & & & & & 1,03 \\
\hline (+)-9-RispOH & Czapeck & $25-500$ & $y=0,01184 x-0,0923$ & 0,994 & \\
\hline \multirow[t]{2}{*}{ (-)-9-RispOH } & Pool & $25-500$ & $y=0,01208 x-0,1165$ & 0,995 & \\
\hline & & & & & 1,02 \\
\hline (-)-9-RispOH & Czapeck & $25-500$ & $y=0,01186 x-0,0984$ & 0,994 & \\
\hline \multirow[t]{2}{*}{ RISP } & Pool & $50-3750$ & $y=0,01980 x+0,2501$ & 0,989 & \\
\hline & & & & & 1,02 \\
\hline RISP & Czapeck & $50-3750$ & $y=0,01939 x+0,2588$ & 0,999 & \\
\hline
\end{tabular}

Além disso, para garantir que a quantificação em meio líquido Czapeck não pudesse gerar erros, ensaios de precisão e exatidão foram feitos empregando um branco da matriz de pool de fungos adicionadas dos analitos e tais amostras foram quantificadas utilizando curva analítica preparada em meio de cultura Czapeck, como já explicado no item 3.7.4. Os resultados de coeficiente de variação e erro relativo se apresentaram inferiores a $15 \%$, como demonstrados na Tabela 8. Dessa forma, toda a validação analítica foi realizada empregando o meio de cultura líquido Czapeck. Esse meio foi empregado, pois não gera resíduo biológico e também é um meio de fácil e rápido preparo. 
Tabela 8 - Precisão e exatidão das amostras de pool de fungos para análise da RISP e seus metabólitos por SPME-LC-MS/MS, quantificadas com curva analítica preparada em meio de cultura líquido Czapeck.

\begin{tabular}{ccccc}
\hline Analitos & $\begin{array}{c}\text { Concentração } \\
\text { nominal }\left(\mathbf{n g ~ m L} \mathbf{~ m}^{-1}\right)\end{array}$ & $\begin{array}{c}\text { Concentração } \\
\text { obtida }\left(\mathrm{ng} \mathrm{mL}^{-1}\right)\end{array}$ & $\begin{array}{c}\text { Exatidão, } \\
\mathrm{E}(\%)\end{array}$ & $\begin{array}{c}\text { Precisão, } \\
\text { CV (\%) }\end{array}$ \\
\hline 7-RispOH (E1) & $45 / 187 / 500$ & $46 / 175 / 445$ & $+2 /-6 /-11$ & $6 / 3 / 2$ \\
7-RispOH (E2) & $45 / 187 / 500$ & $46 / 173 / 446$ & $+2 /-7 /-11$ & $6 / 5 / 2$ \\
(+)-9-RispOH & $37 / 187 / 500$ & $33 / 189 / 474$ & $-11 /+1 /-5$ & $2 / 2 / 2$ \\
(-)-9-RispOH & $37 / 187 / 500$ & $33 / 191 / 474$ & $-11 /+2 /-5$ & $2 / 2 / 2$ \\
RISP & $75 / 500 / 2000$ & $70 / 512 / 2136$ & $-7 /+2 /+7$ & $5 / 3 / 3$ \\
\hline
\end{tabular}

\subsubsection{LIMITE DE QUANTIFICAÇÃO}

Nas condições descritas, o limites de quantificação (LOQ) para os enantiômeros dos principais metabólitos da RISP foi de $25 \mathrm{ng} \mathrm{mL}^{-1}$ e para a RISP de $50 \mathrm{ng} \mathrm{mL}^{-1}$. Os resultados estão representados na Tabela 9. Como pode ser observado os coeficientes de variação e de erro relativo foram inferiores a $15 \%$.

Tabela 9 - Limite de quantificação para análise da RISP e seus metabólitos por SPME-LCMS/MS em meio de cultura Czapeck.

\begin{tabular}{cccc}
\hline Analitos & $\begin{array}{c}\text { Concentração } \\
\text { Nominal }\left(\mathbf{n g ~ m L}^{-1}\right)\end{array}$ & $\begin{array}{c}\text { Exatidão, } \\
\text { E (\%) }\end{array}$ & $\begin{array}{c}\text { Precisão, } \\
\text { CV (\%) }\end{array}$ \\
\hline 7-RispOH (E1) & 25 & -7 & 10 \\
7-RispOH (E2) & 25 & -4 & 5 \\
(+)-9-RispOH & 25 & $+0,2$ & 5 \\
(-)-9-RispOH & 25 & $+0,3$ & 7 \\
RISP & 50 & $+0,8$ & 10 \\
\hline
\end{tabular}




\subsubsection{RECUPERAÇÃo}

Os dados referentes à recuperação dos analitos estão descritos na Tabela 10. Como pode ser observado, os valores de recuperação da RISP e seus metabólitos por SPME ficaram próximos de $26 \%$ e coeficiente de variação inferior a $12 \%$. Entretanto, tais valores não são preocupantes visto que a quantidade absoluta recuperada em SPME pode ser baixa em relação à quantidade inicial presente (< 1\%) (LORD, PAWLISZYN, 2000) e podem ser aceitos desde que os dados sejam precisos e não haja prejuízo em sua detectabilidade.

Outro detalhe que pode ser observado pela Tabela 10, é a maior recuperação dos enantiômeros da 9-RispOH (17\%) em relação aos enantiômeros da 7-RispOH (13\%). Isto pode ser explicado baseado na estrutura química destes metabólitos.

A 9-RispOH (Figura 1), apresenta a posição da hidroxila muito próxima ao nitrogênio (do anel pirimidinona), este nitrogênio possui um par de elétrons disponível que pode fazer uma ligação de hidrogênio intramolecular com o hidrogênio da hidroxila. Por este motivo, a 9-RispOH torna-se mais apolar e compatível (em termos de polaridade) com o revestimento C18 da fibra de SPME. Já, a estrutura da 7-RispOH (Figura 1), nos mostra a impossibilidade desta ligação de hidrogênio intramolecular, uma vez que a hidroxila está distante de pares de elétrons disponíveis para efetuar ligações deste tipo. Esta maior distância torna a 7-RispOH um pouco mais polar que a 9-RispOH e com menor atração à fibra $\mathrm{C} 18 \mathrm{e}$, consequentemente, apresentando menores valores de recuperação. 
Tabela 10 - Recuperação do método para análise da RISP e seus metabólitos por SPME-LCMS/MS

\begin{tabular}{lcc}
\hline \multirow{2}{*}{ Analitos } & Recuperação & Precisão \\
\cline { 2 - 3 } & $\%$ & CV (\%) \\
\hline 7-RispOH (E1) & 13 & 8 \\
7-RispOH (E2) & 13 & 8 \\
(+)-9-RispOH & 17 & 8 \\
RISP & 17 & 8 \\
\hline
\end{tabular}

\subsubsection{Precisão e Exatidão}

A precisão e exatidão são medidas de confiabilidade dos resultados analíticos obtidos. A precisão é o parâmetro que demonstra o quão próximo estão os resultados obtidos de amostras independentes e, a exatidão, demonstra a concordância do resultado obtido e o valor real (CASSIANO et al., 2009). Para a precisão e exatidão intraensaios foram avaliadas três concentrações através de cinco replicatas e os resultados obtidos foram expressos na Tabela 11. As mesmas três concentrações foram avaliadas para a determinação da precisão e exatidão interensaios, durante três dias consecutivos. Os resultados obtidos estão representados na Tabela 12. Todos os dados de coeficiente de variação e erro relativo demonstrados nas Tabelas 11 e 12 estão de acordo com os guias de validação para métodos bioanalíticos (ANVISA, 2003; FDA, 2001), mantendo-se inferior a $15 \%$. 
Tabela 11 - Precisão e exatidão intraensaios do método desenvolvido para análise da RISP e seus metabólitos por SPME-LC-MS/MS em meio de cultura Czapeck.

\begin{tabular}{|c|c|c|c|c|}
\hline Analitos & $\begin{array}{c}\text { Concentração } \\
\text { nominal }\left(\mathrm{ng} \mathrm{mL}^{-1}\right)\end{array}$ & $\begin{array}{l}\text { Concentração } \\
\left.\text { obtida (ng mL }{ }^{-1}\right)\end{array}$ & $\begin{array}{l}\text { Exatidão, } \\
\text { E (\%) }\end{array}$ & $\begin{array}{c}\text { Precisão, } \\
\text { CV (\%) }\end{array}$ \\
\hline $\begin{array}{c}\text { 7-RispOH } \\
\text { (E1) }\end{array}$ & $50 / 200 / 400$ & 49 / 195 / 407 & $-2 /-3 /+2$ & $5 / 11 / 8$ \\
\hline $\begin{array}{l}\text { 7-RispOH } \\
\text { (E2) }\end{array}$ & $50 / 200 / 400$ & 49 / 190 / 420 & $-2 /-5 /+5$ & $11 / 8 / 5$ \\
\hline (+)-9-RispOH & $50 / 200 / 400$ & 49 / $217 / 373$ & $-2 /+9 /-7$ & $11 / 5 / 7$ \\
\hline (-)-9-RispOH & $50 / 200 / 400$ & $48 / 217 / 366$ & $-4 /+9 /-9$ & $7 / 7 / 10$ \\
\hline RISP & $100 / 1000 / 2000$ & 99 / 1067 / 1888 & $-1 /+7 /-6$ & $7 / 3 / 9$ \\
\hline
\end{tabular}

Tabela 12 - Precisão e exatidão interensaio do método desenvolvido para análise da RISP e seus metabólitos por SPME-LC-MS/MS em meio de cultura Czapeck.

\begin{tabular}{ccccc}
\hline Analitos & $\begin{array}{c}\text { Concentração } \\
\text { nominal }\left(\mathbf{n g ~ m L} \mathbf{~ m}^{-1}\right)\end{array}$ & $\begin{array}{c}\text { Concentração } \\
\text { obtida }\left(\mathbf{n g ~ m L}^{-1}\right)\end{array}$ & $\begin{array}{c}\text { Exatidão, } \\
\text { E (\%) }\end{array}$ & $\begin{array}{c}\text { Precisão, } \\
\text { CV (\%) }\end{array}$ \\
\hline 7-RispOH (E1) & $50 / 200 / 400$ & $50 / 202 / 395$ & $0 /+1 /+1$ & $7 / 9 / 9$ \\
7-RispOH (E2) & $50 / 200 / 400$ & $50 / 197 / 404$ & $0 /-2 /+1$ & $8 / 10 / 8$ \\
(+)-9-RispOH & $50 / 200 / 400$ & $49 / 218 / 370$ & $-2 /+9 /-8$ & $9 / 9 / 8$ \\
(-)-9-RispOH & $50 / 200 / 400$ & $49 / 218 / 368$ & $-2 /+9 /-8$ & $7 / 8 / 11$ \\
RISP & $100 / 1000 / 2000$ & $100 / 1065 / 1875$ & $0 /+7 /-6$ & $8 / 5 / 8$ \\
\hline
\end{tabular}




\subsubsection{ESTABILIDADE}

A estabilidade foi determinada submetendo as amostras a ciclos de congelamento e descongelamento e nas condições de análise (Tabela 13). Ambos os testes foram realizados em duas concentrações e o teste "One-way" ANOVA foi aplicado considerando $p \leq 0,05$ estatisticamente significativo. Os resultados mostram que as amostras se mantém estáveis nos testes avaliados. A avaliação da estabilidade dos analitos nas condições de incubação e a racemização dos enantiômeros da 9-RispOH já foi avaliada por outro projeto de nosso grupo (DE JESUS et al., 2011), sendo que ambos os testes foram positivos e os analitos se mantém estáveis durante o período de incubação e nas condições de análise não há racemização da 9-RispOH.

Tabela 13 - Teste de estabilidade do método desenvolvido para análise da RISP e seus metabólitos por SPME-LC-MS/MS, $(n=6)$

\begin{tabular}{|c|c|c|c|}
\hline Analitos & $\begin{array}{c}\text { Concentração } \\
\text { nominal } \\
\left(\mathrm{ng} \mathrm{mL} \mathrm{m}^{-1}\right)\end{array}$ & $\begin{array}{c}\text { Ciclos de } \\
\text { congelamento e } \\
\text { descongelamento }\end{array}$ & $\begin{array}{c}\text { Estabilidade em } \\
\text { tempo e condições } \\
\text { de análise }\end{array}$ \\
\hline & & valores de $p$ & valores de $p$ \\
\hline 7-RispOH (E1) & $50 / 400$ & $0,720 / 0,681$ & $0,055 / 0,079$ \\
\hline 7-RispOH (E2) & $50 / 400$ & $0,615 / 0,667$ & $0,076 / 0,090$ \\
\hline (+)-9-RispOH & $50 / 400$ & $0,255 / 0,781$ & $0,238 / 0,469$ \\
\hline (-)-9-RispOH & $50 / 400$ & $0,197 / 0,686$ & $0,303 / 0,519$ \\
\hline RISP & $100 / 800$ & $0,150 / 0,999$ & $0,433 / 0,058$ \\
\hline
\end{tabular}




\subsubsection{Efeito da Matriz na lonização dos Analitos}

A análise por LC-MS/MS no modo MRM é muito seletiva, não deixando que prováveis interferentes provenientes da matriz coeluam com os analitos de interesse e assim interfiram nos resultados gerados. Porém, estes interferentes presentes na matriz podem interferir na ionização dos analitos, diminuindo ou aumentando a resposta do detector e levando a uma variabilidade na resposta em função da composição da matriz (FDA, 2001; ANVISA, 2003; CASSIANO et al., 2009).

Neste trabalho, o efeito de matriz na ionização da RISP, 9-RispOH, 7RispOH e do padrão interno ranolazina foi avaliado conforme descrito na seção 3.6.5., empregando tanto a matriz de pool de fungos quanto meio de cultura líquido Czapeck (Tabela 14). As diferenças de áreas obtidas foram inferiores a $12 \%$ para todos os analitos nas concentrações estudadas, o que demonstra que componentes endógenos das matrizes não afetam significativamente a ionização dos analitos.

Tabela 14 - Estudo do efeito da matriz na ionização dos analitos em meio de cultura líquido Czapeck e em pool de fungos

\begin{tabular}{|c|c|c|c|c|c|}
\hline Analitos & $\begin{array}{c}\text { Concentração } \\
\text { Nominal } \\
\left(\text { ng mL }{ }^{-1}\right)\end{array}$ & $\begin{array}{c}\text { Meio } \\
\text { Czapeck } \\
(\%)\end{array}$ & CV (\%) & $\begin{array}{l}\text { Pool de } \\
\text { fungos } \\
(\%)\end{array}$ & CV (\%) \\
\hline 7-RispOH (E1) & $50 / 200 / 400$ & $-2 /-5 /-4$ & $1 / 1 / 1$ & $-5 /-8 /+1$ & $5 / 1 / 5$ \\
\hline 7-RispOH (E2) & $50 / 200 / 400$ & $-6 /-7 /-8$ & $1 / 1 / 1$ & $-3 /-7 /+2$ & $4 / 2 / 5$ \\
\hline (+)-9-RispOH & $50 / 200 / 400$ & $-9 /-3 /+1$ & $4 / 1 / 1$ & $-6 /-9 /-1$ & $2 / 5 / 1$ \\
\hline (-)-9-RispOH & $50 / 200 / 400$ & $-8 /-4 /-6$ & $4 / 1 / 5$ & $-10 /-10 /-1$ & $3 / 6 / 1$ \\
\hline RISP & $100 / 1000 / 2000$ & $-2 /-1 / 0$ & $1 / 1 / 4$ & $--6 /-4 /-7$ & $11 / 8 / 1$ \\
\hline Ranolazina & 750 & -4 & 2 & -10 & 2 \\
\hline
\end{tabular}




\subsection{Aplicação do MÉtodo em Estudos de Biotransformação com FUNGOS}

As análises das amostras do estudo de biotransformação de cada espécie de fungo (cujo procedimento foi descrito na seção 3.7.6) foram realizadas empregando as condições de LC-MS/MS e SPME otimizadas e validadas.

Entre os fungos endofíticos avaliados, nenhum apresentou uma biotransformação significativa. Por outro lado, os fungos filamentosos Cunninghamella echinulata var. elegans ATCC 8688A e Cunninghamella elegans: NRRL 1393 ATCC 10028B foram capazes de biotransformar estereosseletivamente a RISP em seu metabólito ativo 9-RispOH. A formação dos enantiômeros da 7-RispOH não foi observada.

O fungo Cunninghamella echinulata foi capaz de biotransformar estereosseletivamente a RISP no enantiômero (+)-9-RispOH com excesso enantiomérico de 100\% (Figura 28). As análises demonstraram que este enantiômero começou a surgir a partir de 96 horas de biotransformação.

O fungo Cunninghamella elegans também foi capaz de biotransformar estereosseletivamente a RISP em ambos enantiômeros da 9-RispOH, porém o enantiômero (+)-9-RispOH foi produzido com maior intensidade que 0 enantiômero (-)-9-RispOH (Figura 29). As análises demonstraram que estes enantiômeros começaram a surgir a partir de 168 horas de biotransformação. A Tabela 15 mostra o excesso enantiomérico (ee) para cada gênero Cunninghamella e a concentração obtida em cada período. 
Tabela 15 - Estudos de biotransformação empregando fungos do gênero Cunninghamella.

Cunninghamella echinulata

Cunninghamella elegans

\begin{tabular}{|c|c|c|c|c|c|}
\hline Horas & $\begin{array}{c}\text { (+)-9-RispOH } \\
\text { ng mL }\end{array}$ & ee $(\%)$ & $\begin{array}{c}\text { (+)-9-RispOH } \\
\text { ng mL }^{-1}\end{array}$ & $\begin{array}{c}\text { (-)-9-RispOH } \\
\text { ng mL }^{-1}\end{array}$ & ee $(\%)$ \\
\hline 96 & 147 & 100 & ND & ND & - \\
\hline 120 & 577 & 100 & ND & ND & - \\
\hline 144 & 1094 & 100 & ND & ND & - \\
\hline 168 & 1558 & 100 & 26 & $19^{*}$ & 15 \\
\hline 192 & 968 & 100 & 38 & 25 & 21 \\
\hline 216 & 1506 & 100 & 58 & 40 & 18 \\
\hline
\end{tabular}

$\mathrm{ND}$ = valor inferior ao $\mathrm{LQ}$

*Valor inferior ao LQ mas empregado para estimar o excesso enantiomérico 


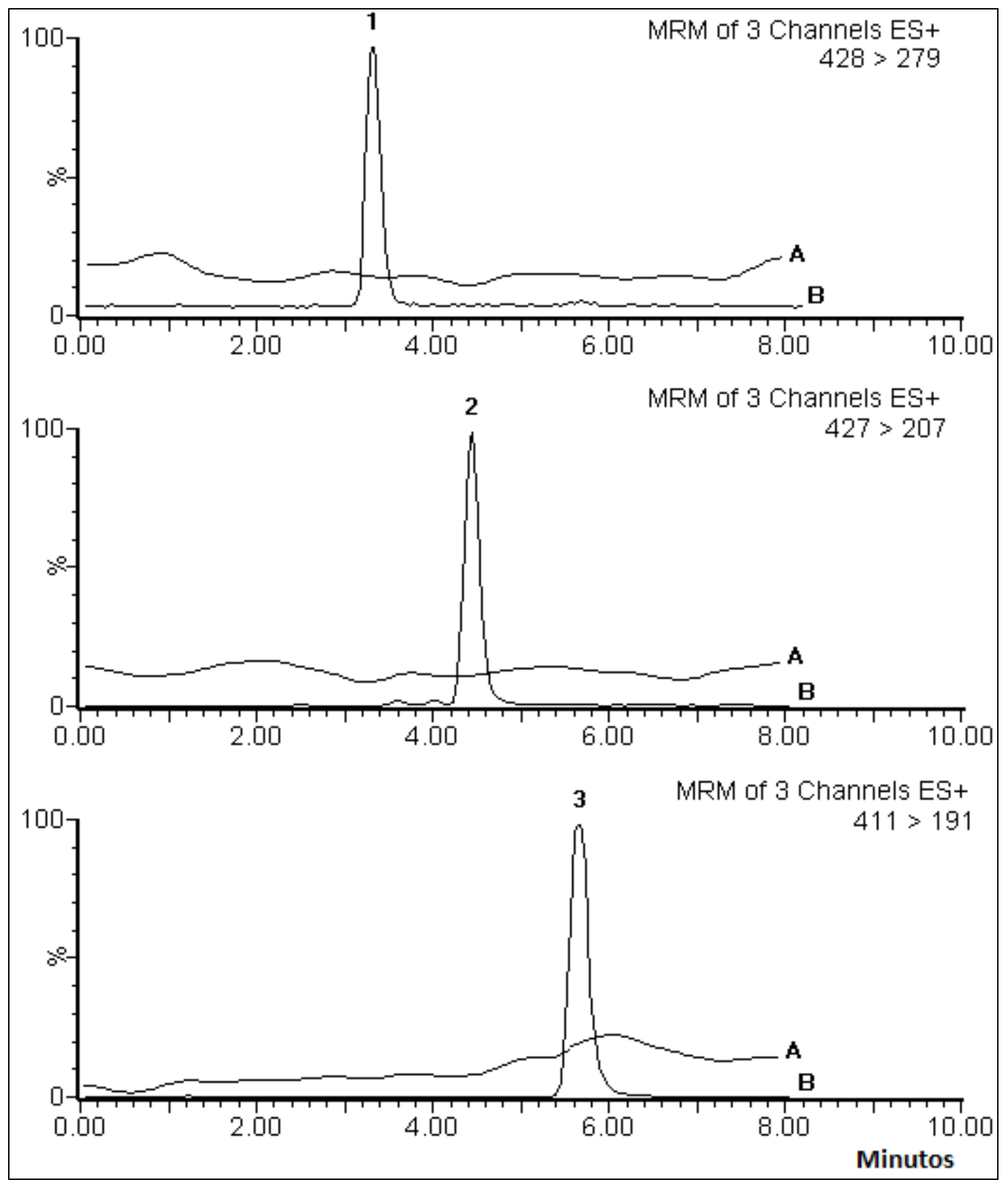

Figura 28 - A) Cromatograma representativo de meio de cultura líquido Czapeck incubado com o Cunninghamella echinulata var. elegans ATCC 8688A (controle) mostrando que este fungo não produz quaisquer metabólitos secundários no tempo de retenção dos analitos. B) Cromatograma representativo de 3 canais em modo MRM do fungo Cunninghamella echinulata var. elegans ATCC 8688A, após 168 horas de incubação. Padrão interno (1), (+)-9-RispOH (2) e RISP (3). Condições de separação e análise descritas, respectivamente, em 3.2.3. e 3.3. 


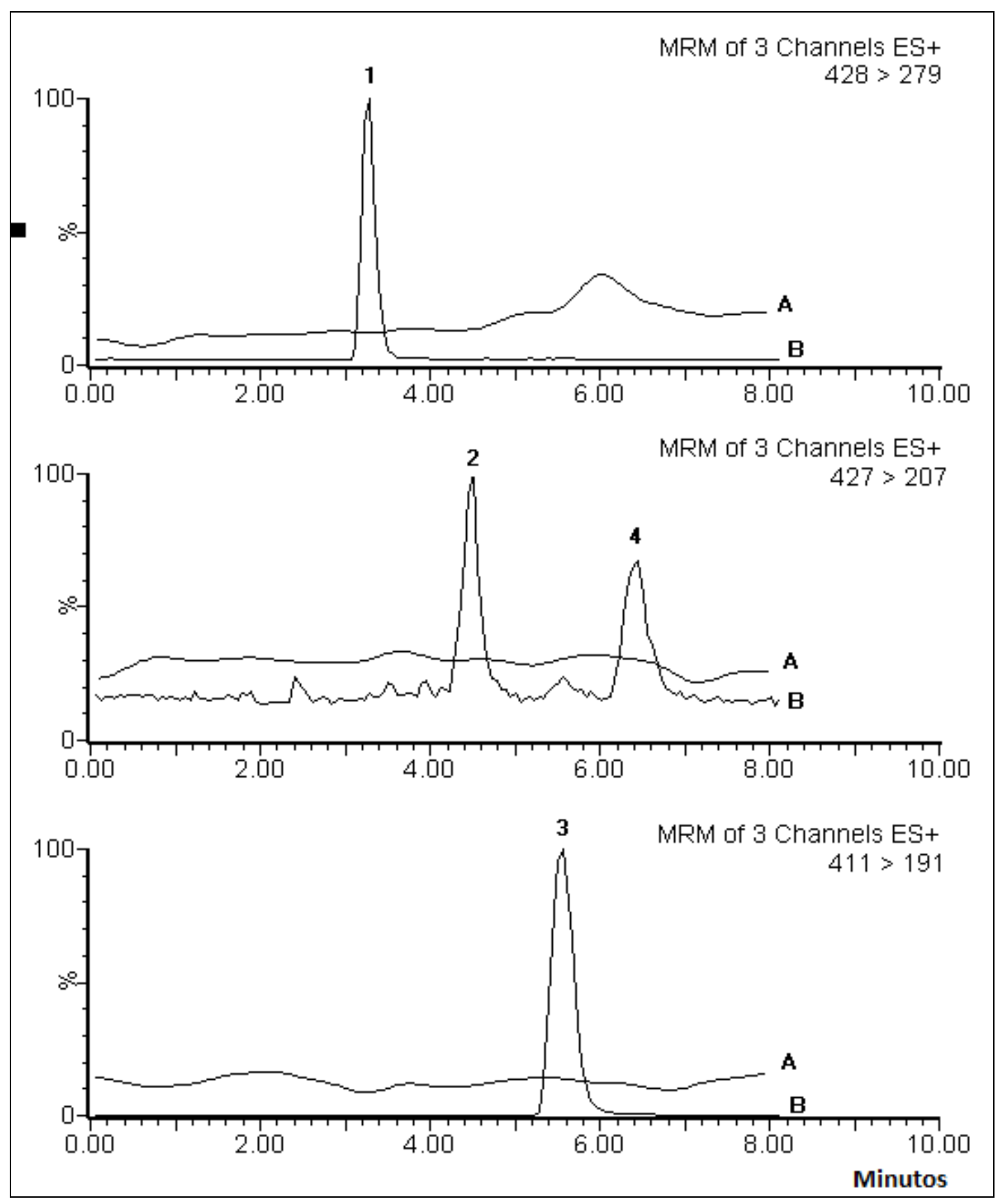

Figura 29 - A) Cromatograma representativo de meio de cultura líquido Czapeck incubado com o Cunninghamella elegans ATCC 10028B (controle) mostrando que este fungo não produz quaisquer metabólitos secundários no tempo de retenção dos analitos. B) Cromatograma representativo em modo MRM do fungo Cunninghamella elegans ATCC 10028B, após 168 horas de incubação com o padrão da RISP. Padrão interno (1), (+)-9-RispOH (2), RISP (3) e (-)-9-RispOH (4). Condições de separação e análise descritas, respectivamente, em 3.2.3. e 3.3. 


\subsection{Estudos Preliminares de Catálise Assimétrica da Risperidona EMPREgANDO CompleXos de JACOBSEN}

Além dos "catalisadores" biológicos, neste projeto foi avaliado a possibilidade de reações enantiosseletivas empregando catalisadores assimétricos, do tipo Jacobsen. Esses catalisadores apresentam uma estrutura semelhante ao grupamento Heme das enzimas do citocromo P450 e, portanto, a catálise enantiosseletiva pode ocorrer em condições otimizadas de concentração de oxidante, catalisador e tempo reacional. Como o objetivo nessa etapa foi somente um estudo preliminar, uma otimização sistemática das condições reacionais não foi realizada. Contudo, como pode ser observado na Figura 30 esses catalisadores apresentam um grande potencial para catálise assimétrica de fármacos. As reações de oxidação da RISP foram realizadas empregando três tipos de oxidante e os catalisadores de Jacobsen: $(R, R)$ Jacobsen e $(S, S)$-Jacobsen. As condições avaliadas foram descritas no item 3.7.7.

Os resultados foram positivos apenas para a catálise empregando como oxidante $m$-CPBA e catalisador ( $S, S)$-Jacobsen. Os resultados obtidos foram analisados comparando-se os tempos de retenção do cromatograma da catálise com os tempos de retenção dos padrões e, através destes dados e dos espectros de absorção, pode-se concluir que houve a formação do enantiômero 7-RispOH (E1). 


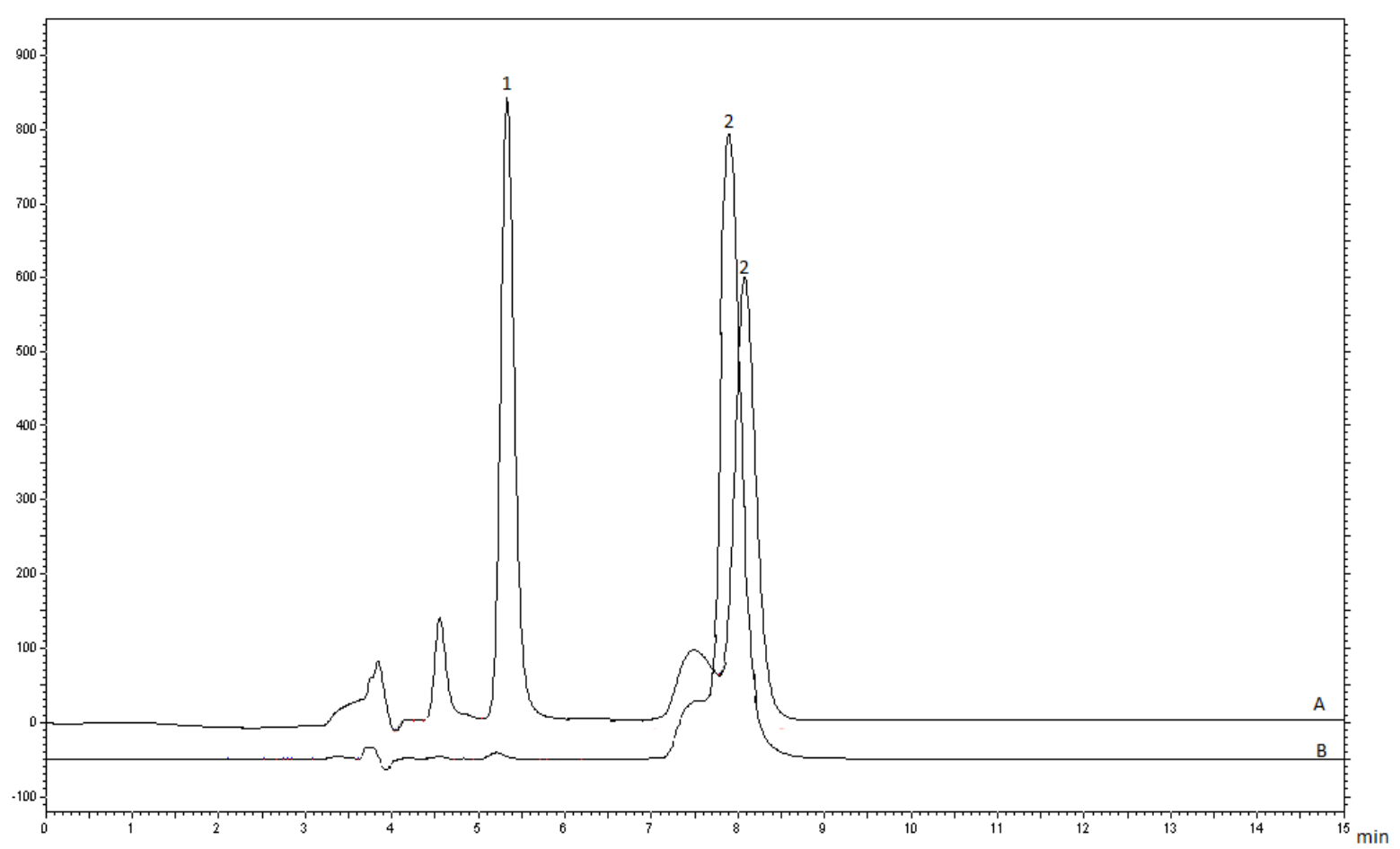

Figura 30 - Cromatograma após 24 horas de reação com o catalisador (S,S)-Jacobsen utilizando como oxidante m-CPBA, na proporção 1:50:50 (catalisador:oxidante:substrato, em número de mols e condições descritas na seção 3.7.7). Condições cromatográficas descritas na seção 4.1.7. (A) Cromatograma relativo à catálise com o catalisador de Jacobsen. (B) Controle de reação. 1) 7-RispOH (E1) e 2) RISP.

Nas condições descritas no item 3.7.7, as reações avaliadas com os oxidantes $\mathrm{H}_{2} \mathrm{O}_{2}$ e PhlO também na proporção 1:50:50 (catalisador:oxidante:substrato, em número de mols), tanto para o catalisador $(R, R)$-Jacobsen quanto para o catalisador $(S, S)$-Jacobsen, não apresentaram resultados satisfatórios (Figuras 31 e 32, respectivamente). Na Figura 31, pode-se perceber que não houve reação. Isso pode ser explicado pelo fato do oxidante PhIO apresentar característica oxidante mais fraca se comparado ao oxidante $m$-CPBA, fazendo com que a molécula da RISP permaneça intacta mesmo após 24 horas de reação.

Já, na Figura 32, o oxidante $\mathrm{H}_{2} \mathrm{O}_{2}$ é mais forte, e em 4 horas de reação, apresentou vários picos cromatográficos que não puderam ser identificados, pois apresentavam coeluição e seus espectros de absorção não apareceram 
muito bem definidos. $\mathrm{O}$ oxidante $\mathrm{H}_{2} \mathrm{O}_{2}$, em 4 horas de reação, consumiu praticamente toda a RISP disponível no meio.

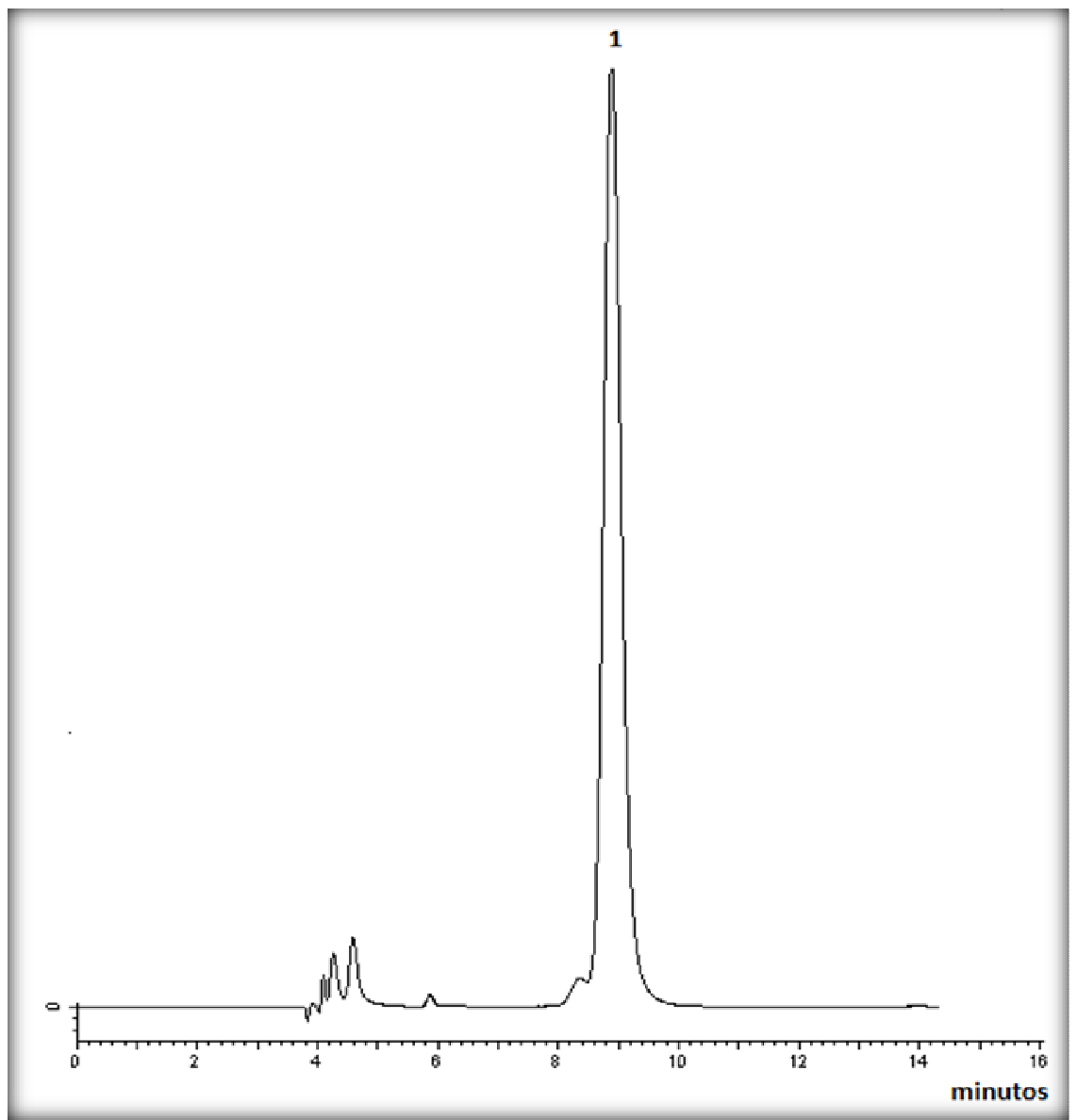

Figura 31 - Cromatograma após 24 horas de reação com o catalisador (S,S)-Jacobsen utilizando como oxidante $\mathrm{PhIO}$, na proporção 1:50:50 (catalisador:oxidante:substrato, em número de mols e condições descritas na seção 3.7.7). Condições cromatográficas descritas na seção 4.1.7. Cromatograma relativo à catálise com o catalisador de Jacobsen.1) RISP. 


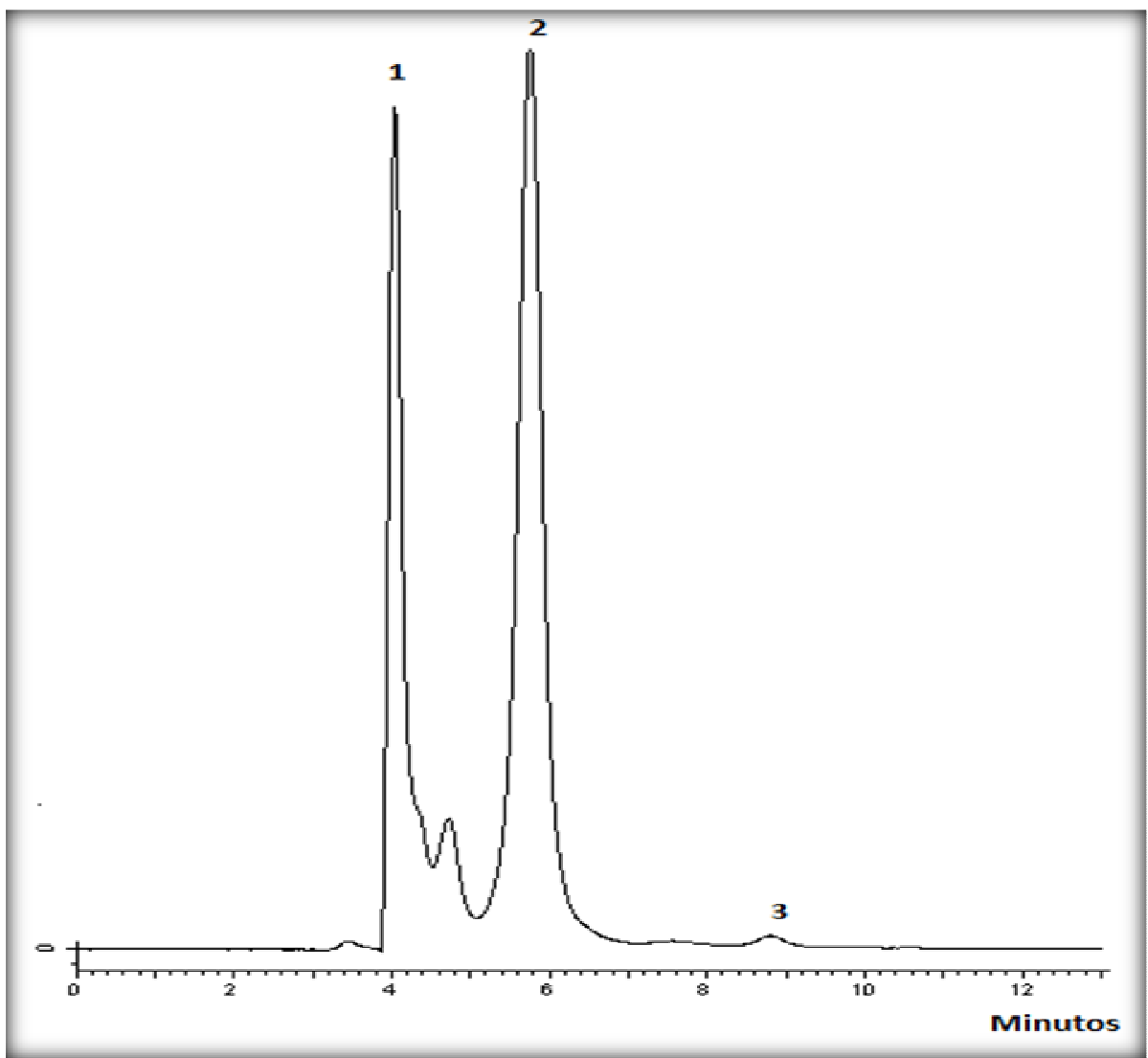

Figura 32 - Cromatograma após 4 horas de reação com o catalisador (S,S)-Jacobsen utilizando como oxidante $\mathrm{H}_{2} \mathrm{O}_{2}$, na proporção 1:50:50 (catalisador:oxidante:substrato, em número de mols e condições descritas na seção 3.7.7). Condições cromatográficas descritas na seção 4.1.7. Cromatograma relativo à catálise com o catalisador de Jacobsen.1) e 2) picos não-identificadas. 3) RISP. 


\section{5 - CONCLUSÕES}

Este trabalho teve como objetivo avaliar a capacidade de algumas espécies de fungos e de modelos biomiméticos em (bio)transformar estereosseletivamente a RISP em seu metabólito quiral e ativo 9-RispOH. Para tanto, foram desenvolvidas técnicas de preparação de amostras (SPME) e análise (HPLC-UV e LC-MS/MS). O desenvolvimento e a validação dessas técnicas permitiram a quantificação dos metabólitos da RISP em meio de cultura e permitiu avaliar a capacidade de complexos de Jacobsen em ensaios preliminares de catálise enantiosseletiva. Após o desenvolvimento dos métodos, algumas conclusões podem ser mencionadas:

Nesse projeto foi desenvolvido pela primeira vez um método para análise da risperidona e análise enantiosseletiva de seus metabólitos empregando o modo polar-orgânico. O método desenvolvido é rápido, apresenta um baixo consumo de solventes orgânicos e uma excelente compatibilidade com o sistema LCMS/MS.

Para extração dos analitos em meio de cultura, foi aplicado pela primeira vez a SPME. Até o momento, não há dados na literatura que empreguem a SPME como técnica de preparação de amostras em meio de cultura. A técnica mostrou ser simples, reprodutível, reduziu a quantidade de solventes orgânicos e possui custo baixo, pois a fibras apresentam a possibilidade de reutilização e as fibras C18 baixo custo. Além disso, o formato da fibra C18 utilizada possibilitou que o processo de extração fosse rápido, já que 36 amostras puderam ser extraídas ao mesmo tempo. Não há relatos na literatura desse tipo de configuração para SPME.

Entre as desvantagens da técnica de SPME estão: os baixos valores de recuperação, o que limita que a técnica seja aplicada em análises com detectores de alta sensibilidade como o espectrômetro de massas para que amostras de fármacos em fluidos biológicos possam ser quantificados; o baixo número de fibras disponíveis no mercado que sejam compatíveis com cromatografia líquida e suas restrições de $\mathrm{pH}$, uso de solventes e outros fatores (já que estes fatores podem provocar a degradação destas fibras). Essas fibras C18 apresentam visivelmente muita variabilidade individual, sendo que o uso da padronização interna é um fator crucial no desenvolvimento do método. 
Melhoras na tecnologia de produção dessas fibras poderão, futuramente, resolver esse problema.

Os fungos filamentosos da coleção da ATCC Cunninghamella echinulata var. elegans ATCC 8688A e Cunninghamella elegans ATCC 10028B foram capazes de biotransformar estereosseletivamente a RISP em seu metabólito ativo 9-RispOH, sendo que o Cunninghamella echinulata foi capaz de produzir o enantiômero (+)-9-RispOH com excesso enantiomérico de 100\%. Melhoria nas condições de cultivo pode favorecer uma alta eficiência na biotransformação e, desta forma, pode ser empregado para produzir o metabólito ativo em sua forma enantiomericamente pura.

Os dados relativos a esses estudos de biotransformação com os fungos Cunninghamella foram publicados no periódico Analytica Chimica Acta (DOI 10.1016/j.aca.2012.05.056) o qual se encontra em fase final de revisão (revisão do "proof")

Apesar dos fungos endofíticos serem uma alternativa viável devido sua abundância em nossa região, os mesmos não apresentaram capacidade de biotransformação nas condições empregadas nesse projeto.

Os catalisadores de Jacobsen apresentaram uma catálise assimétrica, com um alto excesso enantiomérico e alta eficiência de catálise mostrando o potencial desses catalisadores em síntese assimétrica. Contudo estudos sistemáticos e validados devem ser conduzidos para uma melhor compreensão dos mecanismos e, portanto, propor uma síntese mais dirigida em favorecimento do enantiômero ativo. 


\section{6- $\quad$ REFERÊNCIAS BIBLIOGRÁFICAS}

ANVISA - AGÊNCIA NACIONAL DE VIGILÂNCIA SANITÁRIA. Guia para validação de métodos analíticos e bioanalíticos RE. $\mathrm{N}^{\circ}$. 899, de 29 de maio de 2003, Brasília, DF, 2003. Disponível em http://www.anvisa.gov.br/legis/resol/2003/re/899_03re.htm. Acesso em 10 de maio de 2012.

ARMSTRONG, D.W.; TANG, Y.; CHEN, S.; ZHOU, Y.; BAGWILL, C.; CHEN, J.-R. Macrocyclic antibiotics as a new class of chiral selectors for liquid chromatography. Analytical Chemistry, Washington, v.66, p.1473-1484, 1994.

ARTHUR, C.L.; PAWLISZYN, J. Solid phase microextraction with thermal desorption using fused silica optical fibers. Analytical Chemistry, Washington, v.62, p.2145-2148, 1990.

ASHA, S.; VIDYAVATHI, M. Cunninghamella - A microbial model for drug metabolism studies - A review. Biotechnology Advances, Andhra Pradesh, v.27, p.16-29, 2009.

BALEIZÃO, C.; GARCIA, H. Chiral Salen complexes: An Overview to Recoverable and Reusable Homogeneous and Heterogeneous Catalysts, Chemical Reviews, Washington v.106, p.3987-4043, 2006.

BARTH, T.; PUPO, M.T.; BORGES, K.B.; OKANO, L.T.; BONATO, P.S. Stereoselective determination of midodrine and desglymidodrine in culture medium: application to a biotransformation study employing endophytic fungi. Electrophoresis, Weinhem v.31 (9), p.1512-1528, 2010.

BONATO, P.S.; JABOR, V.A.P.; GAITANI, C.M. Análise Enantiosseletiva de fármacos: contribuição da cromatografia líquida de alta eficiência e eletroforese capilar. Química Nova, São Paulo, v.28 (4), p.683-691, 2005.

BOJKO, B.; CUDJOE, E.; WASOWICZ, M.; PAWLISZYN, J. Solid-phase microextraction. How far are we from clinical practice? Trends in Analytical Chemistry, Amsterdam, v.30 (9), p.1505-1512, 2011.

BORGES, K.B.; DE OLIVEIRA, A.R.M.; BARTH, T.; JABOR, V.A.P.; PUPO, M.T.; BONATO, P.S. LC-MS/MS determination of ibuprofen, 2-hydroxybuprofen enantiomers, and carboxybuprofen stereoisomer for application in 
biotransformation studies employing endophytic fungi. Analytical and Bioanalytical Chemistry, Washington, v.399 (2), p.915-925, 2010.

CABOVSKA, B.; COX, S.L.; VINKS, A.A. Determination of risperidone and enantiomers 9-hydroxyrisperidone in human plasma by LC-MS/MS. Journal of Chromatography B, Amsterdam, v.852, p.497-504, 2007.

CASS, Q.B.; DEGANI, A.L.G; CASSIANO, N. The use of a polysaccharidebased column on multimodal elution. Journal Liquid Chromatography \& Related Technologies, New York, v.23, p.1029-1038, 2000.

CASSIANO, N.M.; BARREIRO, J.C.; MARTINS, L.R.R.; OLIVEIRA, R.V.; CASS, Q.B. Validação em métodos cromatográficos para análise de pequenas moléculas em matrizes biológicas. Química Nova, São Paulo, v.32 (4), p.10211030, 2009.

CHANKVETADZE, B.; KARTOZIA, I.; YAMAMOTO, C.; OKAMOTO, Y. Comparative enantioseparation of selected chiral drugs on four different polysaccharide-type chiral stationary phases using polar organic mobile phases. Journal Pharmaceutical and Biomedical Analysis, Oxford, v.27, p.467-478, 2002.

CHIARADIA, M.C.; COLLINS, C.H.; JARDIM, I.C.S. O estado da arte da cromatografia associada à espectrometria de massas acoplada à espectrometria de massas na análise de compostos tóxicos em alimentos. Química Nova, São Paulo, v.31 (3), p.623-636, 2008.

CROTTI, A.E.M.; VESSECCHI, R.; CALLEGARI, J.L.; LOPES, N.P. Espectrometria de massas com ionização por "electrospray": processos químicos envolvidos na formação de íons de substâncias orgânicas de baixo peso molecular. Química Nova, São Paulo, v.29 (2), p.287-292, 2006.

DANEL, C.; BARTHÉLÉMY, C.; AZARZAR, D.; ROBERT, H.; BONTE, J.P.; ODOU, P.; VACCHER, C. Analytical and semipreparative enantioseparation of 9-hydroxyrisperidone, the main metabolite of risperidone, using highperformance liquid chromatography and capillary electrophoresis Validation and determination of enantiomeric purity. Journal of Chromatography A, Amsterdam, v.1163, p.228-236, 2007.

DAVIS, P.J. Microbial models of mammalian drug metabolism. Developments in Industrial Microbiology, Washington, v.29, p.197-291, 1988. 
DE JESUS, L.I.; ALBUQUERQUE, N.C.P.; BORGES, K.B.; SIMÕES, R.A.; CALIXTO, L.A.; FURTADO, N.A.J.C.; GAITANI, C.M.; PUPO, M.T.; DE OLIVEIRA, A.R.M. Enantioselective fungal biotransformation of risperidone in liquid culture medium by capillary electrophoresis and hollow fiber liquid-phase microextraction. Electrophoresis, Weinhem, v.32, p.2765-2775, 2011.

DE OLIVEIRA, A.R.M.; MAGALHÃES, I.R.S.; DE SANTANA, F.J.M.; BONATO, P.S. Microextração em fase líquida (LPME): fundamentos da técnica e aplicações na análise de fármacos em fluidos biológicos. Química Nova, São Paulo, v.31, p.627-644, 2008.

FARAMARZI, M.; ADRANGI, S.; YAZDI, M.T. Microalgals biotransformation of steroids. Journal of Phycology, New York, v.44, p.27-37, 2008.

FDA. U.S. Department of Health and Human Services, Food and Drug Administration (FDA), Center for Drug Evaluation and Research (CDER). Guidance for industry. Bioanalytical method validation, 2001. Disponivel em: www.fda.gov/cder/guidance/index.htm. Acesso em: 7 de junho de 2012.

FRAGOSO, V.M.; SILVA, D.; CRUZ, F.A.O.; CORTEZ, C.M. Risperidone interacts with serum albumim forming complex. Environmental Toxicology and Pharmacology, New York, v.33 (2), p.262-266, 2012.

GATES, P.; SANTOS, M.D.; GOBBO-NETO, L.; CAROLLO, C.A.; CROTTI, A.E.M.; VESSECCHI, R.; LOPES, N.P. Mass spectrometry ionization techniques and applications for the analysis of organic compounds. Current Methods in medicinal Chemistry and Biological Physics, Ontario, v.37, p.118, 2006.

GORECKI, T.; PAWLISZYN, J.; Sample introduction approaches for solidphase microextraction rapid CG. Analytical Chemistry, Washington, v.67, p.3265-3274, 1995.

GRITTI, F.; GUIOCHON, G. Mass transfer kinetics, band broadening and column efficiency. Journal of Chromatography A, Amsterdam, v. 1221, p.1-7, 2012.

HAGINAKA, J. Mechanistic aspects of chiral recognition on protein-based stationary phases. Advances in Chromatography, New York, v.49, p-37-69, 2011. 
HEYKANTS, J.; HUANG, M-L.; MANNENS, G.; MEULDERMANS, W.; SNOECK, E.; VAN, B.L.; VAN PEER, A.; WOESTENBORGHS, R. The pharmacokinetics of risperidone in humans: a summary. Journal of Clinical Psychiatry, Washington, v. 55, p.513-517, 1994.

HILARIO, V.C; CARRÃO, D.B.; BARTH, T.; BORGES, K.B.; FURTADO, N.A.J.C.; PUPO, M.T.; DE OLIVEIRA, A.R.M. Assessment of the stereoselective fungal biotransformation of albendazole and its analysis by HPLC in polar organic mode. Journal of Pharmaceutical and biomedical analysis, Oxford, v.61, p.100-107.

http://www.daicelchiral.com/appguide/index/column_table.htm. Acessado em $11 / 06 / 2012$

http://www.allcrom.com.br/colunas-hplc/lux. Acessado em 11/06/2012

http://www.sigmaaldrich.com/analytical-

chromatography/hplc/columns/chiral/chirobiotic-r.html. Acessado em 12/06/2012.

http://www.sigmaaldrich.com/analytical-

chromatography/analyticalproducts.html?TablePage $=9645337$. Acessado em 12/06/2012.

HADLEY, M.S.; CAMILLERI, P.; HUTT, A.J. Enantiospecific analysis by capillary electrophoresis: applications in drug metabolism and pharmacokinetics. Electrophoresis, Weinheim, v.21, p.1953-1976, 2000.

HUANG, M-L.; VAN PEER, A.; WOESTENBORGHS, R.; DE COSTER, R.; HEYKANTS, J.; JANSEN, A.; ZYLICS, A.; VISSCHER, H.; JONKMAN, J. Pharmacokinetics of the novel antipsychotic agent risperidone and the prolactin response in healthy subjects. Clinical Pharmacology Therapeutics, New York, v.54, p.257-268, 1993.

ILISZ, I.; BERKECZ, R.; PETER, A. HPLC separation of amino acid enantiomers and small peptides on macrocyclic antibiotic-based chiral stationary phases: A review. Journal of Separation Science, Weinheim, v.29, p.1305-1321, 2006.

ILISZ, I.; BERKECZ, R.; PETER, A. Retention mechanism of HPLC enantioseparations on macrocyclic glycopeptides-based chiral stationary phases. Journal of Chromatography A, Amsterdam, v.1216, p.1845-1860, 2009. 
ISAKE, E.L.; Chiral Discrimination and stereoselective analysis of drugs. Journal of Pharmaceutical Sciences, Queensland, v.96, p.1659-1676, 2007.

JACOBSEN, E.N; ZHANG, W.; GULER, M.L. Electronic tuning of asymmetric catalysts, Journal American Chemical Society, Washington, v.113 (17), p.6703-6704, 1991.

KUMAZAWA, T.; LEE, X.P.; SATO, K.; SUZUKI, O. Solid-phase microextraction and liquid chromatography/mass spectrometry in drug analysis. Analytica Chimica Acta, Amsterdam, v.492, p.49-67, 2003.

KUDLEJOVA, L. RISTECEVIC, S.; VUCKOVIC, D. Solid Phase Microextraction method development. In: Handbook of Solid Phase Microextraction: SPME $1^{\text {st }}$ ed. (ed. Pawliszyn, J.), University of Waterloo, Waterloo, p.128-171, 2007.

LAMMERHOFER, M. Chiral recognition by enantioselective liquid chromatography: Mechanisms and modern chiral stationary phases. Journal of Chromatography A, Amsterdam, v.1217 (6), p.814-856, 2010.

LIN, H.H.; SUNG, Y.H.; HUANG, S.D. Solid-phase microextraction coupled with high-performance liquid chromatography for the determination of phenylurea herbicides in aqueous samples. Journal of Chromatography A, Amsterdam, v.1012, p.57-66, 2003.

LIU, Y.; BERTHOD, A.; MITCHELLI, C.R.; XIAO, T-L.; ZHANG, B.; ARMSTRONG, D.W. Super / Subcritical fluid chromatography chiral separation with macrocyclic glycopeptides stationary phases. Journal of Chromatography A, Amsterdam, v.948, p.185-204, 2002.

LOCATELLI, I.; MRHAR, A.; GRABNAR, I. Simultaneous determination of risperidone and 9-hydroxyrisperidone enantiomers in human blood plasma by liquid chromatography with electrochemical detection. Journal of Pharmaceutical and Biomedical Analysis, Oxford, v.50 (5), p.905-910, 2009.

LORD, H.; PAWLISZYN, J. Microextraction of drugs. Journal of Chromatography A, Amsterdam, v.902, p.17-63, 2000. 
LOURENÇO, T.C.; CASSIANO, N.M.; CASS, Q.B. Fases estacionárias quirais para cromatografia líquida de alta eficiência. Química nova, São Paulo, v.33 (10), p.2155-2164, 2010.

LUCAS, H.J.; KENEDY, E.R.; FORNO, N.W. lodosobenzene. Organic Syntheses Coll., Amsterdam, v.43, p.60, 1963.

MACIÁ-VICENTE, J.G.; JANSSON, H.B.; ABDULLAH, S.K.; DESCALS, E.; SALINAS, J.; LOPEZ-LLORCA, L.V. Fungal root endophytics from natural vegetation in Mediterranean environmental with special reference to Fusarium ssp. Federation of European microbiological Societies: Microbiology Ecology, London, v.66, p.90-105, 2008.

MANNENS, G.; HUANG, M-L.; MEULDERMANS, W.; HENDRICKX, R.; WOESTENBORGHS, R.; HEYKANTS, J. Absorption, metabolism and excretion of risperidone in humans. Drug metabolism and Disposition: the biological fate of chemicals, London, v.21 (6), p.1134-1141, 1994.

MANSUY, D. A brief history of the contribution of metalloporphyrin models to cytochrome P450 chemistry and oxidation catalysis. Competes Rendus Chimie, Paris, v.10, p.392-413, 2007.

MARAKOV, A. Electrostatic axially harmonic orbital trapping: a highperformance technique of mass analysis. Analytical Chemistry, Washington, v.921, p.227-236, 2000.

MATTHIJS, N.; MAFTOUH, M.; HEYDEN, Y.V. Screening approach for chiral separation of pharmaceuticals: IV. Polar organic solvent chromatography. Journal of Chromatography A, Amsterdam, v.1111 (1), p.48-61, 2006.

MATUSZEWSKI, B.K. Standard line slopes as a measure of a relative matrix effect in qualitative HPLC-MS bioanalysis. Journal of Chromatography B, Amsterdam, v.830, p.293-300, 2006.

MEULDER, M.; REMMERIE, B.M.M; DE VRIES, R.; SIPS, L.L.A; BOOM, S.; HOOIJSCHUUR, E.W.J.; VAN DER MERBER, N.C.; TIMMERMAN, P.M.M.B.L. Validated LC-MS/MS methods for the determination of risperidone and the enantiomers of 9-hydroxyrisperidone in human plasma and urine. Journal of Chromatography B, Amsterdam, v.870, p.8-16, 2008. 
MIRNAGHI, F.S.; CHEN, Y.; SIDISKY, L.M.; PAWLISZYN, J. Optimization of the coating procedure for a high-throughput 96-Blade Solid Phase Microextraction System Coupled with LC-MS/MS for Analysis of Complex Samples. Analytical Chemistry, Washington, v.83, p.6018-6025, 2011.

MISLANOVÁ, C.; HUTTA, M. Role of biological matrices during the analysis of chiral drugs by liquid chromatography. Journal of Chromatography B, Amsterdam, v.797, p. 91-109, 2003.

MOODY, J.D.; FREEMAN, J.P.; FU, P.P, CENIGLIA, C.E. Biotransformation of mirtazapine by Cunninghamella elegans. Drug metabolism and disposition, Baltimore, v. 30 (11), p.1274-1279, 2002.

MORI, K. Bioactive natural products and chirality. Chirality, New York, v. 23 (6), p.442-462, 20111.

NATARAJAN, R.; BASAK, S.C.; Numerical Descriptors for the characterization of chiral compounds and their applications in modeling biological and toxicological activities. Current Topics in Medicinal Chemistry, Netherlands, v.11 (7), p.771-787, 2011.

OKAMOTO, Y.; YASHIMA, E. Polysaccharides derivates for chromatography separation of enantiomers. Angewandte Chemie International Edition, Weinheim, v.37 (8), p.1020-1043, 1998.

OKAMOTO, Y.; KAIDA, Y. Resolution by high-performance liquidchromatography using polysaccharide carbamates and benzoates as chiral stationary phases. Journal of Chromatography A, Amsterdam, v. 666, p. 403419, 1994.

PAWLISZYN, J. SPME method development. In: Solid Phase Microextraction: Theory and Practice, $1^{\text {st }}$ edn (ed. Pawliszyn, J.), p. 97-139, Wiley-VCH, New York, 1997.

PĖREZ, S.; BACELÓ, D. Applications of LC-MS to quantitation and evaluation of the environmental fate of chiral drugs and their metabolites. Trends in Analytical Chemistry, Washington, v.27, p.836-846, 2008. 
PUBCHEM. Pubchem Compounds, National Center for Biotechnology Information, U.S. National library of medicine, Bethesda, MD, U.S. Disponivel em:

http://pubchem.ncbi.nem.nih.gov/summary/summary.cgi?cid=5073\&loc=ec_rcs. Acesso em 7 de junho de 2012.

PUPO, M.T.; BORGES, K.B.; BORGES, W.S.; BONATO, P.S. Fungal biotransformation: a Powerful Tool in Drug Metabolism Studies. In: Ratul Saikai; Rajib L. Bezbaruah; Tarun Ch. Bora. (Org.) Microbial biotechnology. New India Publishing Agency, New Delhi, p.47-66, 2008.

QIU, H.D.; LIANG, X.J.; SUN, M.; JIANG, S.X. Development of silica-based stationary phases for high-performance liquid chromatography. Analytical and Bioanalytical Chemistry, Washington, v.399 (10), p.3307-3322, 2011.

RAYLEIGH, L. On the equilibrium of liquid conducting masses charged with electricity. Philosophical Magazine, Cambridge, v.14, p.184-186, 1882.

RISTECEVIC, S.; LORD, H.; GÓRECKI, T.; ARTHUR, L.C.; PAWLISYN, J. Protocol for solid-phase microextraction method development. Nature Protocols, v.5 (1), p.122-139, 2010.

SHAREFKIN, J.G.; SALTZMAN, H. lodosobenzene. Organic Syntheses Coll., Amsterdam, v.5, p.658, 1973.

SCHNEIDER, P; MISIEK, M.; HOFFMEISTER, D. In vivo and In vitro production options for fungal secondary metabolites. Molecular Pharmaceutics, St. Paul, v.5 (2), p.234-242, 2007.

SILVA JUNIOR, I.J.; VEREDAS, V.; SANTOS, M.A.G.; SANTANA, C.C. Cromatografia em leito móvel simulado na produção de substâncias enantioméricas puras ou enriquecidas em larga escala. Química Nova, São Paulo, v.29 (5), p. 1027-1037, 2006.

SMITH, S.W. Chiral Toxicology: It's the same thing...Only different. Toxicological Sciences, New York, Cary v.110 (1), p.4-30, 2009.

SNYDER, L.R.; KIRKLAND, J.J.; GLAJCH, J.L. Practical HPLC method development (2ed.), John Wiley \& Sons, Inc., New York, p.765, 1997. 
SPIETELUM, A.; ILARCZYK, M; KLOSKOWSKI, A.; NAMIÉSNIK, J. Current trends in solid-phase microextraction (SPME) fiber coatings. Chemical Society Reviews, Cambridge, v. 39 (11), p.4524-4537, 2010.

STAHL, S.M. Describing an Atypical Antipsychotic: Receptor binding and its role in pathophysiology. Primary Care Companion of the Journal of Clinical Psychiatry, New York, v. 5, p.9-13, 2003.

SUPELCO. SPME Applications Guide, $3^{\text {rd }}$ ed., Supelco, Bellefonte, PA, EUA, p.64, 2001.

SUPELCO. Ficha de dados, SPME LC Fiber probes, cat. №57281-U, Supelco, Bellefonte, PA, EUA, 2010.

TACHIBANA, K.; OHNISH, A. Reversed-phase liquid chromatographic separation of enantiomers on polysaccharide type chiral stationary phases. Journal of Chromatography A, Amsterdam, v.906, p.127-154, 2001.

THEODORIDIS, G.; KOSTER, E.H.M.; JONG, G.J.; Solid-phase microextraction for analysis of biological samples. Journal of Chromatography B, Amsterdam, v.745, p.49-82, 2000.

THEODORIDIS, G.; GIKA, H.G.; WANT, E.J.; WILSON, J.D. Liquidchromatography-mass spectrometry based global metabolite profiling: A review. Analytica Chimica Acta, Amsterdam, v.711, p.7-16, 2012.

THONSON, B.A. Atmospheric pressure ionization and liquid chromatography mass spectrometry: together at last. Journal American Society Mass Spectrometry, Ontario, v.9, p.187-193, 1998.

TRAPP, O. Chromatographic peak deconvolution of constitutional isomers by multiple-reaction-monitoring mass spectrometry. Journal of Chromatography A, Amsterdam, v.1217 (7), p.1010-1016, 2010.

TRUFELLI, H.; PALMA, P.; FAMIGLINI, G.; CAPPIELLO, A. An overview of matrix effects in liquid-chromatography mass spectrometry, Mass Spectrometry Reviews, v.30, p.491-509, 2011.

ULRICH, S. Solid-Phase microextraction in biomedical analysis. Journal of Chromatography A, Amsterdam, v.902, p.167-194, 2000. 
VAN BEIJSTERVELDT, L.E.; GEETS, R.; LEYSEN, J.; MEGENS, A.; EYNDE, H.V.; MEULDERMANS, W.; HEYKANTS, J. Regional brains distribution of risperidone and its active metabolite 9-hydroxy-risperidone in rat. Psychopharmacology, Beerse, v.114, p.53-62, 1994.

VEKEY, K. Mass spectrometry and mass-selective detection in chromatography. Journal of Chromatography A, Amsterdam, v.291, p.227236, 2001.

VOYKSNER, R.D.; In: COLE, R.B. (ed.). Electrospray Ionization Mass Spectrometry, Fundamentals, Instrumentation and Applications. Willey, New York, v.67, p.323-341, 1997.

VUCKOVIC, D.; SHIREY, R., CHEN, Y.; SIDISKY, L.; AURAND, C.; STENERSON, K.; PAWLISZYN, J. In vitro evaluation of new biocompatible coatings for solid-phase microextraction: Implications for drug analysis in vivo sampling applications. Analytica Chimica Acta, Amsterdam, v.638, p.175-185, 2009.

VUCKOVIC, D.; CUDJOE, E.; MUSTEATA, F.M.; PAWLISZYN, J. Automated solid-phase microextraction and thin-film microextraction for hig-throughput analysis of biological fluids and ligand-receptor binding studies. Nature protocols, v.5, p.140-161, 2010.

VUCKOVIC, D.; ZHANG, X.; CUDJOE, E.; PAWLISZYN, J. Solid-phase microextraction in bioanalysis: new devices and directions. Journal of Chromatography A, Amsterdam, v.1217, p.4041-4060, 2010.

WARD, T.J; FARRIS, A.B. Chiral separations using macrocyclic antibiotics: a review. Journal of Chromatography A, Amsterdam, v.906, p.73-89, 2001.

WILLE, S.M.R.; LAMBERT, W.E.E. Recent developments in extraction procedures relevant to analytical toxicology. Analytical and Bioanalytical Chemistry, Washington, v.388, p.1381-1391, 2007.

WRIGHT, P. Metabolite identification by mass spectrometry: forty years of evolution. Xenobiotica, Oxon, v.41 (8), p.670-686, 2011. 
YASHIMA, E. Polysaccharide-based chiral stationary phases for highperformance liquid chromatographic enantioseparation. Journal of Chromatography A, Amsterdam, v.906, p.105-125, 2001.

YASHIMA, E.; OKAMOTO, Y. Chiral discrimination on polysaccharides derivatives. Bulletin of Chemical Society of Japan, Tokyo, v.68, p.3289-3307, 1995. 